\title{
CHARACTERIZATION OF TWO BACTERIAL PROTEINS (ARLA AND ARLB) ASSOCIATED WITH RESISTANCE TO HOST DEFENSE PEPTIDES
}

\author{
by \\ Mario Antonio Vargas \\ Honours Bachelor of Science, 2013 \\ University of Toronto \\ A thesis \\ presented to Ryerson University \\ in partial fulfillment of the \\ requirements for the degree of \\ Master of Science \\ in the program of \\ Molecular Science
}

Toronto, Ontario, Canada, 2018

(C) Mario Antonio Vargas, 2018 


\section{AUTHOR'S DECLARATION FOR ELECTRONIC SUBMISSION OF A THESIS}

I hereby declare that I am the sole author of this thesis. This is a true copy of the thesis, including any required final revisions, as accepted by my examiners.

I authorize Ryerson University to lend this thesis to other institutions or individuals for the purpose of scholarly research.

I further authorize Ryerson University to reproduce this thesis by photocopying or by other means, in total or in part, at the request of other institutions or individuals for the purpose of scholarly research.

I understand that my thesis may be made electronically available to the public. 


\section{ABSTRACT}

\section{Characterization of two bacterial proteins (ArlA and ArlB) associated with resistance to host defense peptides}

Mario Antonio Vargas, Master of Science, Molecular Science, Ryerson University, 2018

Inflammatory bowel disease is a complex condition with a multifactorial etiology. An interplay of various factors can lead to an inflamed gut with the overproduction of host-defense peptides (HDPs) and microbiome alterations, such as increases in pathogenic bacteria. Through processes involving either core gene regulation or acquisition of new genes, bacteria have evolved mechanisms to resist HDPs. Previously, a novel genetic locus, $\operatorname{arl} A B C$, was identified in adherent-invasive Escherichia coli (AIEC) strain NRG857c that contributes to high-level HDP resistance. ArlC is an outer membrane protease, but the function(s) of ArlA and ArlB are unknown. Thus, characterization was performed on strains mutated in these genes.

Lipopolysaccharide gels suggest a change in the core structure of the mutant strains, but several phenotypic assays gave varying results. We demonstrate that the ArlB protein is regulated by the PhoPQ two-component system. We anticipate that these investigations will lead to a better understanding of HDP resistance in AIEC. 


\section{ACKNOWLEDGEMENTS}

The completion of this project would have been impossible without the support and insight from many individuals that I had the pleasure to become acquainted with while in this program.

First, I would like to thank my dedicated supervisor and mentor, Dr. Joseph B. McPhee, who took me on as the very first graduate student of his new laboratory group. He welcomed me into the field of microbiology and never ceases to teach me and provide me with interesting and helpful information. I am very grateful for all the opportunities he has given me and for being very patient with me as I develop into a more mature scientist.

Also, I would like to thank the members of my supervisory committee, Dr. Debora Foster and Dr. Warren Wakarchuk, who provided a lot of guidance in the development of my work and very useful input on different aspects of the methods I used. I would like to extend this thanks to the various individuals from their laboratory groups that did not hesitate to lend a hand, especially Veronica Cojocari, and to the rest of the collaborative community at the Ryerson University MaRS Research Facility, born from a very successful and exciting launch.

A very warm and special thanks to my lab mates of the McPhee Laboratory, both old and new trainees, but especially to Monir Riasad Fadle Aziz, Youn Hee Cho,

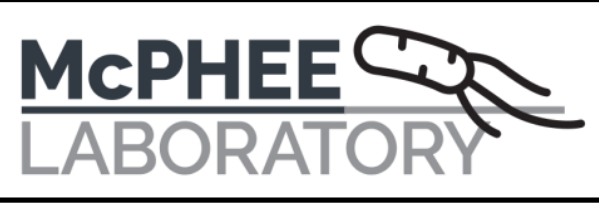
and Michael Renouf for their immeasurable assistance, perseverance, patience, and friendship. The CP10A peptides used in this study were generously provided by Dr. Bob Hancock. Also, special thanks to Lauren Phillips, Dr. Grace Flock, Stephen Bautista, Dr. Matthew Gray, Bushra Ilyas, Dr. Jonathan Stokes, Dr. Brian K. Coombes, and Dr. Eric Brown for their various assistances and for answering my questions.

Finally, I would like to acknowledge my immediate family: my parents, Leonel and Bertha, and all my siblings, Elizabeth, Rosa Maria, Juan, Miguel, and Gabriel, for their unending support and sacrifice, for through all the challenges, they have been by my side and have given me everything from encouragement to prayers. 


\section{TABLE OF CONTENTS}

1 INTRODUCTION

1.1 Inflammatory bowel disease.............................................................................................................. 1

1.2 Host-defense peptides ............................................................................................................................. 3

1.2.1 General overview of host-defense peptides …………................................................ 3

1.2.2 Targets of host-defense peptides ............................................................................. 4

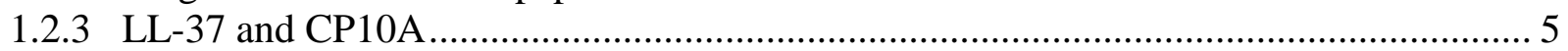

1.3 Bacterial resistance to host-defense peptides .................................................................................. 7

1.3.1 Two-component regulatory systems ........................................................................ 7

1.3.2 Lipopolysaccharide structure ……………………................................................. 9

1.3.3 Examples of known resistance mechanisms ................................................................ 10

1.4 Adherent-invasive Escherichia coli ........................................................................................... 12

1.4.1 Overview of adherent-invasive Escherichia coli .................................................. 12

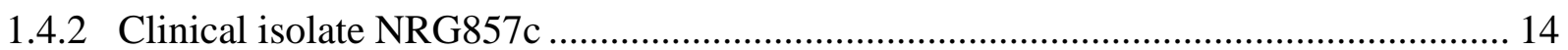

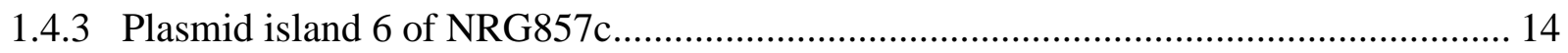

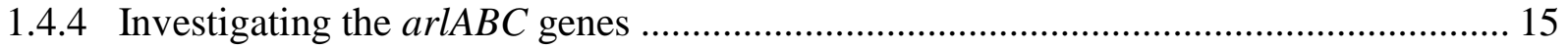

2 PURPOSE, HYPOTHESES, AND OBJECTIVES................................21

2.1 Rationale and Purpose...................................................................................................................... 21

2.2 Hypotheses and Objectives..................................................................................................... 21

2.2.1 The ArlA and ArlB proteins are involved in altering the structure and the permeability

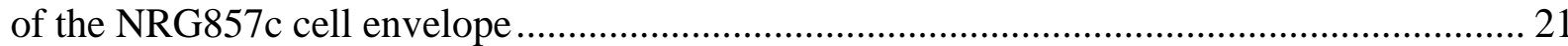

2.2.2 The ArlA and ArlB proteins are transcriptionally regulated by conserved regulatory

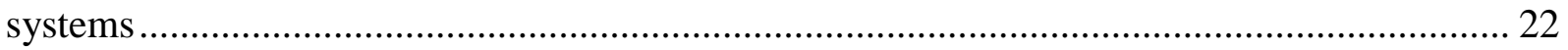

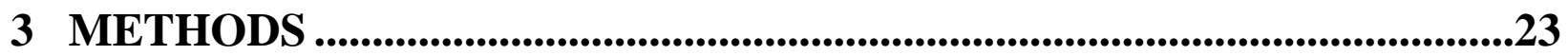

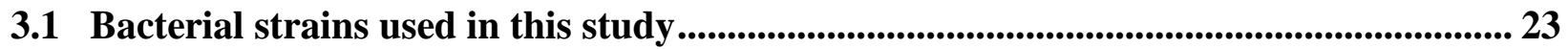

3.2 Bacterial growth and harvest....................................................................................................... 24

3.3 Silver staining of LPS on gels....................................................................................................... 24

3.4 NPN OM permeabilization assay ............................................................................................. 25

3.5 Lysozyme-mediated permeabilization assay ........................................................................... 26

3.6 Light microscopy ......................................................................................................................... 26 
3.7 Radial diffusion assay ……......................................................................................................... 27

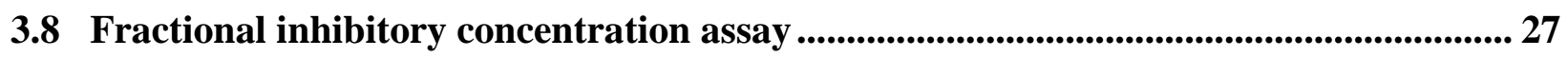

3.9 Bacterial invasion/survival assay ........................................................................................ 28

3.10 Translational fusion and mutagenesis............................................................................... 28

3.11 Western blotting and densitometry ……...................................................................................... 29

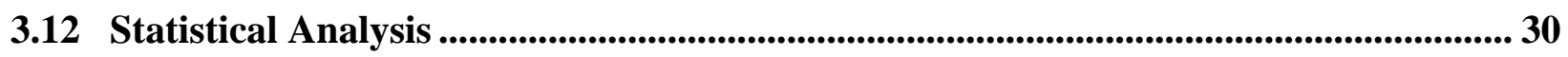

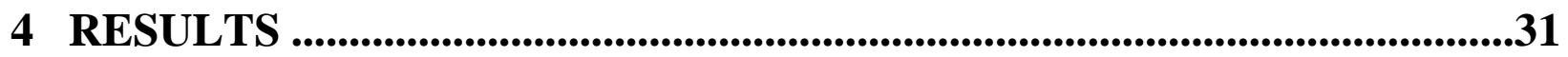

4.1 Mutants of arlB show evidence of altered LPS structure...................................................... 31

4.2 The $\triangle p h o P$ mutant has significantly higher NPN uptake factors than WT NRG857c in varying concentrations of polymyxin $B$............................................................................................... 34

4.3 The NUFs among NRG857c and its mutants vary in different and sometimes unexpected ways in NPN assays using LL-37 or CP10A............................................................... 36

4.3.1 Differences in NUFs among LB-grown strains does not depend on the concentration of

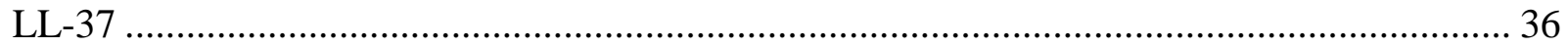

4.3.2 The concentration of CP10A contributes partially to differences in NUF among LB-

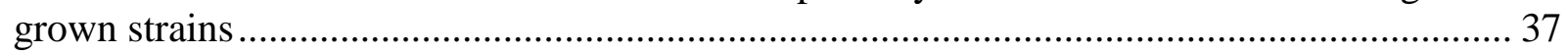

4.3.3 Growth in low concentrations of $\mathrm{Mg}^{2+}$ does not affect CP10A-mediated NPN uptake 38

4.4 The concentration of polymyxin B contributes to differences in $\triangle O D$ values in preliminary trials of the lysozyme assay ................................................................................................. 39

4.5 Using CP10A causes the formation of aggregated clumps in the lysozyme assay ......... 42

4.6 The $\triangle \mathrm{PI}-6$ strain is more sensitive to $\mathrm{CP10A}$ than the $\triangle \mathrm{arlA}$ or $\triangle \mathrm{ArlB}$ strains in radial

diffusion assays............................................................................................................................................ 45

4.7 There are no differences in fractional inhibitory concentration indices between WT NRG857c and its $\triangle \mathrm{PI}-6$ mutant using the fractional inhibitory concentration assay ........... 47

4.8 Deletion of PI-6, arlA, or arlB did not affect the ability for NRG857c to invade or survive in macrophages

4.9 The expression of arlB is increased in the early stationary phase of $\mathrm{LB}$ growth .......... 52

4.10 The expression of arlAB is likely regulated by the PhoPQ TCS, but not by the PmrAB TCS..........................................................................................................................................5 54

4.10.1 ArlB:HA is expressed in low magnesium conditions, but not in high magnesium

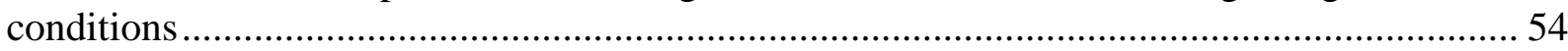

4.10.2 ArlB:HA expression is abolished in the $\triangle p h o P$ mutant ......................................... 55 
4.10.3 ArlB:HA is not expressed in growth media with high magnesium and high iron ....... 56

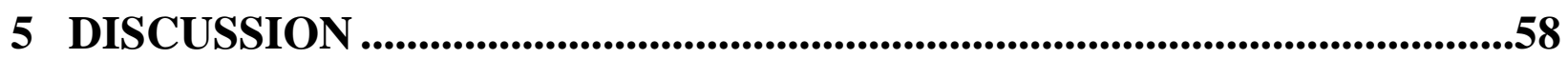

5.1 The change in bands of the core region of LPS gels suggest that the ArlB protein is involved in an LPS core modification system............................................................................ 58

5.2 Phenotypic differences among WT NRG857c and its isogenic mutants in the PI-6 genes were usually not significant among various OM permeabilization and susceptibility assays

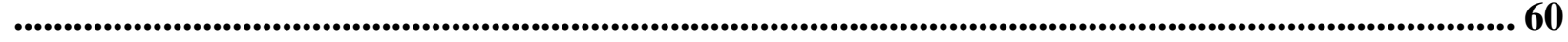

5.3 ArlB:HA is regulated by low $\mathrm{Mg}^{2+}$ conditions in a PhoP-dependent manner................ 66

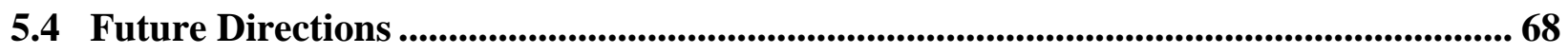

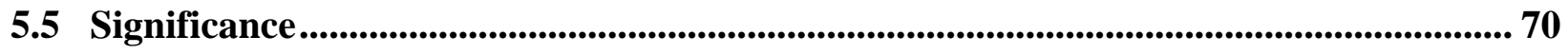

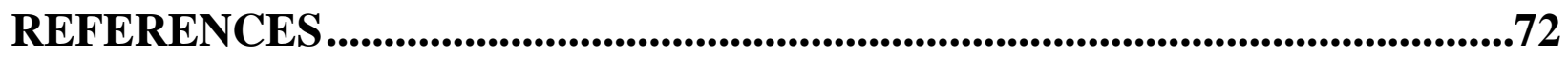




\section{LIST OF TABLES}

Table 1. Representative human host-defense peptides ......................................................... 3

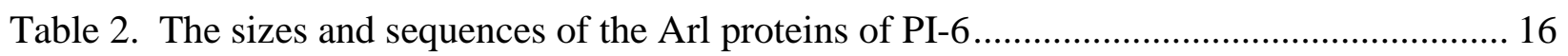

Table 3. The MICs of LL-37 or CP10A for various NRG857c and LF82 strains ..................... 17

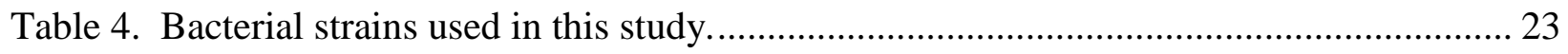

Table 5. The MIC and FIC values obtained in FIC assays testing WT NRG857c and the $\Delta$ PI-6 mutant by using rifampicin in combination with pentamidine or CP10A.............................. 48 


\section{LIST OF FIGURES}

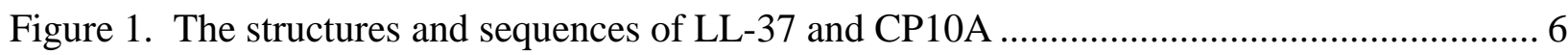

Figure 2. The PhoPQ and PmrAB two-component regulatory systems and common lipid A modifications in E. coli ...................................................................................................... 8

Figure 3. The structure of LPS with R1-type core ................................................................... 9

Figure 4. The genomic island PI-6 with genes arlABC, from AIEC strain NRG857c................ 15

Figure 5. Predicted structures of ArlA and ArlB generated with Phyre2 based on top alignment

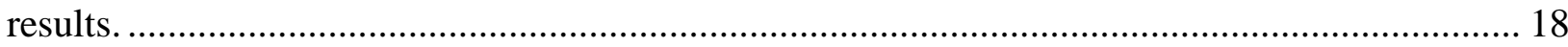

Figure 6. The profile regions where the different types of LPS fragments can be visualized is marked in both gels............................................................................................................... 32

Figure 7. Visualization of LPS on polyacrylamide gradient (4 to 20\%) gels............................... 33

Figure 8. The NUFs calculated in a preliminary trial of the NPN assay using WT and $\Delta p h o P$

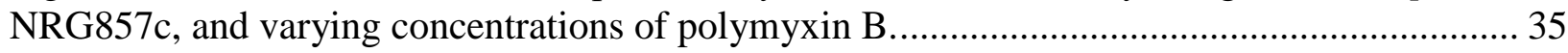

Figure 9. The NUFs calculated in the NPN assay using WT NRG857c and isogenic mutants

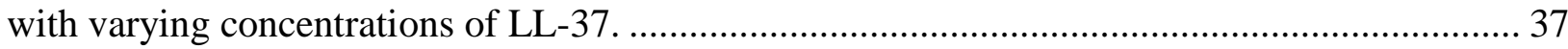

Figure 10. The NUFs calculated in the NPN assay using LB-grown WT NRG857c and isogenic mutants with varying concentrations of CP10A. ....................................................................... 38

Figure 11. The NUFs calculated in the NPN assay using low $\mathrm{Mg}^{2+}$-grown WT NRG857c and isogenic mutants with varying concentration of CP10A. .......................................................... 39

Figure 12. The $\triangle \mathrm{OD}$, normalized to ODs after adding lysozyme, calculated over time in seconds.

Figure 13. Stabilizing $\Delta \mathrm{OD}$, normalized to ODs after adding lysozyme, calculated after 1 minute of adding varying concentrations of polymyxin $\mathrm{B}$. 41

Figure 14. Stabilizing $\triangle \mathrm{OD}$, normalized to ODs after adding lysozyme, calculated after 1 minute of adding varying concentrations of $\mathrm{CP} 10 \mathrm{~A}$ or polymyxin $\mathrm{B}$. 42

Figure 15. The $\triangle \mathrm{OD}$ "control" tests (no lysozyme), normalized to ODs before adding CP10A or polymyxin $\mathrm{B}$, calculated over time in seconds. 43

Figure 16. Samples of Gram-stained WT NRG857c obtained from the lysozyme assay and observed under $100 \times$ oil immersion objective lens.

Figure 17. The clearance zone diameters measured around varying concentrations of CP10A in radial diffusion assays of WT NRG857c and the $\Delta \mathrm{PI}-6, \triangle \operatorname{arl} A$, and $\triangle \operatorname{arl} B$ mutants. 46 
Figure 18. The calculated CFUs, percentage invasion, and percentage survival of WT NRG857c and its isogenic mutants, with K12 and Salmonella controls, in experiments of bacterial survival after invasion of RAW264.7 macrophages

Figure 19. The western blots of membranes with the NRG857c WT, arlA:HA, or arlB:HA, using samples obtained at different time intervals of growth in LB as shown.

Figure 20. The western blots of membranes with NRG857 arlB:HA, using samples obtained from different growth phases of varying growth media. 55

Figure 21. The western blots of membranes with NRG857 $\Delta$ phoP arlB:HA, using samples obtained from different growth phases of varying growth media...... 56

Figure 22. The western blots of membranes with NRG857 arlB:HA, using samples obtained from different growth phases of $\mathrm{N}$ minimal media with varying conditions. 


\section{LIST OF ABBREVIATIONS}

$\begin{array}{ll}\text { AIEC } & \text { adherent-invasive Escherichia coli } \\ \text { Ara4N } & \text { 4-amino-4-deoxy-L-arabinose } \\ \text { arlABC } & \text { antimicrobial peptide resistance locus ABC } \\ \text { ATG16L1 } & \text { autophagy-related protein 16-like 1 } \\ \text { BCA } & \text { bicinchoninic acid } \\ \text { Bis-TRIS } & \text { 2-[Bis(2-hydroxyethyl)amino]-2-(hydroxymethyl)propane-1,3-diol } \\ \text { BSA } & \text { bovine serum albumin } \\ \text { CCCP } & \text { carbonyl cyanide } m \text {-chlorophenyl hydrazine } \\ \text { CD } & \text { Crohn's disease } \\ \text { CFU } & \text { colony forming unit } \\ \text { DMEM } & \text { Dulbecco's modified Eagle's medium } \\ \text { DNA } & \text { deoxyribonucleic acid } \\ \text { EHEC } & \text { enterohaemorrhagic Escherichia coli } \\ \text { EPEC } & \text { enteropathogenic Escherichia coli } \\ \text { FIC } & \text { fractional inhibitory concentration } \\ \text { FRT } & \text { FLP recombinase recognition targets } \\ \text { Gal } & \text { D-galactose } \\ \text { Glc } & \text { D-glucose } \\ \text { GlcN } & \text { D-glucosamine } \\ \text { GlcNAc } & \text { D- } N \text {-acetylglucosamine } \\ \text { GNAT } & \text { Gcn5-related } N \text {-acetyltransferase } \\ \text { HA } & \text { hemagglutinin } \\ \text { hBD } & \text { human beta-defensin } \\ \text { hCAP-18 } & \text { human cationic antimicrobial protein, } 18 \text { kDa } \\ \text { HD } & \text { human defensin } \\ \text { HDP } & \text { host defense peptide } \\ \text { Hep } & \text { L-glycero-D-manno-heptose } \\ \text { HEPES } & N \text {-2-hydroxyethylpiperazine- } N \text { '-2-ethanesulfonic acid } \\ \text { HNP } & \text { human neutrophil peptide } \\ \text { IBD } & \text { inflammatory bowel disease } \\ \text { Kdo } & \text { 3-deoxy-D-manno-oct-2-ulosonic acid } \\ \text { LB } & \text { Luria-Bertani } \\ \text { LPS } & \text { lipopolysacharide } \\ \text { MALDI-TOF } & \text { matrix assisted laser desorption/ionization-time of flight } \\ \text { MIC } & \text { minimum inhibitory concentration } \\ \text { NAD } & \text { nicotinamide adenine dinucleotide } \\ \text { NAPB } & \text { sodium phosphate buffer } \\ \text { NMEC } & \text { neonatal meningitis Escherichia coli } \\ \text { NMR } & \text { nuclear magnetic resonance } \\ \text { NOD2 } & \text { nucleotide-binding oligomerization domain-containing protein } 2 \\ \text { NPN } & \text { 1- } N \text {-phenylnaphthylamine } \\ \text { NUF } & \text { optical density } \\ \text { OD } & \\ \text { OM } & \end{array}$




\begin{tabular}{ll} 
P & phosphate \\
PAGE & polyacrylamide gel electrophoresis \\
PBS & phosphate buffer saline \\
PCR & polymerase chain reaction \\
PEtN & phosphoethanolamine \\
PI-6 & plasmid island 6 \\
PxB & polymyxin B \\
RDA & radial diffusion assay \\
RNA & ribonucleic acid \\
SDS & sodium dodecyl sulfate \\
SNP & single-nucleotide polymorphism \\
TBST & TRIS-buffered saline with Tween 20 \\
TCS & two-component regulatory system \\
TLR & toll-like receptor \\
TRIS & tris(hydroxymethyl)aminomethane \\
TSB & tryptic soy broth \\
UC & ulcerative colitis \\
UPEC & uropathogenic Escherichia coli \\
WT & wild-type \\
X-gal & 5-bromo-4-chloro-3-indolyl- $\beta$-D-galactopyranoside \\
XBP1 & X-box binding protein 1 \\
\hline
\end{tabular}




\section{INTRODUCTION}

\subsection{Inflammatory bowel disease}

The microbiota of the human intestine, in particular the distal ileum and colon, contains a large number of species in as many as 1800 genera, with $99 \%$ of species falling within four major bacterial divisions: Firmicutes, Bacteroidetes, Proteobacteria, and Actinobacteria (1). The intestinal environment is very complex and consists of an incredible number of interactions among the microbiota, intestinal epithelial cells, and the mucosal immune system of the human host. Continuous communication via chemical signals and protein regulators between the human host and the microbiota may allow healthy individuals to maintain a balanced homeostasis. However, genetic or immunological abnormalities in certain individuals can lead to the development of harmful chronic inflammation in the host tissue, resulting in inflammatory bowel disease (IBD). The two major known forms of IBD are ulcerative colitis and Crohn's disease (1). Crohn's disease (CD) involves discontinuous ulceration and intestinal inflammation, and may include the development of fistulae (2). Symptoms include abdominal pain, diarrhea, rectal bleeding, weight loss, fever and fatigue. Ulcerative colitis (UC), however, is exclusive to the colon, involves the continuous inflammation of the mucosa, and does not include the development of fistulae. Similar symptoms occur in UC patients (2). Although a number of therapies have been developed to treat the symptoms of IBD, including steroidal antiinflammatories, immunosuppressant therapies, and antibody-mediated inhibition of immune signaling proteins, at present, there is no cure.

Genome wide association studies have identified over 200 loci with single-nucleotide polymorphisms (SNPs) associated with these diseases, in which more than 100 of the loci are common to both $\mathrm{CD}$ and $\mathrm{UC}$, and ongoing studies continue to identify more (3-7). Many of 
these loci include genes that have been associated with immunodeficiencies that cause severe infections (3), and this can be seen in the excess production of certain cytokines in individuals with IBD, in particular interleukins 12,17 , and 23, and interferon gamma in CD, and interleukin 13 in UC (2). Similarly, mutations in the nucleotide-binding oligomerization domain-containing protein 2 gene (NOD2) are well-known to be strongly associated with susceptibility to $\mathrm{CD}$. The NOD2 receptor, along with other NOD-like and toll-like receptors (TLRs) on host cells are used to detect bacterial components, and this leads to the activation of signaling cascades that cause an immune response. In healthy individuals, however, the signaling cascades are normally downregulated in epithelial and immune cells in the presence of commensal bacteria in the gut. In abnormal host conditions with an excess production of cytokines and mutations in genes like $N O D 2$, an augmented immune response develops that disrupts homeostatic host-microbial relationships, produces even more cytokines, and causes inflammation of host tissue (1).

Other well-known IBD susceptibility genes include the autophagy-related protein 16-like $1(A T G 16 L 1)$ and X-box binding protein $1(X B P 1)$ genes (8). Defective ATG16L1 protein disrupts normal functioning of autophagy, which is necessary to recycle cellular materials and maintain homeostasis, and defective XBP1 transcription factor disrupts the expression of genes required for endoplasmic reticulum stress responses. Along with $N O D 2$, these and other genes have been directly linked to Paneth cell secretory processes. The Paneth cells, found at the base of the small intestine crypts of Lieberkühn, are major producers of host defense peptides (HDPs), small antimicrobial proteins that are essential for gut homeostasis. Polymorphisms in the susceptibility genes can result in defective proteins that disrupt normal Paneth cell functions and lead to specific alterations in HDP secretions (8).

Although the causes of IBD involve an interplay of host genetics and the intestinal 
environment, the microbiota is also altered in distinct ways. Decreased numbers in bacteria from Bacteroidetes and Lachnospiraceae groups, which are normally predominant, and an increase in relative abundance of Gram-negative Proteobacteria such as Escherichia coli are commonly observed in IBD patients. Particularly in $\mathrm{CD}$, there is an increased abundance of E. coli in the fecal and mucosally associated microbiota. In general, a decrease in species diversity is observed in both CD and UC. These changes can lead to additional adverse effects and worsen the conditions of IBD patients (1). In order to establish the context of this study, further details on HDPs and bacterial resistance to them is discussed below.

\subsection{Host-defense peptides}

\subsubsection{General overview of host-defense peptides}

HDPs, also known as cationic antimicrobial peptides, are a class of small protein compounds (about 12-50 amino acids) produced by cells to target and kill microbes (9). They can be found ubiquitously and produced by all forms of life, including within the human host,

Table 1. Representative human host-defense peptides

\begin{tabular}{|c|c|c|}
\hline Peptide & Class & Sources \\
\hline $\begin{array}{l}\text { human neutrophil peptide (HNP, a-defensin) } \\
\text { e.g. HNP-1, HNP-2, HNP-3, HNP-4 }\end{array}$ & $\beta$-sheet & neutrophils, bone marrow \\
\hline $\begin{array}{l}\text { human defensin (HD, a-defensin) } \\
\text { e.g. HD5, HD6 }\end{array}$ & $\beta$-sheet & Paneth cells / intestine \\
\hline $\begin{array}{l}\text { human beta-defensin (hBD, } \beta \text {-defensin) } \\
\text { e.g. hBD1, hBD2, hBD3, hBD4 }\end{array}$ & $\beta$-sheet & $\begin{array}{l}\text { skin, epithelia, salivary } \\
\text { glands, kidney, lung }\end{array}$ \\
\hline cathelicidin, e.g. LL-37 & a-helical & neutrophils, skin \\
\hline histatin, dermcidin & Extended & skin, saliva, sweat \\
\hline
\end{tabular}


where host cells can produce HDPs to prevent infection as part of the innate immune system. HDPs come in four major structural categories: $\beta$-sheet, $\alpha$-helices, loop structures, and extended structures. Examples of the known major HDPs in humans are shown in Table 1 (10). In the human gut, the major producers of HDPs are the Paneth cells, as discussed above, and intestinal epithelial cells, which produce all classes of HDPs, including the $\alpha$ - and $\beta$-defensins, and LL-37 (8).

As discussed above, there can be alterations in the secretion of HDPs by the Paneth cells in individuals with IBD. Some individuals with CD have decreased production and secretion of human defensins (HDs) such as HD5 and HD6 (2), although this is not the case for all patients $(11,12)$, while other studies also showed increased levels of HDPs such as hBD2, hBD3, and LL-37 in the inflamed gut environment of certain $\operatorname{IBD}$ patients $(13,14)$. Although the specific HDP milieu produced in a person with IBD can vary in individual ways, the altered HDP production is associated with the altered microbial composition of the intestinal tract. For example, specialized opportunistic bacteria, that can resist the inflamed environment and altered HDP compositions (e.g. resistance to increased amounts of LL-37), would be able to thrive and outcompete other commensal species (8). Understanding the properties of relevant HDPs and determining which species or pathotypes of bacteria are resistant to them can lead to the discovery of virulence factors and other bacterial methods of pathogenesis.

\subsubsection{Targets of host-defense peptides}

A common target of these HDPs, and the first site of interaction, is the OM of Gramnegative bacteria (15). The bacterial OM consists principally of lipopolysaccharide (LPS), an anionic polymer that is described in more detail below. Due to the anionic nature of the bacterial 
OM, HDPs initially bind the surface through electrostatic interactions and they displace the divalent cations that are normally present and that maintain OM integrity. Two major models include the barrel-stave model, in which hydrophobic domains of HDPs insert into the membrane to form pores, and the carpet model, in which hydrophilic HDPs surround portions of the membrane surface that eventually break apart. Through these modes of action, the OM becomes leaky, which allows the passage of more HDP molecules into the membrane that could form more pore-like structures that causes further leakage, or reach other targets within the bacteria and eventually lead to bacterial death. Some of these other targets and effects include binding bacterial DNA, inhibition of cell wall components, DNA, RNA, or protein synthesis, inhibition of enzymatic activities, and alteration of the inner membrane to prevent septum formation. The targets for each HDP varies, but through the combined effect of HDPs with multiple targets, or multiple types of HDPs, bacterial killing is achieved (15).

\subsubsection{LL-37 and CP10A}

In previous work, McPhee et al. showed that the loss of bacterial genes arlABC (discussed in detail below) resulted in significant alterations in susceptibility to two certain $\alpha$ helical peptides, LL-37 and CP10A (16). The structures and sequences of these peptides are shown in Figure 1. The cathelicidin LL-37 is the 37 -amino acid peptide product that is produced from the $\mathrm{C}$-terminal end of the precursor, human cationic antimicrobial protein $18 \mathrm{kDa}(\mathrm{hCAP}-$ 18). It is a major HDP produced by certain leukocytes, such as neutrophils and macrophages, and it contains several cationic residues (five arginine and six lysine residues, as shown in blue in Figure 1) that are mainly concentrated to one side of the helix (while the other side consists mainly of hydrophobic residues, shown in white). This configuration allows LL-37 to favourably 
(A)
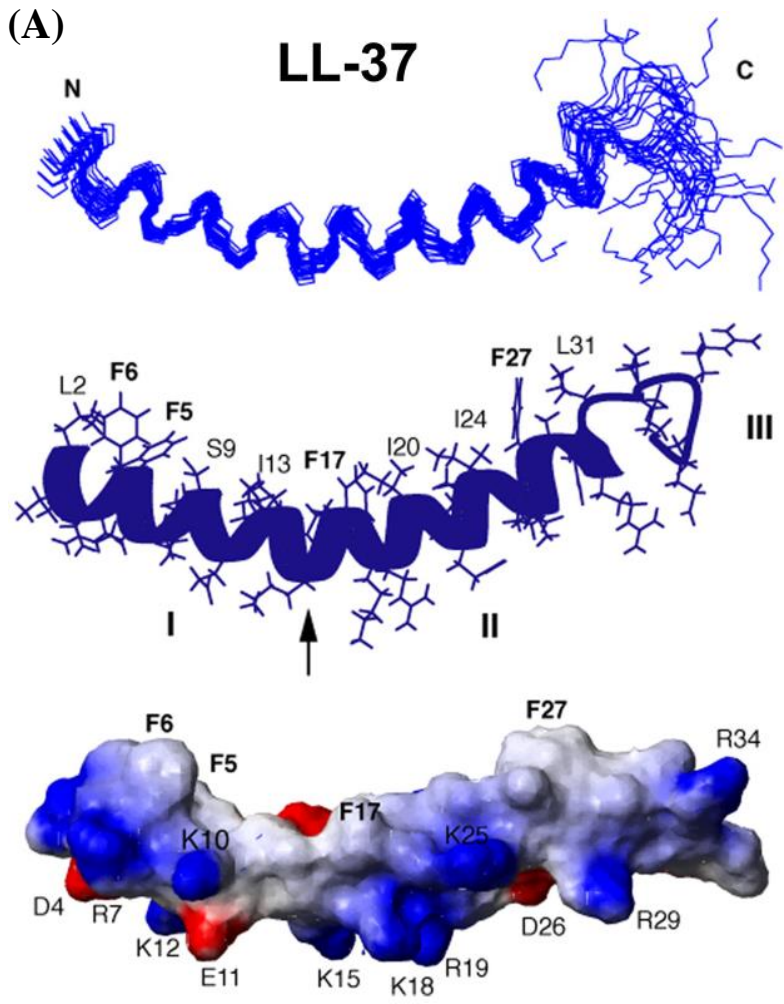

(B) CP10A

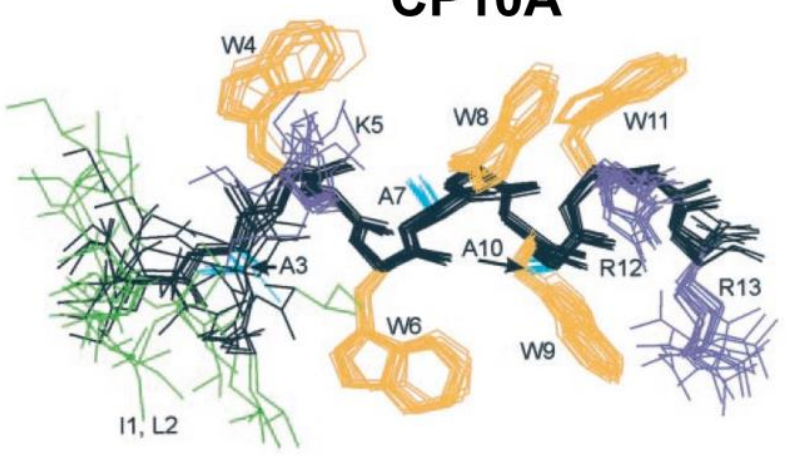

(C)

\section{LL-37 sequence LLGDFFRKSKEKIGKEFK- RIVQRIKDFLRNLVPRTES}

\section{CP10A sequence ILAWKWAWWAWRR-NH ${ }_{2}$}

Figure 1. The structures and sequences of LL-37 and CP10A

(A) The experimentally determined backbone 3D structures of the LL-37 peptide is shown at the top, then the ribbon and side chain structure and the space-filling models underneath. In the space-filling model, blue represents positively charged residues, red for negatively charged residues, and white for hydrophobic residues (17). (B) The experimentally determined stick models for the 3D structure of CP10A (18). (C) The amino acid sequences for LL-37 and CP10A, where blue represents positively charged residues and red for negatively charged residues $(17,18)$.

target and bind to the negatively charged OM of Gram-negative bacteria (17). CP10A is a synthetic derivative of the bovine HDP indolicidin in which proline residues have been replaced by alanine residues. CP10A contains three positively charged residues (and no cancelling effects from any negatively charged residues), and an $\alpha$-helical structure. Due to this, CP10A may have a similar mechanism of action in targeting the bacterial OM, although indolicidin and CP10A are unique in containing five tryptophan residues which may contribute to their antimicrobial activity by targeting the hydrophobic region within the OM. Also, similar to LL-37, the 
positively charged residues of CP10A concentrate to one side of the helix, while the tryptophan residues concentrate to the opposite side of the helix along with other more hydrophobic residues (18). This distribution of positively charged residues and hydrophobic groups would optimize peptide adherence to and insertion in the bacterial OM. However, although peptides such as these have evolved to target bacteria, bacteria have also evolved several methods to resist the action of the HDPs (19) and these are discussed in more detail below.

\subsection{Bacterial resistance to host-defense peptides}

\subsubsection{Two-component regulatory systems}

Bacteria have developed mechanisms in order to resist and evade the killing effects of HDPs, including in the context of the human gut environment (20). Several types of Gramnegative bacteria, including $E$. coli, use specialized two-component regulatory systems (TCS), in particular the PhoPQ and PmrAB systems, in order to control the regulation of virulence factors and resistance to host defense peptides (21). A figure summarizing the activity of these TCSs is shown in Figure 2, as adapted from Rubin et al (22). Each TCS consists of a membrane-bound sensor kinase (PhoQ and $\mathrm{PmrB}$ ) and its corresponding cytoplasmic response regulator (PhoP and PmrA). In response to specific environmental stimuli, the senor kinase autophosphorylates, and then phosphorylates its respective regulator, which in turn activates multiple factors (such as the expression of various virulence genes or other factors, collectively known as its regulon). After the corresponding environmental signal is no longer detected, the sensor kinase then dephosphorylates its respective regulator and expression of the corresponding regulon is stopped.

The PhoPQ TCS is activated in the presence of HDPs and by low $\mathrm{Mg}^{2+}$ conditions, while the PmrAB TCS is activated in the presence of bile salts, and by high $\mathrm{Fe}^{3+}$ or low $\mathrm{pH}$ conditions 
$(22,23)$. These conditions can be set up experimentally in vitro, by using growth media with low $\mathrm{Mg}^{2+}$ or high $\mathrm{Fe}^{3+}$, however these signals are not necessarily physiologically relevant in themselves. Low $\mathrm{Mg}^{2+}$ conditions likely serve as a proxy for the binding of HDPs to the cell membrane, which cause a disruption in the divalent cations that normally maintain OM integrity.

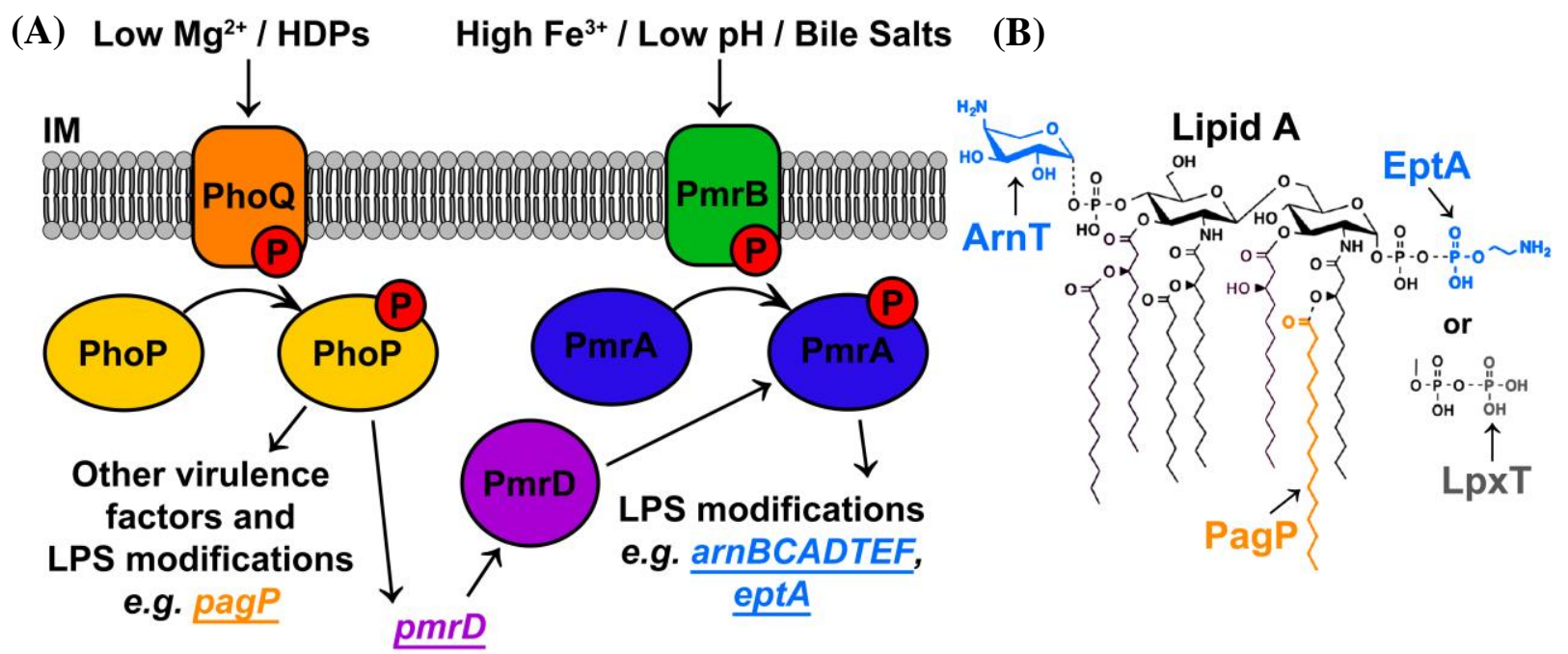

Figure 2. The PhoPQ and PmrAB two-component regulatory systems and common lipid A modifications in E. coli

(A) Only PhoQ is activated by HDPs or in low $\mathrm{Mg}^{2+}$ conditions, and only PmrB is activated by bile salts, in high $\mathrm{Fe}^{3+}$, or in low $\mathrm{pH}$ conditions. Each sensor kinase can then phosphorylate its respective response regulator (PhoP or PmrA) which then activates other factors, such as the expression of pmrD and LPS modification systems $(22,23)$. (B) Some of the major lipid A modifications, including those by PagP (through the PhoPQ TCS), ArnT, and EptA (through the PmrAB TCS). LpxT normally adds a phosphate group in conditions where these TCS are not activated (22).

This activates the protective mechanisms against HDPs through the PhoPQ TCS (22). In terms of PmrAB, bile salts are present in the gut (23), but high $\mathrm{Fe}^{3+}$ is more relevant to hostile environments outside the host, such as in soils, which also contain Paenibacillus polymyxa that produce damaging polymyxin antibiotics. Activating PmrAB would induce defence mechanisms against these antibiotics (24), but these same mechanisms are also relevant within the host. Although these TCSs are directly activated by different stimuli, it is important to note the 
existence of crosstalk between them. In $E$.

coli, PhoP activates the expression of PmrD,

a protein that blocks the dephosphorylation

of PmrA so that it effectively remains

activated. Consequently, although PmrAB is

not directly activated by low $\mathrm{Mg}^{2+}$

conditions, it can be activated indirectly

through PmrD (22). Other than PmrD

expression by PhoP, each TCS activates

common HDP resistance mechanisms, in

particular, the use of LPS modifications to

reduce its affinity to HDPs as shown in

Figure $2(21,22)$. The components of LPS

and how these contribute to specific

resistance mechanisms are described below.

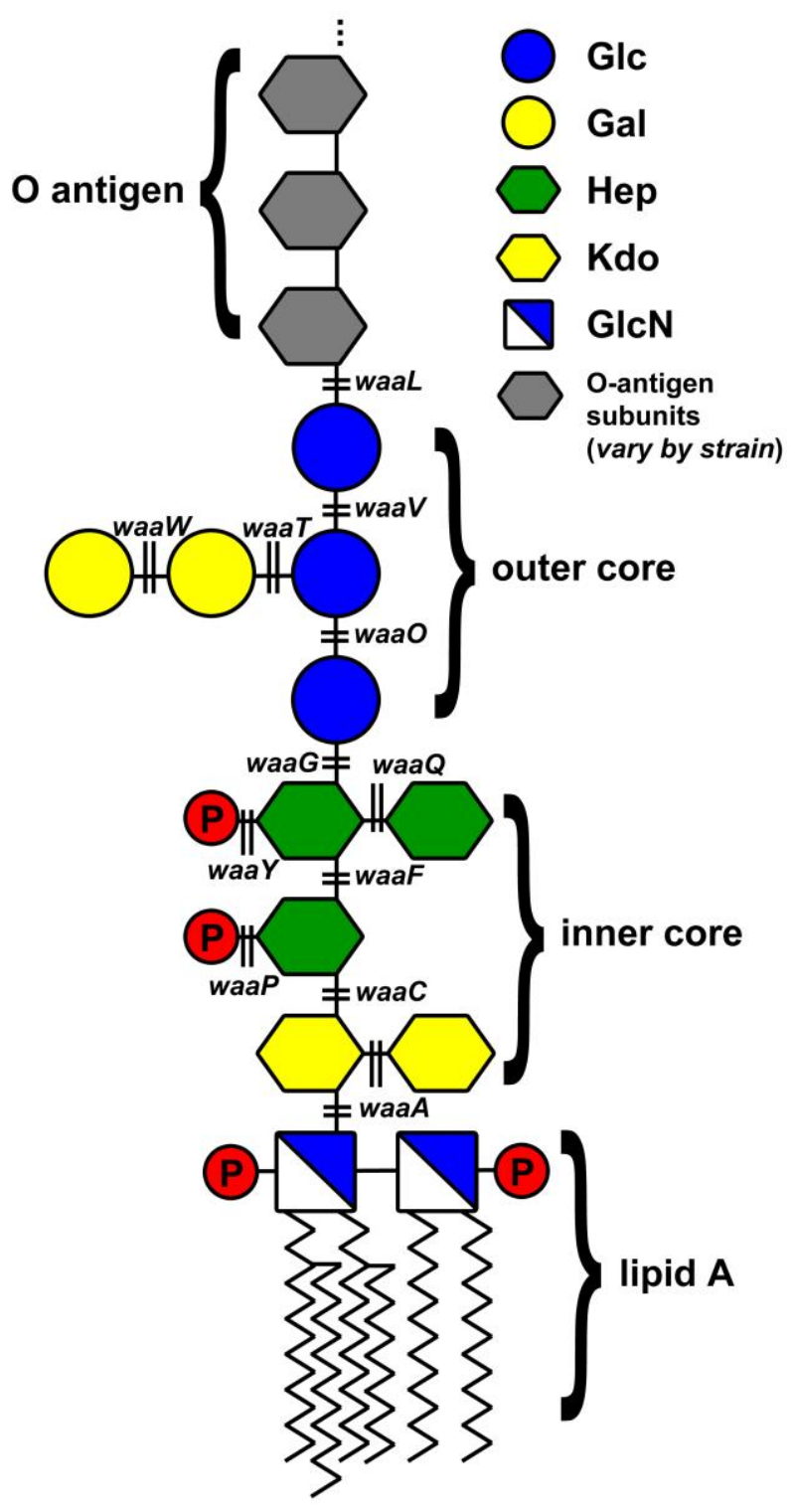

\subsubsection{Lipopolysaccharide structure}

As mentioned above, the $\mathrm{OM}$ of

Gram-negative bacteria, such as E. coli,

contains the endotoxin LPS, which is made

up of the hydrophobic saccharolipid moiety

known as lipid A, inner and outer core sugars

linked to lipid A by 3-deoxy-D-manno-oct-2-

Figure 3. The structure of LPS with R1-type core

Glc (D-glucose), Gal (D-galactose), Hep (L-glycero-

D-manno-heptose), Kdo (3-deoxy-D-manno-oct-2-

ulosonic acid), GlcN (D-glucosamine), P

(phosphate). The waa genes indicated above

correspond to the encoded glycosyltransferases or

phosphotransferases involved in that part of the LPS biosynthesis (26). 
ulosonic acid (Kdo) and O-antigen sugar repeats that extend outwards from the OM base (25). These components can be seen in Figure 3, LPS with an R1-type core, as adapted from Yethon et al (26). LPS can be further described according to which components are present, with smooth LPS containing the full molecule with O-antigen, rough LPS lacking O-antigen, and deep-rough LPS lacking both O-antigen and the outer core oligosaccharide. Lipid A with Kdo is essential for growth, while most strains also contain a complete core and $\mathrm{O}$-antigen, which have a protective and structural role (25). LPS is polyanionic largely due to the multiple phosphate units present in LPS, particularly those that are found in the core LPS (26). The biosynthesis of LPS is a precise and complex process involving numerous proteins, including those encoded by the set of waa genes that are involved in forming the core oligosaccharide. These particular Waa proteins are various glycosyltransferases and phosphotransferases that catalyze the reactions to add core monomers (sugar units or phosphate) to the elongating LPS molecule, such as WaaG that adds the first outer core unit, or WaaL that allows the inclusion of O-antigen, as indicated in Figure 3. It is interesting to note, however, that each of these proteins can also affect other LPS biosynthesis steps, such as how Yethon et al. demonstrated that a mutation in waaG not only produced deep-rough LPS, but also severely affected the addition of phosphate groups to the inner core (26). Specific modifications to certain regions of LPS and other HDP resistance mechanisms used by Gram-negative bacteria are described below (25).

\subsubsection{Examples of known resistance mechanisms}

In conditions where the TCSs are not activated, the LpxT phosphotransferase normally adds a phosphate group to the 1' position of the lipid A portion of LPS (27). However, the activation of the PhoPQ and/or PmrAB TCSs can lead to several potential modifications to the 
different regions of LPS, each of which can increase resistance to HDPs. For example, lipid A can be modified by adding certain chemical groups to reduce its overall negative charge, as shown in Figure 2B (22). Phosphorylated PhoP activates pagP which encodes an acyltransferase that adds a palmitate group to lipid A, stabilizing the OM in stressed conditions (28). In addition, phosphorylation of PmrD results in the post-transcriptional activation of the second response regulator, PmrA. Activating PmrA leads to an even greater variety of modifications, such as inducing the expression of the arnBCADTEF operon (also known as pmrHFIJKLM) and $p m r E$, which together leads to the production of proteins that carry out the addition of 4-amino-4deoxy-L-arabinose (Ara4N) to lipid A at the 1 and/or 4' positions. Other examples that are induced by PmrAB include the $p m r C A B$ operon and eptA gene (addition of phosphoethanolamine, PEtN, to lipid A), the $\operatorname{cptA}$ and eptC genes (PEtN additions to the inner core), and the $p m r R$ gene (represses the $l p x T$ gene). Furthermore, decreased susceptibility to LL37 in E. coli was observed in a mutant lacking waaY, which would encode the transferase that adds a phosphate group to the inner core region, as seen in Figure 3. Similarly, the pmrG (ais) gene, also regulated by PmrAB, encodes a phosphatase that removes the phosphate group at this same position of the core (29). All of these modifications effectively mask the negatively charged groups of LPS in order to reduce its affinity to HDPs $(21,27-30)$.

However, it is also interesting to note the existence of modifications in LPS core with more complex effects. For example, the $r f p$ gene encodes a sugar transferase that can add an entire sugar unit to LPS core which can considerably change the OM architecture. This gene is found in Shigella, and when introduced to a K-12 E. coli strain, LPS modifications were detected and suggested that the Rfp protein is a transferase that adds Gal only to a subset of rough LPS molecules produced by the bacteria. Strain-specific differences in LPS structure and 
heterogeneity occurred due to the presence of $r f p$ and other proteins involved in downstream LPS synthesis mechanisms (31). Also, as mentioned above, certain waa genes may also play roles in LPS core modifications. For example, the proteins encoded by waaL (O-antigen ligase), waaK (GlcNAc transferase), and waaZ (Kdo transferase) showed to affect core structure and LPS heterogeneity, even though some of these are mainly involved in LPS biosynthesis (31-33).

Other HDP resistance mechanisms have been discovered, including the use of efflux pumps to remove HDPs from bacteria, the formation of capsules to prevent HDP association, and the expression of proteases that target and degrade HDPs (21). Of particular relevance, activated PhoP induces the expression of ompT, which encodes an OM protease from the highly conserved omptin protease family (34). OmpT is a $\beta$-barrel protein that cleaves $\alpha$-helical HDPs, such as LL37, by targeting its dibasic residues (35). Crystal structures of the OmpT protein show that it is tightly associated with LPS (36). Overall, through the large variety and complexity of hostpathogen interactions, bacteria have developed a multitude of different HDP resistance mechanisms that have likely co-evolved along with HDPs (19).

\subsection{Adherent-invasive Escherichia coli}

\subsubsection{Overview of adherent-invasive Escherichia coli}

E. coli is a major component of a healthy intestinal microbiota, where it normally colonizes the oxic-anoxic interface at the surface of the colonic mucosal surface. Despite this, $E$. coli can exist in many different pathogenic forms in addition to its commensal form (37). Broadly, they include the diarrhoeagenic group, such as enteropathogenic and enterohaemorrhagic E. coli (EPEC and EHEC) (commonly associated with diarrhea in humans), and the extraintestinal group, which includes uropathogenic and neonatal meningitis E. coli 
(UPEC and NMEC) (the only two known major human-associated pathotypes not associated with the intestine). A recently described pathotype of E. coli, adherent-invasive E. coli (AIEC) has been observed in higher abundance in patients with ileal CD and AIEC strains have been isolated from UC patients as well. AIEC colonizes the gut by tightly adhering to epithelial cells and it can also invade and survive within epithelial cells and macrophages although the mechanisms by which it does so remain enigmatic (38).

A clinical isolate of AIEC from the ileal mucosa of a CD patient, strain LF82, was first described in 1998 by Darfeuille-Michaud et al., and over time, has become a standard "prototype" strain in investigations of AIEC (39). This strain was one of the first to demonstrate the adhering and invasive phenotypes that characterize AIEC. For example, the strain was able to efficiently invade, survive to about 24 hours, and even replicate within several different intestinal epithelial cell lines. LF82 was also compared to other intestinal pathogenic E. coli and it was interesting to discover that it lacked any of the known virulence factors from these pathotypes (40). In studies investigating the genetic mechanisms of LF82, transition metal transport was upregulated in the strain, while other processes, such as glycogen metabolism, were downregulated, as compared to non-invasive control strains (41).

Genome sequencing and comparison studies have been carried out in the effort to determine the virulence factors and mechanisms used by AIEC to generate their observed pathogenic effects (41). Many strains of AIEC have been sequenced to date, including LF82, HM605, UM146, NRG857c, eleven other strains used in comparative genome studies, and ten recently identified strains that were characterized using adherence/invasion and survival/replication assays (41-43). Although AIEC share this phenotype (by definition), AIEC strains are not monophyletic (they can belong to completely different clades) and no genes have 
been identified that are common to all or even the majority of them (43). Thus, different AIEC strains can contain unique genes and mechanisms that can each contribute to their overall pathology, as it was seen with the clinical isolate NRG857c (44).

\subsubsection{Clinical isolate NRG857c}

In 2008, Eaves-Pyles et al. first described the clinical isolate NRG857c with serotype O83: $\mathrm{H} 1$, taken from the terminal ileum of a $\mathrm{CD}$ patient. The strain was considered comparable to LF82 in its ability to promote inflammatory responses, and it required flagella to effectively adhere and invade epithelial cells. Other than this, NRG857c did not appear to have any other known virulence factors of other intestinal pathogenic bacteria (45). In 2010, Nash et al. sequenced its genome, and found it to be very closely related to LF82. This strain contains as many as 66 genes and 41 genomic islands that are found only among AIEC strains. The majority of the genes unique to NRG857c are on the pO83 plasmid, suggesting that this plasmid may be the source of novel fitness determinants in this strain (44).

\subsubsection{Plasmid island 6 of NRG857c}

The unique extrachromosomal plasmid of NRG857c, pO83, is closely related to a plasmid from NMEC (strain S88) and a plasmid found in avian pathogenic E. coli (APECO1) (44). This plasmid appears to contain six encoded genomic islands, and one of the islands, plasmid island 6 (PI-6), as it has been previously investigated by McPhee et al., contains genes responsible for HDP resistance. The island consists of three genes, named arlABC (antimicrobial peptide resistance locus $\mathrm{ABC}$ ), required for resistance to $\alpha$ - and $\beta$-defensins, as well as $\alpha$-helical peptides such as LL-37 and CP10A (16). Mutants lacking PI-6 were significantly less virulent 


\section{PI-6 genomic island}

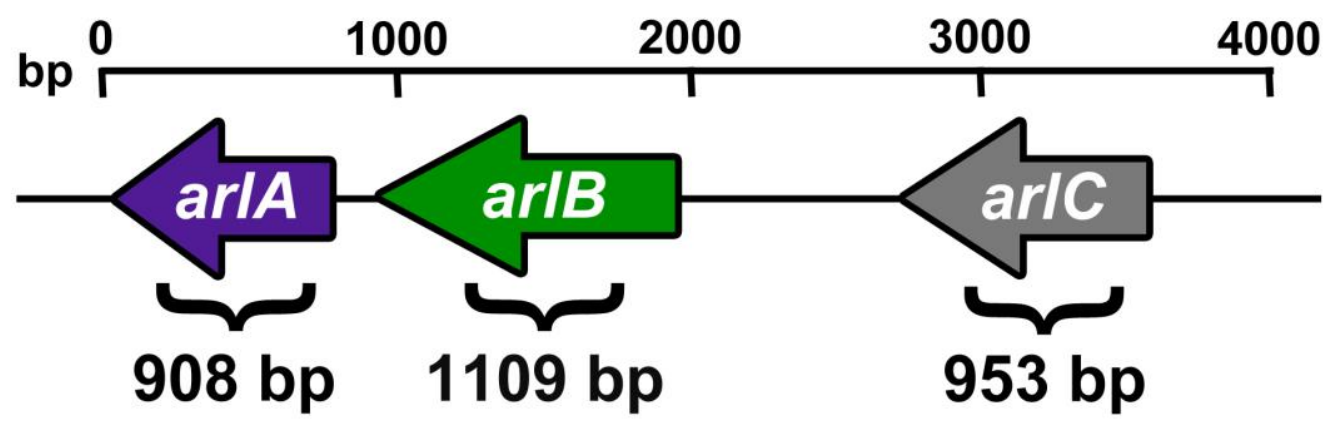

Figure 4. The genomic island PI-6 with genes $\operatorname{arlABC}$, from AIEC strain NRG857c.

than the wild-type (WT) in several models of infection, and the $\operatorname{arlA}$, $\operatorname{arlB}$ and $\operatorname{arlC}$ genes are required for in vivo fitness, and mutants lacking PI-6 failed to expand in the inflamed cecum and ileum of mice after infectious gastroenteritis $(16,46)$. Also, although these genes are not found in LF82, $\operatorname{arlA}$ and $\operatorname{arlC}$ were detected in other clinical isolates in a screen of 64 IBD and 33 nonIBD associated strains. They were only found in isolates from IBD patients, with five strains (5.2\%) with arlA detected and four strains (4.1\%) with arlC detected (16).

\subsubsection{Investigating the $\operatorname{arlABC}$ genes}

The length of the $\operatorname{arlABC}$ genes are shown in Figure 4 and their protein size, sequence, and masses are listed in Table 2 (16). Based on gene spacing, these genes likely form two transcriptional units, with a potential promoter region before $\operatorname{arl} C$ and another between $\operatorname{arlB}$ and $\operatorname{arlC}$. The first would be involved in the expression of $\operatorname{arlA}$ and $\operatorname{arlB}$ together, while the other one would be involved in the expression of $\operatorname{arlC}$ alone.

The initial characterization of this operon demonstrated that the $\operatorname{arl} A B C$ genes were required for high level resistance to peptides like CP10A and LL-37 (Table 3). Resistance to LL37 was principally due to the loss of $\operatorname{arlC}$, but resistance to CP10A depended significantly on the $\operatorname{arlAB}$ genes. This suggests that although $\operatorname{arlC}$ clearly plays a major role in the resistance of 
Table 2. The sizes and sequences of the Arl proteins of PI-6

\begin{tabular}{|c|c|c|c|}
\hline $\begin{array}{c}\text { Arl } \\
\text { Protein }\end{array}$ & Residues & Protein Sequence & $\begin{array}{l}\text { Mass } \\
\text { (kDa) }\end{array}$ \\
\hline ArlA & 302 & $\begin{array}{l}\text { MTLSIKNIKRIITAWKPSTFETYKKTFEKYGGSVNMHPD } \\
\text { VVSYFMIHHDWKFDFFHYEKDGDIKGSYFLCNGKQIGI } \\
\text { MARRSYPLSSDEVLIPFSPHARCFFPDKTNKLSIINKQ } \\
\text { NIINATWKIARKKQNCIIKESFSPKFEKTRRNEIQRFIRN } \\
\text { GGEIKCISQLSDKEISSSYISLFHSRFGGTLPCYEYDNL } \\
\text { LMFISHLRELMFGHVLFWDNKPCAIDIVLKSESSCNVY } \\
\text { YDVPNGAVLNDENCMKLSPGSVLMWLNIDKARRYCQ } \\
\text { DNNKKMIYSIGAFRPEWKYKLLWSVPCKVGKCLC }\end{array}$ & 35.3 \\
\hline ArlB & 369 & $\begin{array}{l}\text { MKLLLLTGATGFLGGAVLDKLLDNCNNINLLLLVRAPT } \\
\text { PQAGLERIKENMRKFNVCEERLHALTNDNILPGDLNN } \\
\text { PEAFLMDPRLDEVTHVINCAAIASFGNNPFIWNVNVTG } \\
\text { TLAFARRMAKVAGLKRFLHVGTAMSCTPHTGSLVKEE } \\
\text { SASSETGEHLVEYTHSKATIEYLMRKQCPDLPLLVARP } \\
\text { SIIVGHSRLGCLPSTSIFWVFRMGLMLQKFMCSLDDKI } \\
\text { DVIPVDYCADALLMLLESSLINGEIVHISAGKESSVTFS } \\
\text { AIDEAVARALNCDPVGDRYTKVSYDILAMSRHDFKNIF } \\
\text { GPCNERLMLKAIRLYGAFSMLNVCFSNDKLLSIGMPKP } \\
\text { PKFTDYIKYCIETTKHLSIQQQMEVDFK }\end{array}$ & 41.0 \\
\hline ArlC & 317 & $\begin{array}{l}\text { MYLKILATALSAPVAFAALASDTGLSFTPEKISTEIDFGT } \\
\text { LSGKAKERVYLPEEKGRKASQLDWKYSNAPIVKGAFN } \\
\text { WDLLPRVSVGASGWTTLAGRGGNMVDRDWLDTSNP } \\
\text { GTWTDESKHPNTRLNFANEFDLNIKGWLLNQPDYQL } \\
\text { GLMAGYQENRYSFTAKGGSYIYSSEGGFRDETGSFP } \\
\text { DGERAIGYKQHFKMPYIGLTGNYRYDSFEFGGSFKYS } \\
\text { GWVKASDNDEHYNPEKRITYRSDVNNQNYYSVSLHA } \\
\text { GYYITPAAKVYVEGTWNRITNKKGDTSLYSRNLNISDH } \\
\text { TKNGAGIESYNFMTTAGLKYYF }\end{array}$ & 35.6 \\
\hline
\end{tabular}

NRG857c to $\alpha$-helical peptides, $\operatorname{arlA}$ and $\operatorname{arlB}$ still appear to also be involved in some aspect of

resistance. It is also very interesting to note that by complementing the $\Delta \mathrm{PI}-6$ mutant or LF82

with a vector containing the $\operatorname{arl} A B C$ genes (compared to an empty vector as a control), the MICs

increased to levels similar to WT NRG857c, demonstrating that the genes can establish effective

resistance in trans (16).

The ArlC protein was shown to function as an OM protease similar to OmpT, based on sequence homology (all active site residues were conserved), the above MIC results, and the 
Table 3. The MICs of LL-37 or CP10A for various NRG857c and LF82 strains

\begin{tabular}{|c|c|c|}
\hline \multirow{2}{*}{ Strain } & \multicolumn{2}{|c|}{ MIC of HDP $(\mu \mathrm{g} / \mathrm{ml})$} \\
\hline & LL-37 & CP10A \\
\hline NRG857c & $32-64$ & $16-32$ \\
\hline NRG857 $\Delta$ phoP & 8 & 4 \\
\hline NRG857 $\Delta$ PI-6 & 8 & $4-8$ \\
\hline NRG857 $\Delta a r I A$ & $16-32$ & 8 \\
\hline NRG857 $\triangle a r I B$ & 32 & 8 \\
\hline NRG857 $\Delta$ arlC & 8 & 4 \\
\hline NRG857 $\Delta$ PI-6(pCR2.1) & 8 & 4 \\
\hline NRG857 $\triangle$ PI-6(pCRarlABC) & 64 & 64 \\
\hline LF82 & 8 & 8 \\
\hline LF82(pCR2.1) & 16 & 8 \\
\hline LF82(pCRarlABC) & 64 & 32 \\
\hline
\end{tabular}

ability for NRG857c to cleave a synthetic LL-37 mimic effectively as compared to the $\triangle a r l C$ mutant (16). With respect to ArlA, although the MIC results showed a more intermediate role as compared to ArlC, it demonstrated a significant role in resistance against HD5, hBD2, and Paneth cell secretions in vitro. Also, the $\triangle$ arlA mutant was the only one of the three individual gene mutants that had significantly impaired fitness in vivo, with results comparable to the $\Delta \mathrm{PI}-6$ mutant (16). However, it remains unclear what the function of ArlA and ArlB are and, although each contributes independently to HDP resistance, the mechanism by which this occurs is unknown.

Based on homology, the ArlA protein is predicted to be an acetyltransferase of the family of Gcn5-related $N$-acetyltransferases (GNATs), while ArlB is predicted to be an nicotinamide adenine dinucleotide (NAD)-dependent epimerase, although the target molecules for these putative activities is unknown (16). To further predict the possible functions of ArlA and ArlB, 
we utilized the online bioinformatics tool Phyre 2 to align the protein sequences with other known and structurally characterized proteins. Through the use of sequence comparisons and detailed analyses, the Phyre2 tool compiles predictions on protein structure, function, and possible sequence mutations. It generates three-dimensional structures that incorporates the predictions determined and includes domain regions and potential active site residues (47). Figure 5 presents the generated ArlA and ArlB structures based on the top results for these two proteins - FemX from the Gram-positive bacteria Weissella viridescens (48) and ArnA from various Gram-negative bacteria (49), respectively. ArlA was modelled with $99.2 \%$ confidence for 142 residues ( $47 \%$ of its sequence) and over $90 \%$ confidence for 263 residues ( $87 \%$ of its sequence), while ArlB was modelled with $100 \%$ confidence for 321 residues (87\% of its sequence) (47).

As it was predicted for ArlA, FemX is also part of the GNAT family and it is involved in the addition of amino acid residues to the peptidoglycan precursor of the cell wall, and it is

(A)

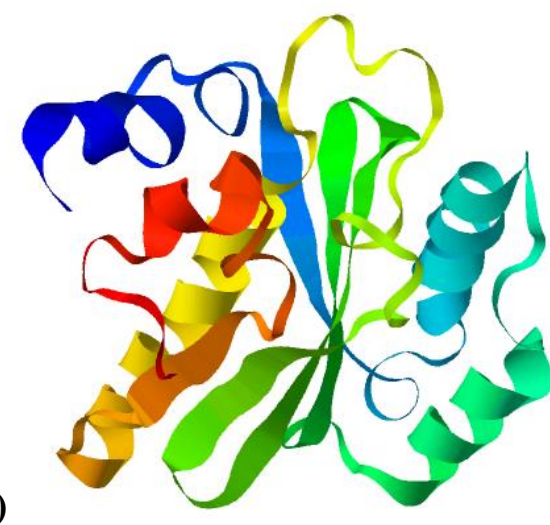

(B)

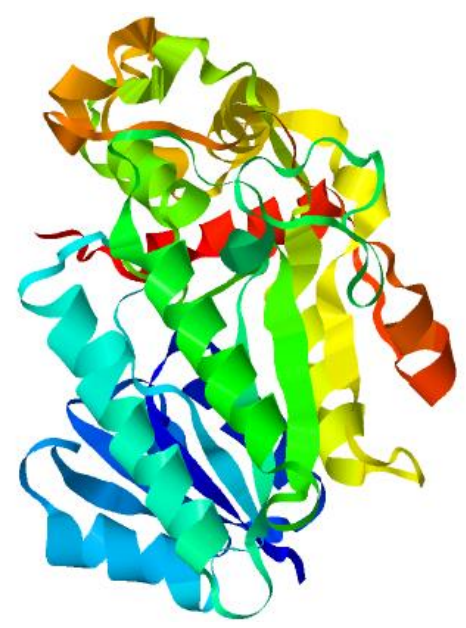

Figure 5. Predicted structures of ArlA and ArlB generated with Phyre2 based on top alignment results.

(A) ArlA predicted structure based on FemX from W. viridescens. (B) ArlB predicted structure based on ArnA from various Gram-negative bacteria. 
possible ArlA is involved in a similar process directly affecting peptidoglycan or other cell membrane components, such as LPS. The homology of a Gram-positive bacterial modification system with a Gram-negative bacterial one was already seen previously: a lipid A modification system in Vibrio cholerae uses amino acid additions to confer HDP resistance and closely resembles the Gram-positive bacterial system of adding amino acids to the teichoic acid of the cell wall, and both systems reduce the overall negative charge of their targets (50). Additionally, McPhee et al. also stated that the ArlA protein is related to the Mig-14 and PA5003 proteins involved in HDP resistance in Salmonella enterica and Pseudomonas aeruginosa, respectively $(16,51,52)$. Like other HDP resistance genes, expression of mig-14 is controlled by the PhoPQ TCS, but it is not involved in LPS modification by Ara4N addition to lipid A (51). Thus, the Mig-14 protein may be involved in other types of LPS modifications or resistance mechanisms, such as the interaction with bacterial membranes to prevent increased permeabilization, and ArlA may have a closely related function (16). Interestingly, the PA5003 protein is part of an operon likely involved in core LPS biosynthesis and it was required by $P$. aeruginosa to resist HDPs in certain conditions, thus ArlA may function in a similar manner (52).

As for the top alignment result for ArlB, the ArnA protein, from the arnBCADTEF operon discussed above, is a NAD-dependent decarboxylase that is involved in the biosynthesis of UDP-Ara4N, a precursor to the Ara4N addition to lipid A. This protein fold is shared by a number of NAD-dependent proteins, including decarboxylases, dehydratases and epimerases. However, decarboxylation activity can be ruled out for ArlB due to its divergence from the residues required for this type of activity (serine is required at the residue analogous to ArnA position 433 and arginine at position 619). Also, dehydratase activity could be possible if the required serine was substituted with aspartate, but ArlB has methionine at this position. This 
suggests that ArlB may have an epimerase function (53). Just as ArnA catalyzes a step in the Ara4N addition resistance mechanism, ArlB may catalyze a necessary epimerase step in another resistance mechanism.

The specific pathways or mechanisms that the ArlA and ArlB proteins are involved in, and their possible targets are unknown. Thus, their mode of action in contributing to HDP resistance remains unclear. This work focuses on the investigation of the phenotypic differences between strains with or without the $\operatorname{arlA}$ and $a r l B$ genes, and it seeks to determine potential regulation pathways that may regulate their expression, such as the well-known TCSs discussed above. This study can lead to a better understanding of the resistance mechanisms used by AIEC strains, such as NRG857c, which may be a significant factor in the development of IBD. 


\section{PURPOSE, HYPOTHESES, AND OBJECTIVES}

\subsection{Rationale and Purpose}

The arlABC genes of PI-6 from AIEC clinical isolate NRG857c confer prominent resistance to HDPs that significantly surpasses what can be seen for AIEC prototype LF82, especially towards $\alpha$-helical peptides and human defensins. Thus, these genes likely encode for proteins involved in specific resistance mechanisms that could play an important role in the development or progression of IBD. ArlC is an omptin protease similar to OmpT, but not much is known about the ArlA and ArlB proteins. In this study, I investigate the potential roles that these two proteins have to altering LPS structure and HDP susceptibility. I also investigate regulatory mechanisms that are involved in the expression of the ArlA and ArlB proteins.

\subsection{Hypotheses and Objectives}

2.2.1 The ArlA and ArIB proteins are involved in altering the structure and the permeability of the NRG857c cell envelope

Objective I: Determine the effect of the proteins on the structure of LPS by comparing LPS profiles on gels. Using NRG857c and isogenic mutants of the strain NRG857c ( $\triangle \mathrm{PI}-6, \Delta p h o P, \Delta a r l A$ and $\triangle a r l B)$, LPS profiles were prepared using sodium dodecyl sulfate-polyacrylamide gel electrophoresis (SDS-PAGE) and a silver staining protocol.

Objective II: Determine the effect of $a r l A$ and $a r l B$ on the permeability of the outer membrane. Phenotypic differences between the different mutants were compared 
utilizing various antimicrobial susceptibility and OM permeability assays.

2.2.2 The ArlA and ArlB proteins are transcriptionally regulated by conserved regulatory systems

Objective III: Prepare translational fusions of the $\operatorname{arlA}$ and $\operatorname{arlB}$ genes in order to monitor changes in regulation due to altered environmental conditions or to the deletion of particular regulatory proteins. 


\section{METHODS}

\subsection{Bacterial strains used in this study}

The list of strains that were used in this study are shown in Table 4. The strains NRG857c and LF82 are both clinical isolates of AIEC, as discussed above. The mutants and fusion tagged Table 4. Bacterial strains used in this study.

\begin{tabular}{|c|c|c|}
\hline Strain & Description & $\begin{array}{l}\text { Source or } \\
\text { Reference }\end{array}$ \\
\hline NRG857c & Clinical AIEC isolate & $\begin{array}{l}\text { Eaves-Pyles et } \\
\text { al. (45) }\end{array}$ \\
\hline NRG857AphoP & Deletion of phoP gene & $\begin{array}{l}\text { McPhee et al. } \\
(16)\end{array}$ \\
\hline NRG857 $\Delta$ PI-6 & Deletion of PI-6 & $\begin{array}{l}\text { McPhee et al. } \\
(16)\end{array}$ \\
\hline NRG857 $\Delta$ arlA & Deletion of arlA gene & $\begin{array}{l}\text { McPhee et al. } \\
(16)\end{array}$ \\
\hline NRG857 $\Delta$ arlB & Deletion of $a r l B$ gene & $\begin{array}{l}\text { McPhee et al. } \\
(16)\end{array}$ \\
\hline NRG857 $\Delta$ cat $\Delta$ ompTAarIC & $\begin{array}{l}\text { Deletion of cat, omp } T \text {, and } a r l C \\
\text { genes (deletion of omptin protease } \\
\text { activity) }\end{array}$ & $\begin{array}{l}\text { McPhee et al. } \\
\text { (16) }\end{array}$ \\
\hline NRG857c arlA:HA & HA fusion tag of arlA & This study \\
\hline NRG857c arIB:HA & HA fusion tag of $\operatorname{arlB}$ & This study \\
\hline NRG857 $\Delta p h o P$ arlB:HA & $\begin{array}{l}\text { phoP mutant in the background } \\
\text { containing the HA fusion tag of } \operatorname{arlB}\end{array}$ & This study \\
\hline LF82 & Clinical AIEC isolate & \begin{tabular}{|l} 
Darfeuille- \\
Michaud et al. \\
(39) \\
\end{tabular} \\
\hline DK K12 & K12 strain with serotype OR:NM & $\begin{array}{l}\text { From collection } \\
\text { of D. O. Krause }\end{array}$ \\
\hline SL1344 & S. enterica serovar Typhimurium & $\begin{array}{l}\text { Stocker et al. } \\
\text { (54) }\end{array}$ \\
\hline
\end{tabular}

constructs in NRG857 were developed previously, or through this study, for the lab collection.

The strains DK K12 (K12 E. coli) and SL1344 (virulent Salmonella) were used as controls for the bacterial invasion/survival assay. 


\subsection{Bacterial growth and harvest}

Bacterial strains are stored frozen at $-80^{\circ} \mathrm{C}$ in Luria-Bertani (LB) broth with $25 \%$ glycerol, and they are routinely grown overnight (12 to 18 hours) in LB broth, shaking at $37^{\circ} \mathrm{C}$. Overnight cultures can then be directly inoculated into fresh sterile LB broth as a subculture, or they can be washed and resuspended in $\mathrm{N}$ minimal media before inoculating into fresh sterile $\mathrm{N}$ minimal media. N minimal media consists of 0.1 M 2-[Bis(2-hydroxyethyl)amino]-2(hydroxymethyl)propane-1,3-diol (Bis-TRIS), $\mathrm{pH} 7.5,5 \mathrm{mM} \mathrm{KCl}, 7.5 \mathrm{mM}\left(\mathrm{NH}_{4}\right)_{2} \mathrm{SO}_{4}, 0.5 \mathrm{mM}$ $\mathrm{K}_{2} \mathrm{SO}_{4}, 1 \mathrm{mM} \mathrm{KH}_{2} \mathrm{PO}_{4}, 0.10 \%$ Casamino Acids, $0.20 \%$ glucose, $0.0002 \%$ thiamine, $15 \mu \mathrm{M}$ $\mathrm{FeSO}_{4}$ or $100 \mu \mathrm{M} \mathrm{FeSO}_{4}$ for high $\mathrm{Fe}^{2+}$ conditions, and $10 \mu \mathrm{M} \mathrm{MgSO}_{4}$ for low $\mathrm{Mg}^{2+}$ conditions or $10 \mathrm{mM} \mathrm{MgSO}_{4}$ for high $\mathrm{Mg}^{2+}$ conditions (22). The ratio of overnight culture to fresh growth media is 1:50 for $\mathrm{LB}$ broth or $\mathrm{N}$ minimal media with high $\mathrm{Mg}^{2+}$, or 1:25 for $\mathrm{N}$ minimal media with low $\mathrm{Mg}^{2+}$.

Bacterial subculture growth is monitored using the optical density (OD) at $600 \mathrm{~nm}$ until the desired associated growth phase is reached (e.g. logarithmic or stationary phase of growth). Based on the OD and specific method requirements, a certain amount of subculture is centrifuged to pellet the cells, then these are washed with phosphate buffer saline and pelleted again. Pellets can be stored frozen at $-20^{\circ} \mathrm{C}$ until they are required, then they are resuspended in appropriate buffer for further treatments, according to the specific method.

\subsection{Silver staining of LPS on gels}

Briefly, based on the protocol by Hitchcock and Brown (55), using overnight cultures, bacterial cultures are subcultured into LB broth to grow to mid-logarithmic, early stationary, or late stationary phases. After the cells are harvested and washed with PBS, they are treated with 
lysing buffer, proteinase K, and DNAse I. The whole-cell lysates are subjected to SDS-PAGE using the Laemmli buffer system on polyacrylamide separating gels. The gels are visualized using the silver staining protocol developed by Zhu et al. (56) in which four solutions are prepared for oxidation (30\% ethanol, $10 \%$ acetic acid, $0.7 \%$ periodic acid), silver staining $(0.2 \%$ silver nitrate), developing the image ( $3 \%$ sodium carbonate, $0.04 \%$ sodium thiosulfate, $0.02 \%$ ascorbic acid, $0.05 \%$ sodium hydroxide, variable time), and stopping (10\% acetic acid) the developing reaction.

\subsection{NPN OM permeabilization assay}

In brief, based on the methods used by Loh et al. (57) and by Helander and MattilaSandholm (58), overnight bacterial cultures grown to mid-logarithmic phase are harvested and suspended in buffer containing $5 \mathrm{mM} N$-2-hydroxyethylpiperazine- $N$ '-2-ethanesulfonic acid (HEPES, $\mathrm{pH} ~ 7.4$ ) and $5 \mu \mathrm{M}$ carbonyl cyanide $m$-chlorophenyl hydrazine (CCCP) as a proton pump inhibitor. Stock 1-N-phenylnaphthylamine (NPN) solution is prepared in acetone and then diluted to $40 \mu \mathrm{M}(4 \times)$ in buffer. The test antimicrobial compound is prepared in appropriate buffers using relevant serial dilutions. Wells in a black opaque microtiter plate are prepared with or without NPN and with different concentrations of the test compound. Cells are then added immediately before fluorescence reading, which is carried out by a microplate fluorometer with an excitation wavelength of $360 \mathrm{~nm}$ (bandwidth $40 \mathrm{~nm}$ ) and emission wavelength of $420 \mathrm{~nm}$ (bandwidth $50 \mathrm{~nm}$ ). Fluorescence readings are then used to calculate uptake factors corrected by subtracting the background values. The fluorescence values are determined using the maximum values obtained for all trials. The NPN uptake factor (NUF) is calculated as follows:

$$
\mathrm{NUF}=\frac{\mathrm{F}_{\mathrm{obs}}-\mathrm{F}_{0}}{\mathrm{~F}_{\mathrm{blank}}}
$$


in which $\mathrm{F}_{\mathrm{obs}}$ is the observed fluorescence, $\mathrm{F}_{0}$ is the fluorescence (background) of buffer (and testing concentration of permeabilizer) and cells with no NPN, and Fblank $_{\text {is }}$ the corrected mean fluorescence of NPN and buffer with no cells obtained by subtracting the fluorescence of buffer with no NPN.

\subsection{Lysozyme-mediated permeabilization assay}

Another method of testing the OM permeabilization, as described by Hancock and Wong (59), uses bacterial samples that are grown to a specific growth phase, washed and resuspended in $5 \mathrm{mM}$ HEPES, then monitored continuously by $\mathrm{OD}_{600}$ in a spectrophotometer as lysozyme is added to a final concentration of $50 \mu \mathrm{g} / \mathrm{ml}$, followed by a permeabilization agent (such as a HDP) to a final testing concentration. The continuous OD readings, which are expected to decrease according to how much lysozyme passes through the permeabilized membrane to cause cell lysis, are recorded and can then be normalized to make comparisons. The results are presented using the percentage relative change in $\mathrm{OD}_{600}(\Delta \mathrm{OD})$, in which $100 \%$ change corresponds to an OD difference of 1.0. The $\Delta \mathrm{OD}$ is normalized to the OD readings taken after adding $50 \mu \mathrm{g} / \mathrm{ml}$ of lysozyme to the reaction. It should also be noted that increasing $\triangle \mathrm{OD}$ values indicate that the $\mathrm{OD}$ was decreasing over time and decreasing values that OD was increasing over time.

\subsection{Light microscopy}

Light microscopy was used to observe bacterial samples obtained from the lysozyme assay. Samples of about $10 \mu \mathrm{l}$ are taken from bacterial stocks prepared for the assay, or directly out of the cuvettes containing bacteria undergoing the assay, then dried on glass microscope slides and heat-fixed over a flame. The slides are then Gram-stained and observed under 100× oil 
immersion objective lens, and images representative of the observed samples are taken digitally.

\subsection{Radial diffusion assay}

Briefly, based on the procedure developed by Lehrer et al. (60), bacterial cultures grown to the desired growth phase are harvested, washed and resuspended in sodium phosphate buffer (NAPB), then added at an appropriate normalized colony forming unit (CFU) concentration to a warm solution of NAPB containing tryptic soy broth (TSB), low-electroendosmosis-type agarose and Tween 20. This is poured onto petri dishes, and cooled until the agar hardens. Next, $3 \mathrm{~mm}$ wide wells with HDPs of interest at varying concentrations are added to the agar. After being left to diffuse for an hour, the plates were overlaid with fresh agar containing more concentrated TSB and agarose, and then left to incubate for 18 to 24 hours at $37^{\circ} \mathrm{C}$. The diameter of clearing can then be measured and compared between bacterial samples and HDPs used.

\subsection{Fractional inhibitory concentration assay}

Based on the checkerboard microdilution protocol used by Stokes et al. (61) and the modified MIC procedure by McPhee et al. (16), 10x stocks of one of the drugs are two-fold serially diluted in appropriate buffer, and the other drug is two-fold serially diluted in appropriate growth media on a 96-well polypropylene plate. The first drug is added to the media with the second drug, to form an eight-by-eight grid of varying concentration combinations of the two drugs. About $5 \times 10^{4} \mathrm{CFU}$ of the test strain is inoculated into the wells and these are incubated for 18 to 24 hours at $37^{\circ} \mathrm{C}$. After visually determining the wells that inhibited growth, the fractional inhibitory concentration (FIC) index can be calculated by: 


$$
\mathrm{FIC}_{\mathrm{i}}=\frac{\mathrm{MIC}_{\mathrm{AB}}}{\mathrm{MIC}_{\mathrm{A}}}+\frac{\mathrm{MIC}_{\mathrm{BA}}}{\mathrm{MIC}_{\mathrm{B}}}=\mathrm{FIC}_{\mathrm{A}}+\mathrm{FIC}_{\mathrm{B}}
$$

in which $\mathrm{MIC}_{\mathrm{A}}$ is the MIC of drug A alone, $\mathrm{MIC}_{\mathrm{B}}$ is the $\mathrm{MIC}$ of drug $\mathrm{B}$ alone, $\mathrm{MIC}_{\mathrm{AB}}$ is the MIC of drug $\mathrm{A}$ in combination with drug $\mathrm{B}, \mathrm{MIC}_{\mathrm{BA}}$ is the MIC of drug $\mathrm{B}$ in combination of drug $\mathrm{A}$, FIC $_{\mathrm{A}}$ is the FIC of drug A, FIC $_{\mathrm{B}}$ is the FIC of drug B, and $\mathrm{FIC}_{\mathrm{i}}$ is the FIC index.

\subsection{Bacterial invasion/survival assay}

In brief, 24-well plates are prepared with $1.3 \times 10^{5}$ RAW264.7 macrophages in Dulbecco's modified eagle's medium (DMEM) with 10\% fetal bovine serum, penicillin, and streptomycin. Before invasion, the cells are washed with PBS and suspended in fresh culture media without antibiotics. Mid-logarithmic growth phase bacteria grown in LB growth media are harvested and resuspended in PBS, then added to the macrophages at a multiplicity of infection of 10:1. The plates are centrifuged then incubated for 1 hour or 24 hours using gentamicin DMEM media, at $37^{\circ} \mathrm{C}$. The cultures are then washed with PBS and suspended in DMEM with gentamicin. This is incubated at $37^{\circ} \mathrm{C}$ for 15 minutes, washed again with PBS, and subjected to $0.1 \%$ Triton-X solution to lyse the macrophages. The lysates solutions are spot plated on LB agar plates, then incubated at $37^{\circ} \mathrm{C}$ overnight. Colonies were counted for each of the spots.

\subsection{Translational fusion and mutagenesis}

To prepare the translational fusions, based on the method by Uzzau et al. (62), DNA fragments with a kanamycin resistance cassette and flanking FLP recombinase recognition target (FRT) sites are amplified by polymerase chain reaction (PCR) using primers to prepare the hemagglutinin (HA) epitope sequence added to sequences targeting the gene of interest. Linear 
DNA fragments are electroporated into competent NRG857c and selection of kanamycin resistant clones is performed. The kanamycin resistance cassette is removed using the FRT technique described by Datsenko and Wanner (63). The cells can then be purified and used to monitor the expression of the gene of interest using antibodies directed to the HA epitope tag in the fusion protein that is produced.

To obtain phoP deletion constructs in the arlB:HA fusion strain, the allelic exchange mutagenesis method was used. In short, a mutant version of the gene to be deleted is produced using single-overlap extension PCR and cloned into pCR2.1-TOPO plasmid. After sequence verification, the fragment is subcloned to $\mathrm{pRE} 112-\mathrm{Gm}$ and this is then transformed into $E$. coli S17-1 $\lambda$ pir cells. Biparental mating is performed and recombinant, gentamicin resistance clones are picked. These merodiploid strains are grown in LB media with $10 \%$ sucrose for 8 hours at $37^{\circ} \mathrm{C}$, then streak plated on LB agar. Clones that are now sensitive to the donor antibiotic are picked and tested under colony PCR using the primers surrounding the gene of interest. Clones that produce the reduced size PCR product have successfully obtained the mutant allele.

\subsection{Western blotting and densitometry}

As described previously (64), bacterial samples are grown in the desired conditions, then harvested and prepared under the Laemmli buffer system. Some of each sample can be used to quantify protein amounts using bicinchoninic acid (BCA) as a standard so that sample loading can be normalized. The samples are subjected to SDS-PAGE, then transferred to nitrocellulose membranes. The membranes are blocked with skim milk, then rinsed with tris(hydroxymethyl)aminomethane (TRIS) buffered saline $+0.1 \%$ Tween 20 (TBST) and treated with anti-HA rabbit IgG (Cell Signaling Technology Inc. \#3724S, 1:1000 dilution) or anti-DnaK 
mouse IgG (Enzo Life Sciences Inc. \#ADI-SPA-880-D, 1:10 000 dilution) antibodies. After rinsing with more TBST, the membranes are treated with goat anti-rabbit IgG (BioShop Canada Inc. \#APA007P.2, 1:10 000 dilution) or goat anti-mouse IgG (Promega Corporation \#W4021, 1:5000 dilution) antibodies that are conjugated with horseradish peroxidase. After final TBST rinses, the membranes are covered with $1.25 \mathrm{mM}$ luminol, $0.2 \mathrm{mM}$ coumaric acid, $0.032 \%$ hydrogen peroxide, and $100 \mathrm{mM}$ TRIS-hydrogen chloride at pH 8.5 (electrochemiluminescence solution) and the blot signals are detected on a gel imager. Densitometry values can be quantified and calculated using appropriate software that analyzes images obtained from the gel imager.

\subsection{Statistical Analysis}

Experiments were routinely completed as three biological replicates, and results are generally presented as means with standard deviations or using one set of representative results, except where otherwise noted. Statistical analyses to determine differences among strains and/or antimicrobial concentrations consisted of one-way or two-way analysis of variance (ANOVA) with Tukey or Bonferroni post-tests, or the Mann-Whitney $U$ test, as appropriate, performed using a 95\% confidence interval. The analyses were completed using GraphPad Prism 5.0 software (GraphPad Software Inc. San Diego, CA). Significances are marked on figures using asterisks $(*)$ to correspond to determined $p$ values, and the actual values are stated in captions. 


\section{RESULTS}

\subsection{Mutants of $\operatorname{arlB}$ show evidence of altered LPS structure}

By isolating and running LPS on gels using SDS-PAGE and visualizing the banding pattern using silver staining, LPS profiles shown along each lane can be compared. The banding pattern in a typical LPS profile appears as a ladder of about 30-40 doublet bands that are gray or red (Figure 6). As with protein SDS-PAGE, the bands correspond to migration according to size, with the larger components at the top of the ladder and the smallest components at the bottom. That being said, the smallest fragments of lipid A with some core would be found at the bottom of the ladder as the leading edge, larger fragments of lipid A with cores would make up most of the lower half of the ladder (generally appearing as the darker, denser bands), and varying sizes of O-antigen repeat polymers of LPS would make up most of the rest of the ladder extending to the top (generally appearing as the lighter, fainter bands). Modifications to any region of LPS should correspond to slight changes in the profiles, such as additional, missing, darker, or lighter bands (55).

In an initial trial of the LPS gel method, WT NRG857c and the isogenic mutants $\Delta$ PI-6, $\triangle a r l A$ and $\triangle a r l B$ were grown to the mid-logarithmic, early stationary, and late stationary phases. After the appropriate treatment of the cells to form whole-cell lysates, the samples were subjected to SDS-PAGE and visualized using the silver stain protocol (developing time was 7 minutes). The gel appeared too dark, but a typical banding pattern could be observed (Figure 6A). Rather faintly, a missing doublet may be seen in the lowest regions of the lipid A profiles in $\Delta \mathrm{PI}-6$ and $\triangle a r l B$, the two strains lacking the $\operatorname{arlB}$ gene. However, as this was an initial trial and visualization was poor, valid conclusions could not be drawn yet. The protocol underwent troubleshooting to enhance the visual quality and obtain clearer results, such as the addition of a 

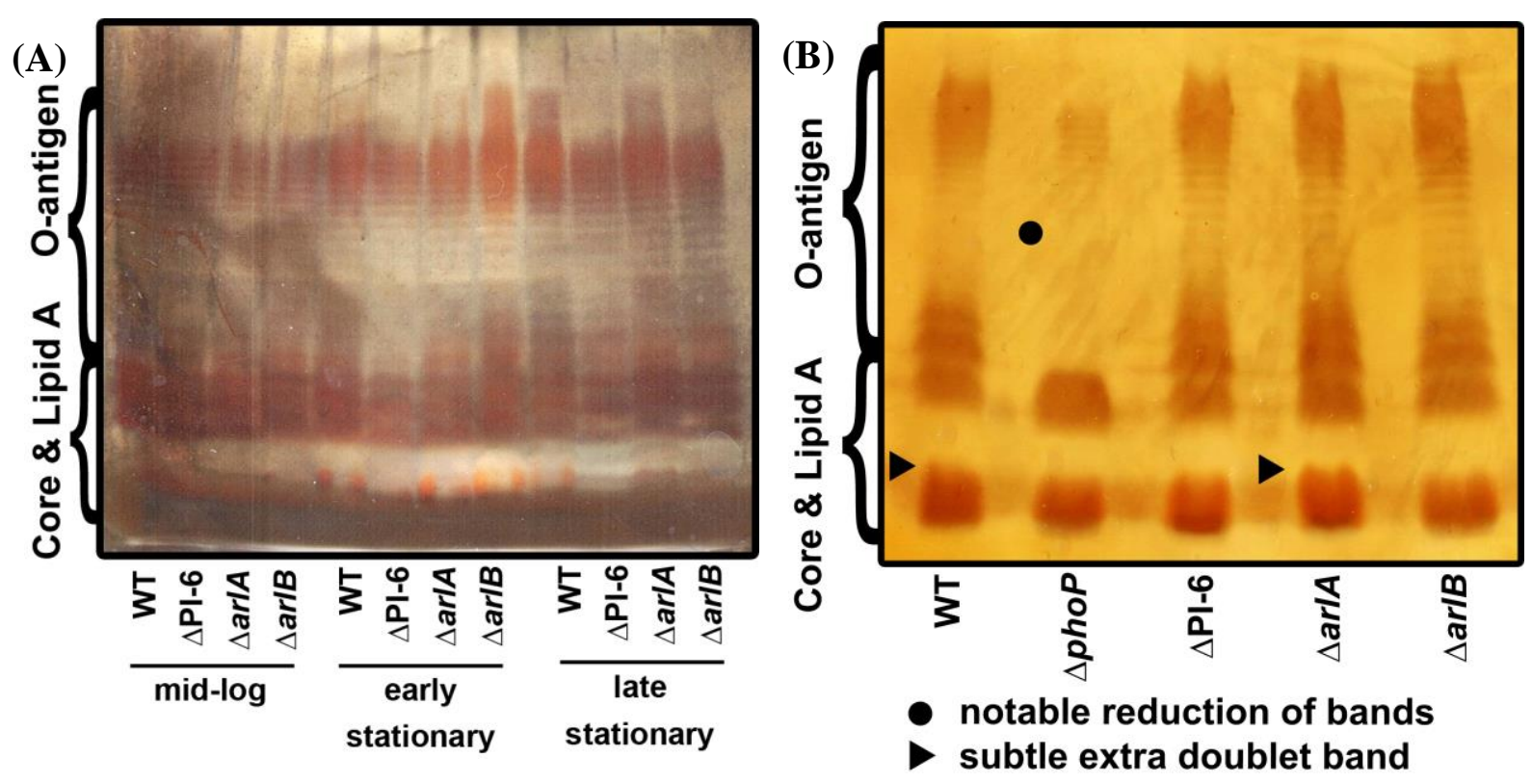

Figure 6. The profile regions where the different types of LPS fragments can be visualized is marked in both gels.

(A) The silver-stained LPS gel profiles of WT NRG857c and the isogenic mutants $\triangle \mathrm{PI}-6, \Delta a r l A$, and $\triangle a r l B$, grown to mid-logarithmic, early stationary, and late stationary phases, as obtained in an initial trial. (B) The silver-stained LPS gel profiles of WT NRG957c and the same isogenic mutants, along with $\Delta p h o P$, grown to late stationary phase.

water rinsing step before the gels are silver stained, and determining optimal developing times. In one of the later trials using the improved protocol, NRG857c and its isogenic mutants $\Delta p h o P$, $\triangle \mathrm{PI}-6, \Delta a r l A$, and $\triangle a r l B$ were grown to late stationary phase and subjected to LPS gel analysis (developing time was only about 1.4 minutes). This gel was much clearer and replicated the missing doublet in the lipid A-core region seen in the $\Delta \mathrm{PI}-6$ and $\triangle a r l B$ profiles (Figure $6 \mathrm{~B}$ ), and interestingly, showed presumably the same missing doublet in $\Delta p h o P$. The doublet is present in the WT and $\triangle a r l A(-)$, the strains that contain $\operatorname{arlB}$. This suggests that ArlB is involved in some modification of the core or lipid A region of LPS, and that PhoP may be required to express $\operatorname{arlB}$. It is also interesting to note in Figure 6B that there is a reduction in $\mathrm{O}$-antigen doublet bands in the $\Delta$ phoP mutant $(\bullet)$, but further investigation of this is beyond the scope of this thesis. 
Various approaches were then taken to attempt to improve the resolution of the banding pattern corresponding to the core region of the LPS gel profiles. This was pursued so that the change seen in the gels could be confirmed before working on further techniques. Increasing the polyacrylamide concentration of the gels to $20 \%$ did not improve resolution in the core region (it appeared very similar to the $12 \%$ gels). Other approaches involved using large-format gels $(20 \times$
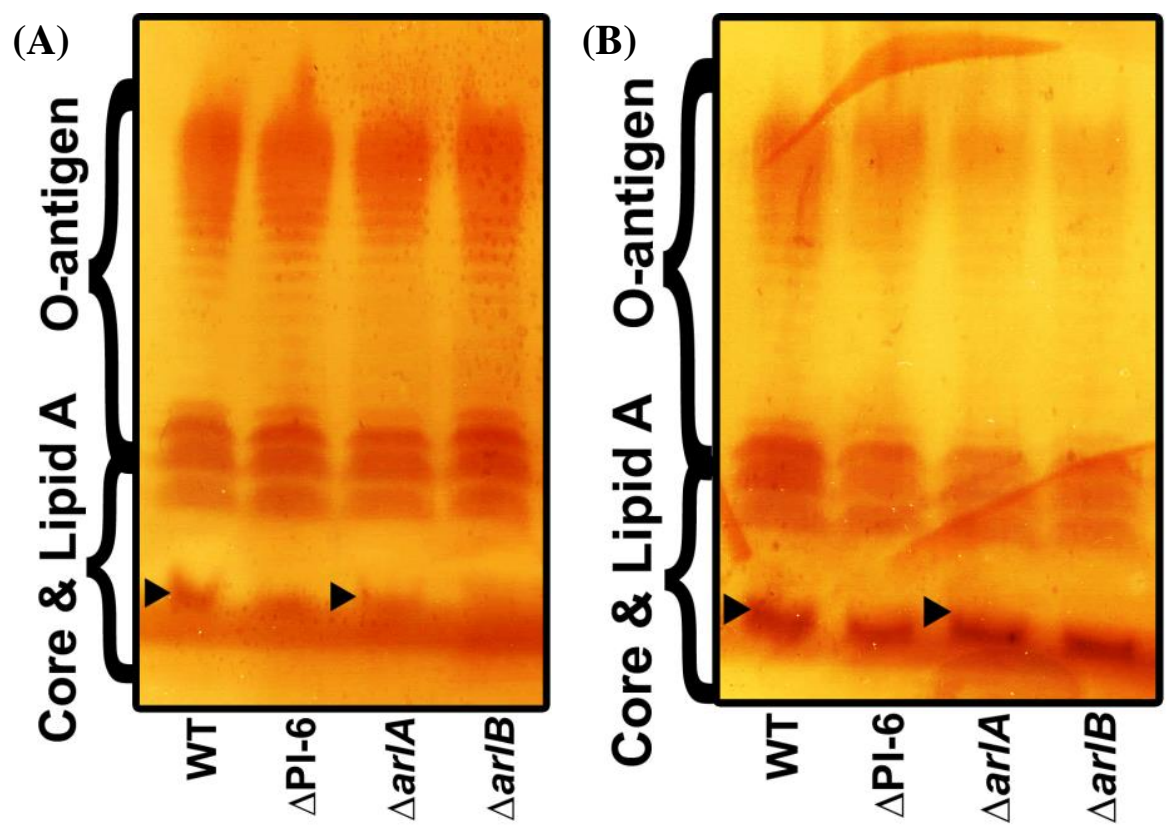

\section{subtle extra doublet band}

Figure 7. Visualization of LPS on polyacrylamide gradient (4 to 20\%) gels.

(A) The same additional banding of the core region in the WT and $\triangle a r l A$ can be seen. (B) Loading twice as much sample allowed the core region to appear darker.

$16 \mathrm{~cm}$ ) or polyacrylamide gradient gels (4 to $20 \%$ ). The first of these was unsuccessful, however using gradient gels allowed for a slight improvement in overall band resolution (Figure 7).

When using similar amounts of processed whole cell lysates in the gradient gels (Figure 7A), the core region shows similar results as previously, as indicated ( ). To further improve visualization on the gradient gels, in the core region specifically, twice as much lysate was loaded instead (Figure 7B). In this final gel, the core region became more clearly defined and the 
same result is shown, however this difference between the strains is still a very subtle one.

\subsection{The $\triangle p h o P$ mutant has significantly higher NPN uptake factors than WT NRG857c in varying concentrations of polymyxin $B$}

As discussed above, as part of their killing mechanism, HDPs can interfere with OM integrity, but strains like NRG857c may utilize resistance methods to reduce this effect. The fluorescent hydrophobic probe 1-N-phenylnaphthylamine (NPN), a three-ring aromatic amine compound, has the ability to insert within the OM of Gram-negative bacteria which can be detected as a high signal relative to a much weaker signal when it is unbound in the aquatic environment (57). This is due to fluorescent parameters, such as polarization and fluorescent lifetimes, which are enhanced in the lipophilic membrane environment (65). However, insertion in the membrane is normally prevented due to the hydrophilic layer of charged LPS and bridging divalent cations. Disruption of the OM, due to the presence of HDPs, permits the insertion of NPN into the hydrophobic region of the membrane. Thus, higher fluorescence values can be associated with increased OM permeabilization; NPN can be used to detect phenotypic differences in permeabilization and to what extent increased permeabilization is prevented with respect to specific HDPs.

Previously, this was demonstrated using aminoglycoside antibiotics, which interacted with the $\mathrm{OM}$ of $P$. aeruginosa and reduced its structural integrity to become more permeable. The more permeable the OM became, the more NPN uptake and embedding occurred in the membrane, and this was observed as faster and higher fluorescent signals. It is also important to note the use of a poison, in particular, a cyanide compound, in the protocol. The cyanide blocks transport mechanisms that would normally cause expulsion of the antibiotics out of the cell. It was even shown that fluorescence signals are rapidly diminished in the absence of the poison, 
while signals remain high for a longer period of time by using the poison (57). Later on, the NPN assay was also developed to determine the effect of different variants of the HDP gramicidin S on the OM permeabilization of a strain of E. coli (66).

Similarly, we utilized the NPN OM permeabilization assay to investigate the effect of specific relevant HDPs on the OM NRG857c of and its mutants. Preliminary trials of the assay were completed, to troubleshoot and develop the protocol, using WT NRG857c and the isogenic mutant $\Delta p h o P$, and the antibiotic polymyxin $\mathrm{B}(\mathrm{PxB})$. This is due to the fact the $\Delta p h o P$ mutant is already known to be very susceptible to polymyxin B, especially compared to the WT (21), and results from the assay between these strains should differ significantly. In these initial trials, it was seen that it is critical to add bacterial samples quickly and accurately as the last step before loading the plate into the reader, since maximum fluorescence can occur within seconds.
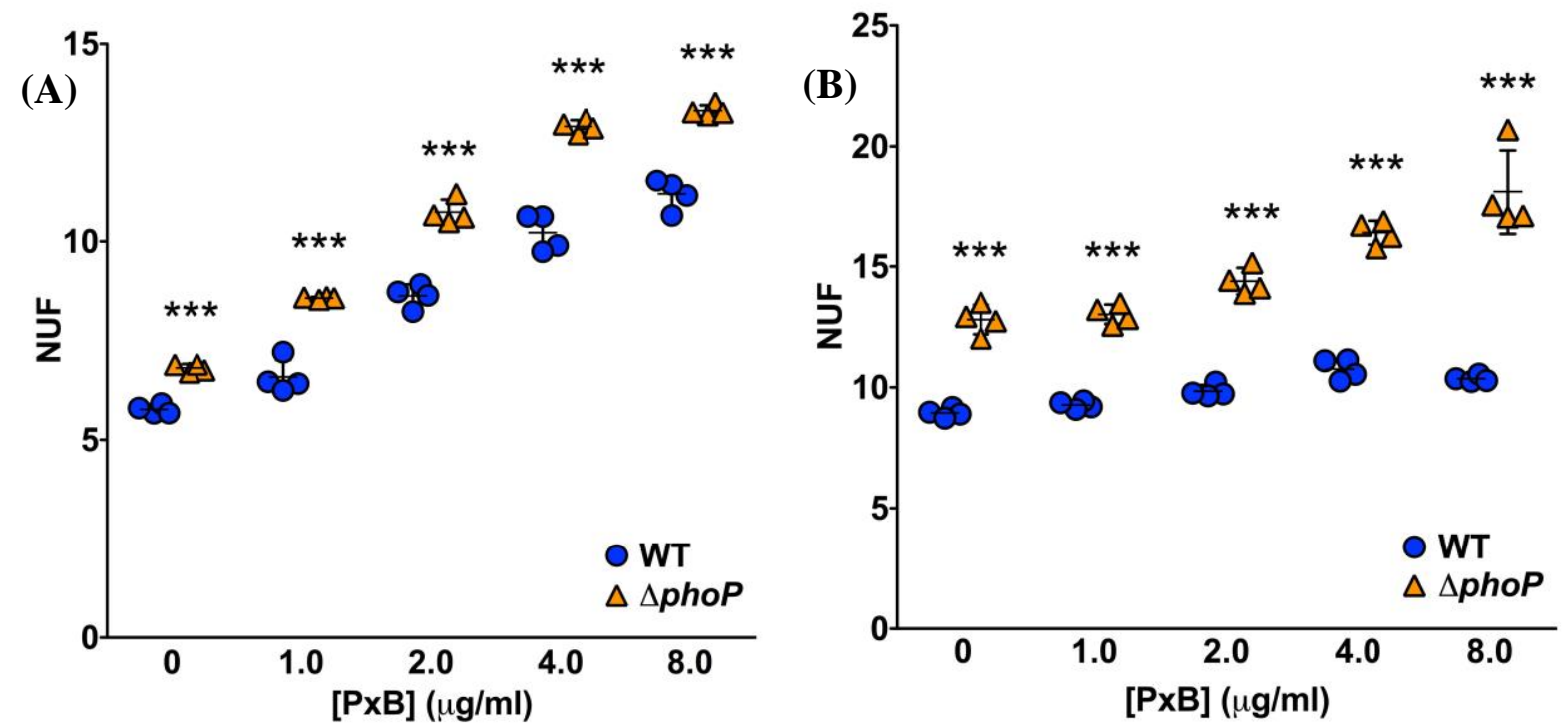

Figure 8. The NUFs calculated in a preliminary trial of the NPN assay using WT and $\Delta p h o P$ NRG857c, and varying concentrations of polymyxin $B$.

Bacteria were grown to mid-logarithmic phase in $\mathrm{N}$ minimal media, with either (A) high $\mathrm{Mg}^{2+}, 10 \mathrm{mM}$, or (B) low $\mathrm{Mg}^{2+}, 10 \mu \mathrm{M}$, conditions. Data points in each cluster represent technical replicates, error bars correspond to the standard deviations of the replicates, and $* * * p<0.001$. 
Results representing of one of these initial trials are shown in Figure 8. In this initial trial, both types of bacteria showed increased NPN uptake factors (NUFs) in a polymyxin B concentration dependent manner, as expected. Also, the $\triangle p h o P$, which is polymyxin B susceptible, consistently showed significantly higher NUFs than the WT at the each polymyxin B concentration, especially in low $\mathrm{Mg}^{2+}$ conditions. This indicates that $\Delta p h o P$ has more of an increased OM permeabilization in the presence of polymyxin B than the WT, again as expected, and these results lead to testing the genes of interest for this study.

\subsection{The NUFs among NRG857c and its mutants vary in different and sometimes unexpected ways in NPN assays using LL-37 or CP10A}

\subsubsection{Differences in NUFs among LB-grown strains does not depend on the concentration of LL-37}

After protocol optimization, one of the first tests was done using the LL-37 as the HDP permeabilizer (Figure 9). Again, NRG857c, WT and $\triangle p h o P$ were tested, but this time along with $\triangle \mathrm{PI}-6, \triangle \operatorname{arl} A, \triangle \operatorname{arlB}$, and $\triangle \operatorname{cat} \Delta \operatorname{arl} C \Delta o m p T$ (complete OM protease activity deficient mutant). Although there was a significant difference between all the NUFs in the absence of LL-37 and all the ones in the presence of LL-37, there were no significant differences between the varying LL37 concentrations. Also, strain differences were not as evident as they were in the polymyxin B trial. There was a significant difference between the NUFs of $\triangle p h o P$ and the WT, but only at 8.0 $\mu \mathrm{g} / \mathrm{ml}$ of LL-37. However, there were consistently significant NUF differences between $\triangle$ cat $\triangle \operatorname{arl} C \Delta o m p T$ and either the $\triangle \operatorname{arl} A$ or $\triangle \operatorname{arl} B$ mutants. These findings suggest that $\triangle p h o P$ is more susceptible to LL-37 than the other strains, while the $\Delta$ cat $\Delta \operatorname{arl} C \Delta o m p T$ mutant is the only one significantly more susceptible to LL-37 than other strains at all concentrations tested. 

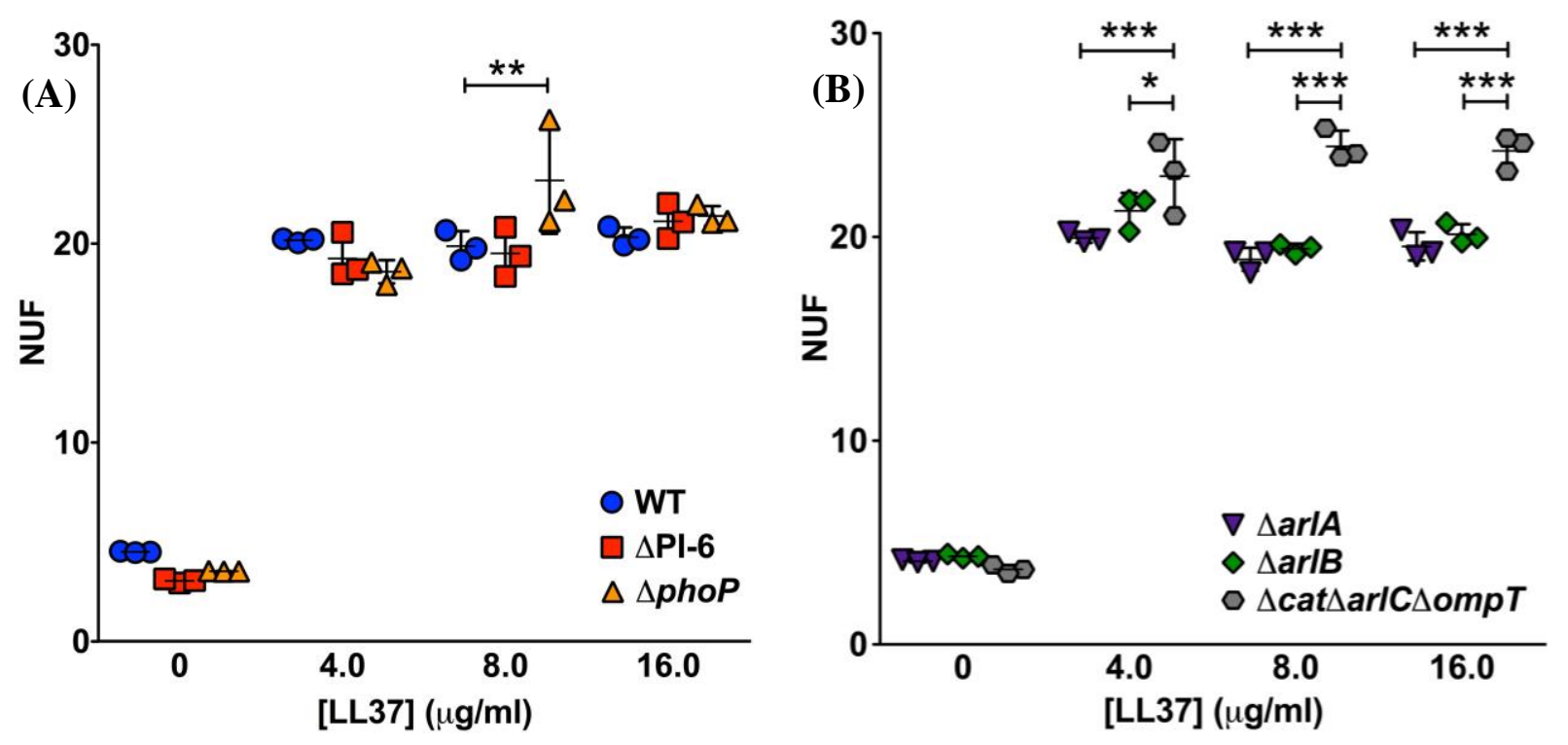

Figure 9. The NUFs calculated in the NPN assay using WT NRG857c and isogenic mutants with varying concentrations of $\mathbf{L L - 3 7 .}$

(A) WT, $\triangle \mathrm{PI}-6$, and $\triangle p h o P$, and (B) $\triangle a r l A, \Delta a r l B$, and $\Delta c a t \Delta \operatorname{arl} C \Delta o m p T$. Bacteria were grown to about mid to late logarithmic phase in LB. Data points in each cluster represent technical replicates, error bars correspond to the standard deviations of the replicates, and $* p<0.05, * * p<0.01$, *** $p<0.001$.

\subsubsection{The concentration of CP10A contributes partially to differences in NUF among LB- grown strains}

The effect of CP10A on the strain panel was tested next. As described above, CP10A is a synthetic antimicrobial peptide and mutants in $\operatorname{arl} A$ and $\operatorname{arl} B$ were previously shown to exhibit sensitivity to it (16). As shown in Figure 10, there was no difference between the WT and the mutants (all produced similar values at the same CP10A concentration) with a few exceptions. The WT had significantly higher NUFs than both $\triangle$ arlA and $\triangle a r l B$ in the absence of CP10A, and higher than $\triangle a r l B$ at two higher levels of CP10A. This would suggest that the loss of the arlA and/or $\operatorname{arlB}$ genes may alter intrinsic permeability to NPN, even in the absence of CP10A. In this case, these mutants appear to be less permeable than the WT, which would allow them to 

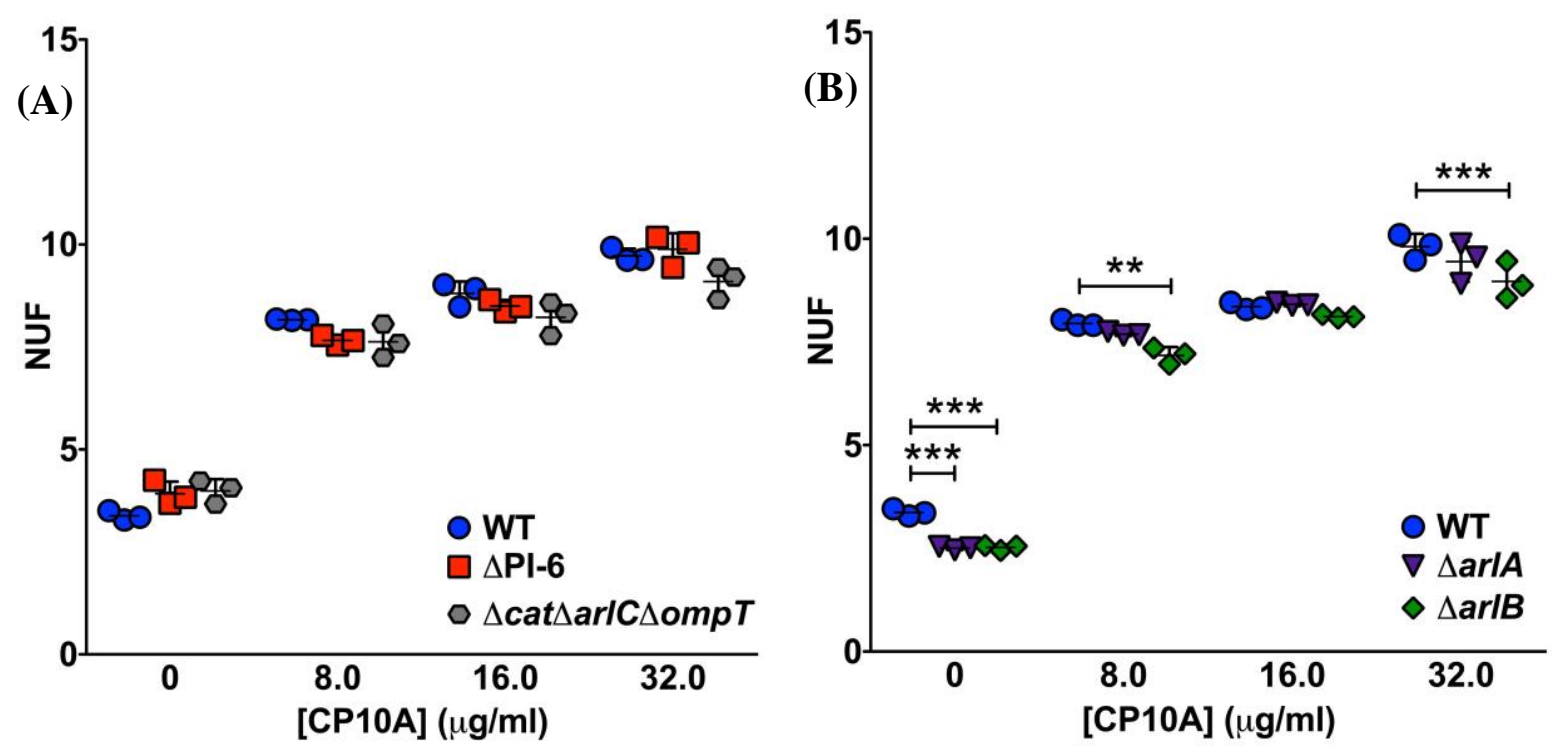

Figure 10. The NUFs calculated in the NPN assay using LB-grown WT NRG857c and isogenic mutants with varying concentrations of CP10A.

(A) WT, $\triangle \mathrm{PI}-6$, and $\Delta c a t \Delta a r l C \Delta o m p T$, and (B) WT, $\Delta a r l A$, and $\triangle a r l B$. Bacteria were grown to about mid to late logarithmic phase in LB. Data points in each cluster represent technical replicates, error bars correspond to the standard deviations of the replicates, and $* * p<0.01$, *** $p<0.001$.

become less susceptible, contrary to what was expected. Despite this, NUFs for all strains show a concentration dependent increase, indicating that CP10A increases NPN uptake into all strains.

\subsubsection{Growth in low concentrations of $\mathrm{Mg}^{2+}$ does not affect CP10A-mediated NPN uptake}

After results from other experiments suggested PhoPQ regulation of the $\operatorname{arl} A B$ genes (see section 4.10), I decided to test whether bacteria grown in $\mathrm{N}$ minimal media with low $\mathrm{Mg}^{2+}$ and challenged with CP10A showed differential uptake of NPN in the mutants versus the wild-type strain. We expected that under low $\mathrm{Mg}^{2+}$ conditions, the WT would be able to utilize both ArlA and ArlB for HDP resistance and would therefore show reduced NPN uptake. The results of a representative biological replicate are shown in Figure 11. Again, rather unexpectedly, no differences in NUFs are seen with respect to the strain or CP10A concentration, with the only 


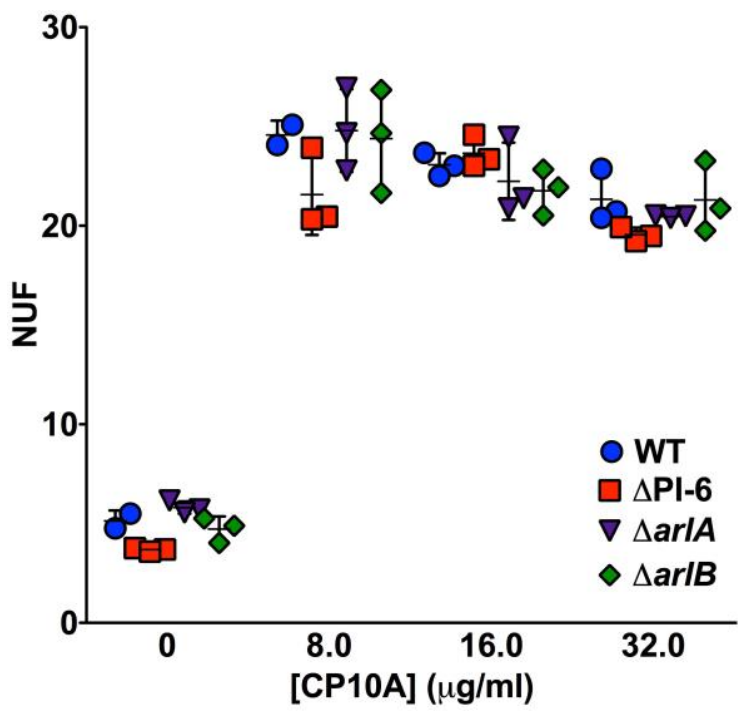

Figure 11. The NUFs calculated in the NPN assay using low $\mathrm{Mg}^{2+}$-grown WT NRG857c and isogenic mutants with varying concentration of CP10A.

The strains included were WT NRG857c and mutants $\triangle \mathrm{PI}-6, \Delta \operatorname{arl}$, and $\triangle a r l B$. Bacteria were grown to about mid to late logarithmic phase in $\mathrm{N}$ minimal media with low $\mathrm{Mg}^{2+}(10 \mu \mathrm{M})$ conditions. Data points in each cluster represent technical replicates and error bars correspond to the standard deviations of the replicates.

major differences being the NUFs between the presence or absence of CP10A. Thus, we interpret these results to mean that even under low $\mathrm{Mg}^{2+}$ conditions, there is no increased NPN uptake in the $\operatorname{arlAB}$ mutants.

\subsection{The concentration of polymyxin $B$ contributes to differences in $\triangle O D$ values in preliminary trials of the lysozyme assay}

To further test the objective concerning phenotypic comparisons between NRG857c and its mutants, an alternative assay to measure OM permeabilization (lysozyme assay) was employed. It also first underwent troubleshooting and optimization; in an initial trial, WT NRG857c and LF82, and the NRG857c mutant $\Delta$ PI-6, were tested using polymyxin B (Figure 12). As mentioned above, the percentage relative changes in $\mathrm{OD}_{600}(\Delta \mathrm{OD})$, calculated for each 


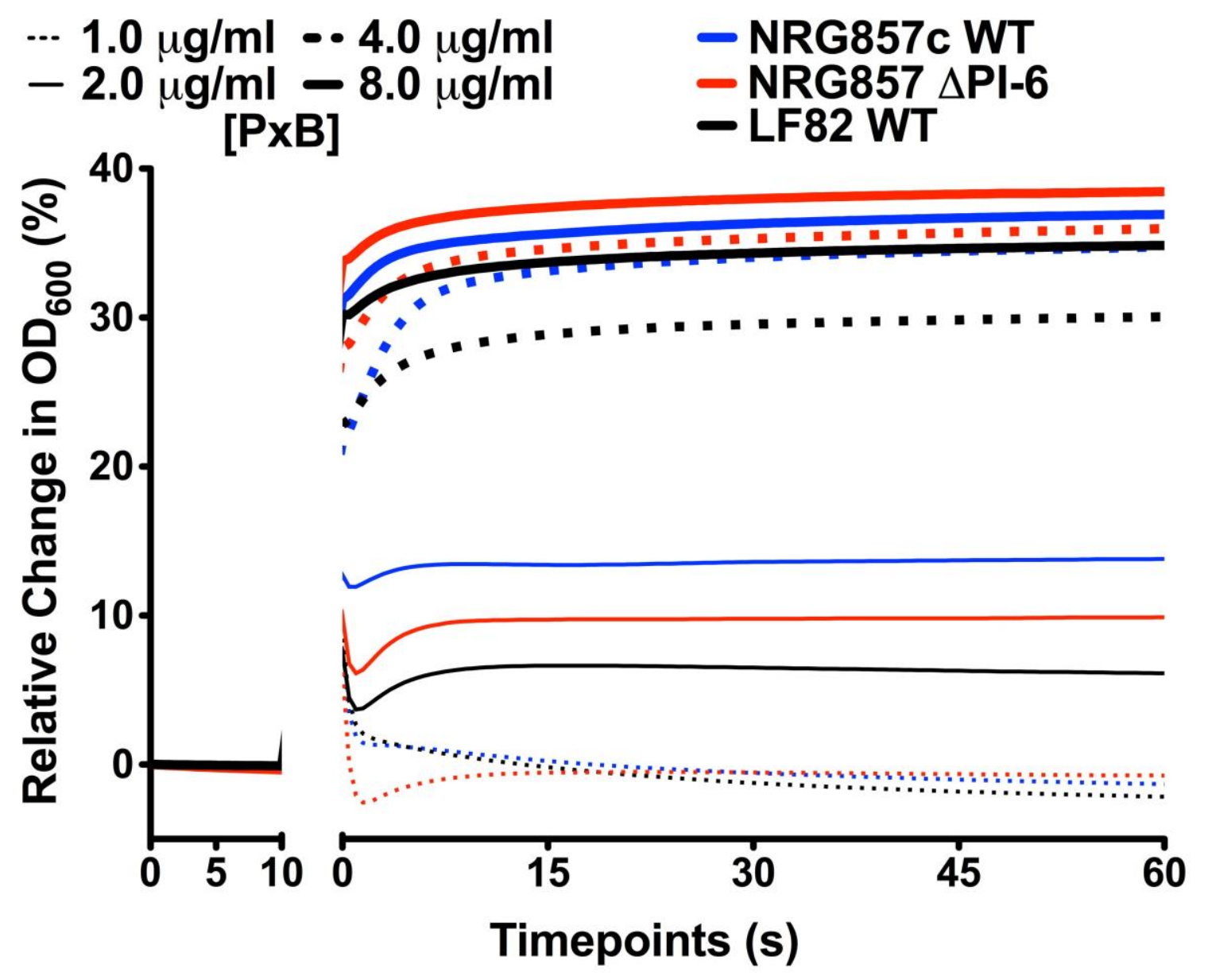

Figure 12. The $\triangle O D$, normalized to ODs after adding lysozyme, calculated over time in seconds. $10 \mathrm{~s}$ of bacteria (WT NRG857c, WT LF82, or NRG857 PPI-6) mixed with $50 \mu \mathrm{g} / \mathrm{ml}$ of lysozyme, and then $60 \mathrm{~s}$ after adding varying concentrations of polymyxin B.

strain where $100 \%$ change corresponds to an OD difference of 1.0 , were normalized to the stable OD readings taken after adding lysozyme. When OD values decrease after adding permeabilizer (indicating lysis is occurring and susceptibility), the $\Delta \mathrm{OD}$ values are increasing. Higher $\Delta \mathrm{OD}$ values indicate increased susceptibility. Likewise, decreasing $\triangle \mathrm{OD}$ values would result if OD values were increasing after adding the permeabilizer (not expected).

In this particular trial, there was a very clear polymyxin B concentration dependence, in which larger $\triangle \mathrm{OD}$ values were obtained when higher concentrations of polymyxin B were used 
(the OD readings dropped much more with higher polymyxin B concentrations). To help visualize these differences more clearly, the "stabilizing" $\Delta \mathrm{OD}$ (the plateauing value after 1 minute of adding the permeabilizer) was plotted for each sample as shown in Figure 13. It could also be noted that, although the different strains had values that clustered to similar levels at each polymyxin B concentration, LF82 consistently had smaller $\triangle \mathrm{OD}$ values at each concentration as

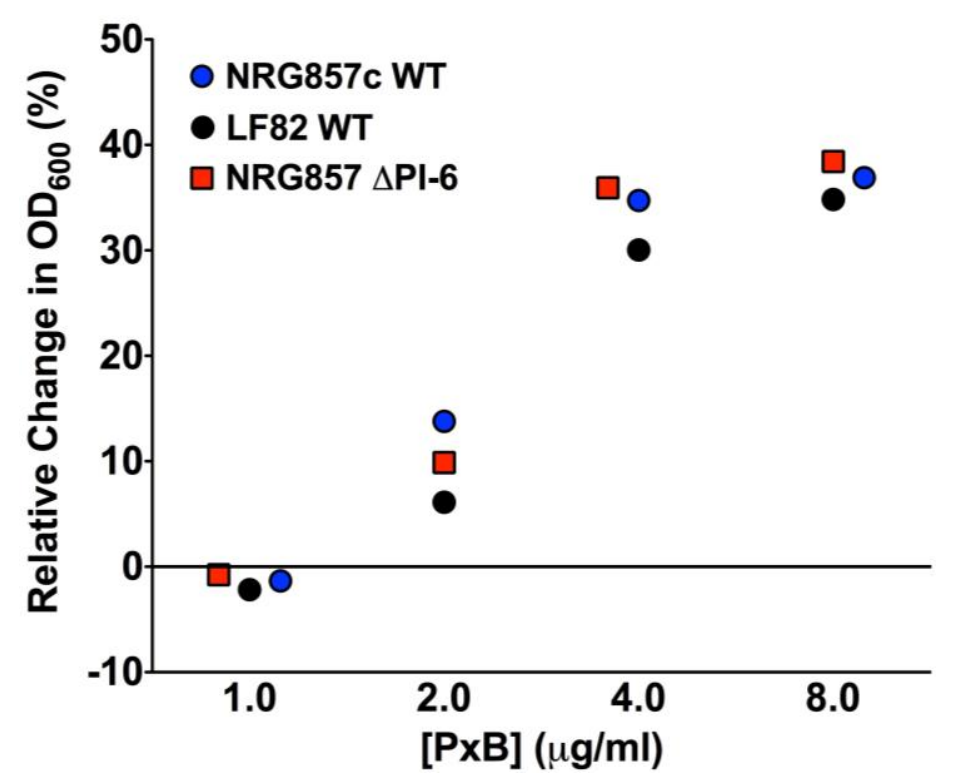

Figure 13. Stabilizing $\triangle O D$, normalized to ODs after adding lysozyme, calculated after 1 minute of adding varying concentrations of polymyxin $B$.

WT NRG857c, WT LF82, and NRG857 $\triangle$ PI-6 were tested, using polymyxin B as the permeabilizer.

compared to both types of NRG857c. This would suggest that LF82 is more polymyxin B resistant than NRG857c, however further trials concentrated on NRG857c for the purpose of this study. Control trials (not shown) were also completed in which polymyxin B was added without any lysozyme; in all cases, the $\Delta \mathrm{OD}$ consistently remained around zero over time for all strains and polymyxin B concentrations, as it was expected. 


\subsection{Using CP10A causes the formation of aggregated clumps in the lysozyme assay}

In trials using $\mathrm{CP} 10 \mathrm{~A}$, unexpected results were continuously obtained in which the $\mathrm{OD}$ readings increased over time after adding CP10A. WT NRG857c and the mutants $\Delta \mathrm{PI}-6, \Delta$ arlA or $\triangle a r l B$ were grown in LB to stationary phase for the trials in Figure 14, where the final stabilizing $\Delta \mathrm{OD}$ values are shown after using $50 \mu \mathrm{g} / \mathrm{ml}$ of lysozyme as usual (note that many of the $\triangle$ ODs are negative). This effect also seemed to depend on the CP10A concentration, where the higher the concentration, the more negative the $\Delta \mathrm{OD}$ values were. Visual observation suggested that the reactions in the cuvettes appeared to become increasingly cloudy. Tests using polymyxin B, prepared as previously, were also done and showed more typical results (also shown in Figure 14). It can be noted that of this particular set of polymyxin B trials, $\Delta \mathrm{PI}-6$ had the greatest values, WT had the lowest, and $\triangle a r l A$ and $\triangle a r l B$ had intermediate values over time,

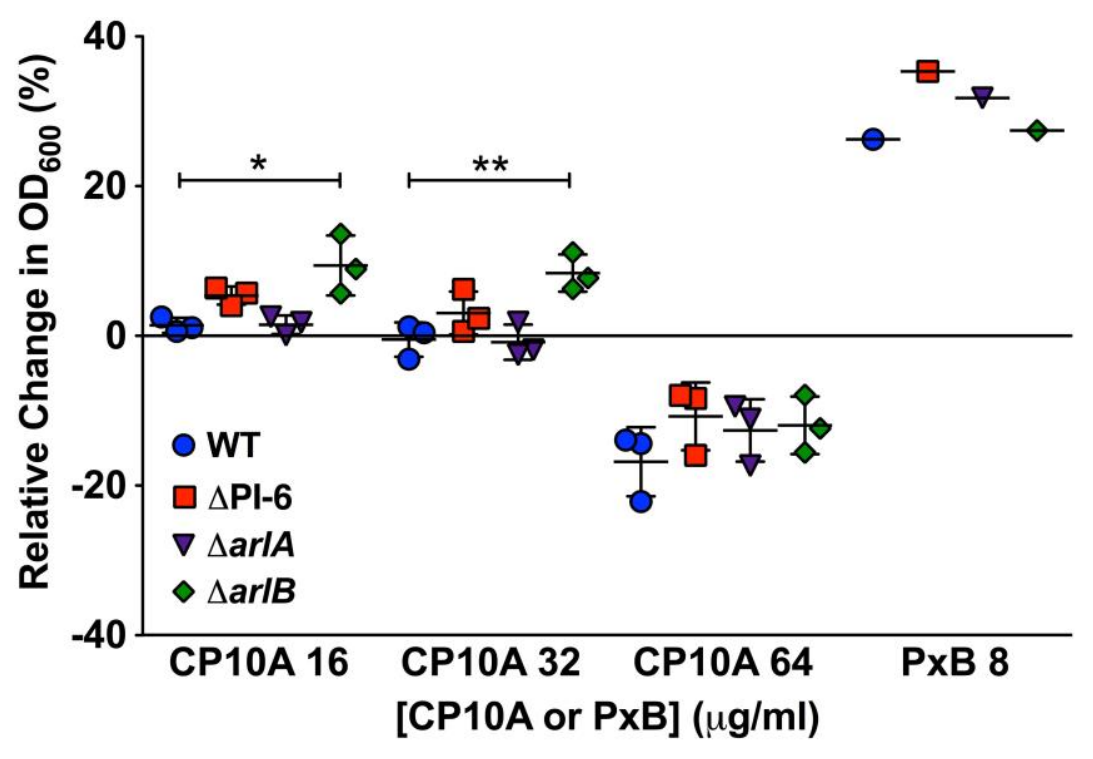

Figure 14. Stabilizing $\triangle O D$, normalized to ODs after adding lysozyme, calculated after 1 minute of adding varying concentrations of CP10A or polymyxin $B$.

NRG857c WT and isogenic mutants $\triangle \mathrm{PI}-6, \triangle \operatorname{arl} A$, and $\triangle a r l B$ were tested, using CP10A or polymyxin B as the permeabilizer. Data points in each cluster represent biological replicates, error bars correspond to the standard deviations of the replicates, and $* p<0.05, * * p<0.01$. 


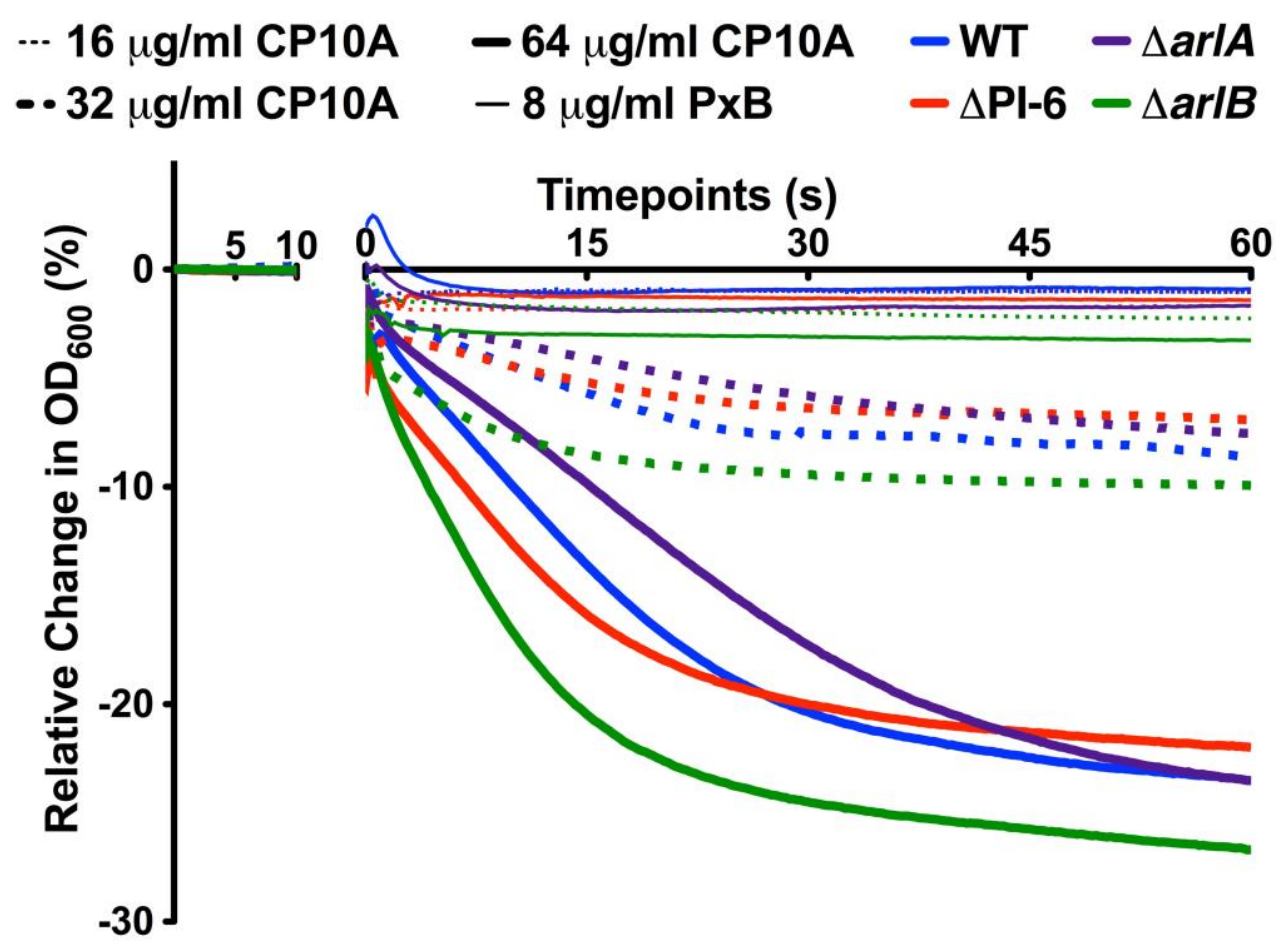

Figure 15. The $\triangle \mathrm{OD}$ "control" tests (no lysozyme), normalized to ODs before adding CP10A or polymyxin B, calculated over time in seconds.

$10 \mathrm{~s}$ of bacteria alone (NRG857c WT, $\triangle \mathrm{PI}-6, \Delta \operatorname{arl} A$ or $\triangle a r l B$ ), and then $60 \mathrm{~s}$ after adding varying concentrations of $\mathrm{CP} 10 \mathrm{~A}$ or polymyxin $\mathrm{B}$.
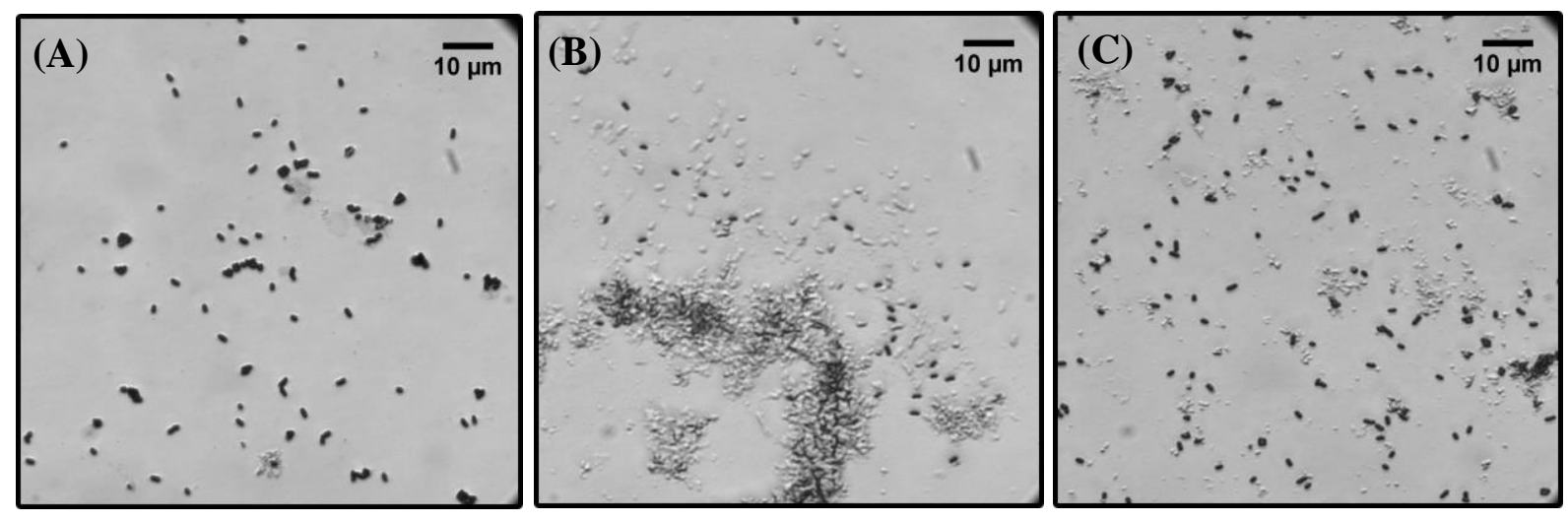

Figure 16. Samples of Gram-stained WT NRG857c obtained from the lysozyme assay and observed under 100x oil immersion objective lens.

(A) Cell sample before adding any treatment. (B) Sample after adding lysozyme and CP10A. (C) Sample after adding CP10A only. 
which supports previous findings that the $\Delta \mathrm{PI}-6$ is the most polymyxin B susceptible and the WT is the most polymyxin $\mathrm{B}$ resistant. Also, although the $\triangle \mathrm{OD}$ values for $\mathrm{CP} 10 \mathrm{~A}$ were unexpected, it may be interesting to note that the $\triangle a r l B$ mutant had significantly higher values than the WT at two different concentrations of CP10A. This could suggest that $\triangle a r l B$ is more susceptible in the conditions of this particular experiment. To further analyze the unexpected results obtained using CP10A, the "control" trials (no lysozyme) were evaluated and graphed in Figure 15. Instead of the usual continuous $\triangle \mathrm{OD}$ values around zero (which is seen for the polymyxin B trials), the CP10A trials showed a more prominently clear decrease in $\triangle$ OD over time after adding CP10A alone, and the effect still appeared to be concentration dependent (values decrease much more at higher CP10A concentrations).

These interesting observations lead to further investigations using light microscopy, to visualize what was happening to the bacterial cells in these conditions (Figure 16). WT NRG857c and the three isogenic mutants from the CP10A trials were visualized before any treatment, after adding both lysozyme and CP10A, or after adding CP10A alone. The samples shown here (WT) are representative of all the strains in the same conditions. As it can be seen, regular rod-shaped bacteria, as expected for E. coli, are seen in (A) and (C), while accumulation of aggregated structures, likely formed from lysed cells, lysozyme, and CP10A, are seen in (B). Similar effects were seen when a K-12 strain and LF82 were used. Although further investigation on the mechanism of this occurrence could be studied, it would be outside the scope of this project. These results indicated that this assay is not appropriate for further testing phenotypic differences between the strains using CP10A as a permeabilizer, and other methods should be used instead. 


\subsection{The $\triangle \mathrm{PI}-6$ strain is more sensitive to CP10A than the $\triangle$ arlA or $\triangle a r l B$ strains in radial diffusion assays}

The radial diffusion assay (RDA) is another classic microbiological method that tests the ability of test strains to resist and grow in the presence of an antimicrobial compound (60). Specific concentrations of the compound are inserted into small spots on agar containing minimal numbers of bacteria, and the compound is left for some time to diffuse radially into the agar. Then, an overlay of rich media is added to allow the surviving bacteria to grow until they create a visible lawn and zones of clearing where the compounds were added. These zones can be measured and analyzed, as they are an indication of the strain's resistance or susceptibility towards the compound.

We expected that by using this assay with CP10A as the antimicrobial compound, differences in the zones of clearance would be obtained between WT NRG857c and the mutants $\Delta \mathrm{PI}-6, \Delta a r l A$, and $\triangle a r l B$. As discussed above, these mutants are more susceptible towards CP10A as compared to the WT in the MIC assays (16). Thus, the RDA could support those findings, or perhaps provide further insight on the differences between the strains if the results are not as expected.

Initial RDA trials were completed to optimize for the use of the NRG857c strains with CP10A. Concentrations of CP10A lower than $1 \mathrm{mg} / \mathrm{ml}$ and bacterial underlay preparations of about $4 \times 10^{6} \mathrm{CFU} / \mathrm{ml}$ produced very small zones of clearance (around 4.0 to $6.0 \mathrm{~mm}$ in

diameter). Thus, CP10A concentrations of $1.0,2.0$, and $4.0 \mathrm{mg} / \mathrm{ml}$, and about $4 \times 10^{5} \mathrm{CFU} / \mathrm{ml}$ of bacterial underlay were used to complete the trials reported here (Figure 17). The results here were obtained for WT NRG857c and the isogenic mutants $\triangle \mathrm{PI}-6, \Delta a r l A$, and $\triangle a r l B$.

Without considering the strains, it can first be seen that there was a rough but significant CP10A concentration dependence, in which higher concentrations tended to create larger 


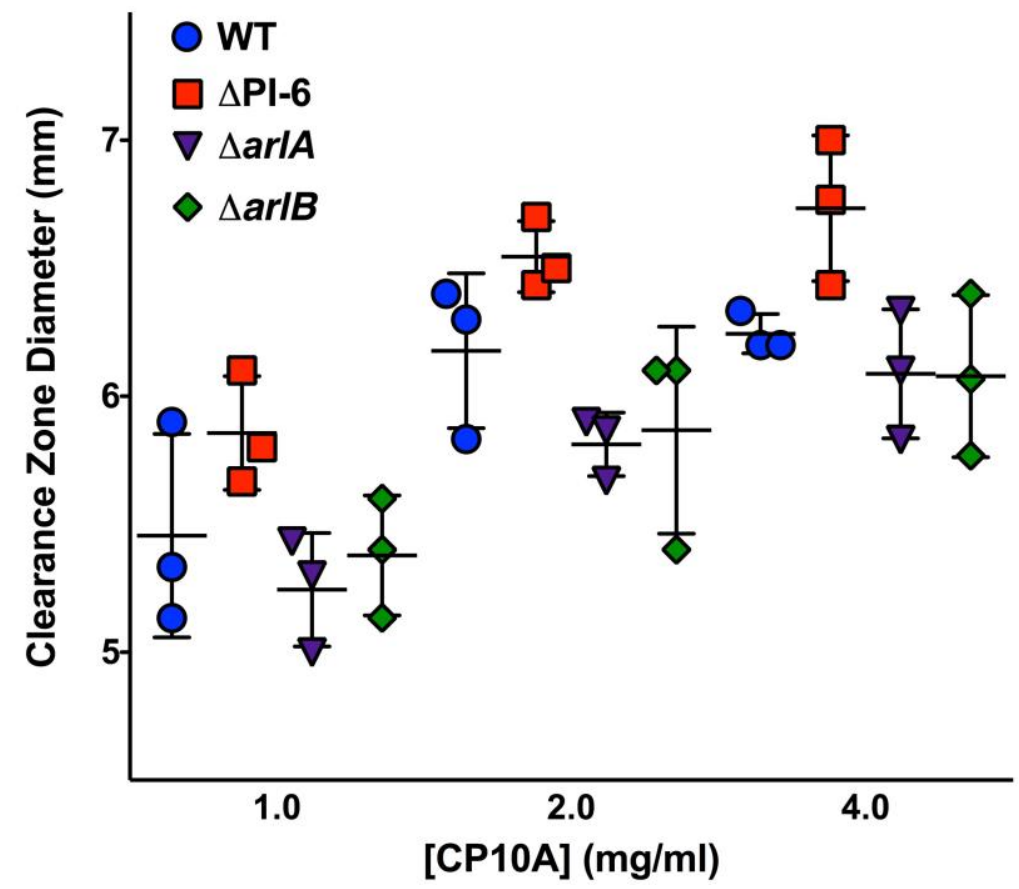

Figure 17. The clearance zone diameters measured around varying concentrations of $\mathrm{CP10A}$ in radial diffusion assays of WT NRG857c and the $\triangle \mathrm{PI}-6, \Delta a r l A$, and $\triangle a r l B$ mutants.

Data points in each cluster represent biological replicates and error bars correspond to the standard deviations of the replicates.

clearance zones, which was expected due to the antimicrobial activity of CP10A that has already been demonstrated. Unlike the final lysozyme polymyxin B trial and the MICs completed previously, in which the $\Delta$ PI-6 seemed to be the most susceptible while the individual gene mutants are less susceptible, no differences in susceptibility can be inferred here since there were no significant differences in clearance zones between the strains at any CP10A concentration. Other factors can be considered in terms of the ramifications of this type of assay, but further testing of phenotypic differences made use of other methods. 


\subsection{There are no differences in fractional inhibitory concentration indices between WT NRG857c and its $\triangle P I-6$ mutant using the fractional inhibitory concentration assay}

As mentioned above, strong phenotypic differences were seen between the WT and the mutants when using LL-37 and CP10A in MIC assays, in which the WT was clearly more resistant (16). After other assays did not show differences between the same strains similar to or as extensive as these previous findings, a method was employed related to the MIC assay, a checkerboard microdilution method known as the fractional inhibitory concentration (FIC) assay.

Stokes et al. recently showed that the antiprotozoal drug pentamidine sensitizes Gramnegative bacteria to hydrophobic drugs, such as rifampicin, due to interactions with the core region of LPS. This sensitization can be observed by conducting FIC assays, between pentamidine and a drug of choice. If two drugs show synergistic activity, this can be demonstrated by obtaining FIC indices lower than 0.5 (61). The FIC assay uses a checkerboard microdilution protocol, which is essentially a two-dimensional MIC assay using varying concentration combinations of the two drugs. Of particular interest from this work was the use of several $E$. coli mutants, with truncated versions of core LPS, in assays using pentamidine in conjunction with rifampicin. All produced FIC indices lower than 0.5, but there were significant differences between the mutants, in which deeper truncations in the core region resulted in lower values. Lower FIC values are an indication of increasing susceptibility (61). This suggested that alterations in the core LPS structure could be measured using this assay. We wished to use pentamidine combined with rifampicin in the FIC assay, as it was done by Stokes et al., to test WT NRG857c and its mutants. Mutants lacking the $\operatorname{arlB}$ gene, as suggested by the LPS gels, have differences in the core region from the WT that could be linked to peptide resistance by LPS modifications. Thus, they may produce significantly lower FIC index values when 
compared with the WT.

FIC assays, with pentamidine and rifampicin, were first done using WT NRG857c and its mutant $\Delta$ PI-6. The results obtained from three biological replicates are summarized in Table 5. First, it is surprising that the MICs were identical with respect to these particular drugs. Also,

Table 5. The MIC and FIC values obtained in FIC assays testing WT NRG857c and the $\Delta$ PI-6 mutant by using rifampicin in combination with pentamidine or CP10A.

Drug A = Rifampicin, Drug B = Pentamidine or CP10A. Statistical tests were completed using the MannWhitney $U$ test; $p$ values are indicated below.

\begin{tabular}{|c|c|c|c|c|}
\hline Drug Pair & \multicolumn{2}{|c|}{ Rifampicin \& Pentamidine } & \multicolumn{2}{c|}{ Rifampicin \& CP10A } \\
\hline Cells Grown & WT & $\Delta$ PI-6 & WT & $\Delta$ PI-6 \\
\hline MIC $_{A}$ & 6 & 6 & 12 & $6-12$ \\
\hline FIC $_{\text {A }}$ & $0.125-0.250$ & $0.125-0.250$ & $0.063-0.125$ & $0.032-0.063$ \\
\hline MIC $_{B}$ & $100-200$ & $100-200$ & $16-32$ & $16-32$ \\
\hline FIC $_{B}$ & $0.125-0.250$ & $0.125-0.250$ & $0.125-0.250$ & $0.125-0.250$ \\
\hline $\begin{array}{c}\text { FIC } \\
\text { Mann- } \\
\text { Whitney }\end{array}$ & $0.25-0.50$ & $0.25-0.38$ & $0.19-0.38$ & $0.19-0.28$ \\
\hline
\end{tabular}

their FIC indices were not significantly different, as tested using the Mann-Whitney $U$ test. Although their FIC indices are considered synergistic, it was concluded that the combined effect of these drugs are similar in these two strains. These tests were then repeated using CP10A in place of pentamidine, since it could serve as a more relevant membrane disruptor. These results are also shown in Table 5. Again, no significant difference was found between the two strains. However, the synergistic effect was stronger by using this pair of drugs, as indicated by obtaining generally lower FIC indices. Nevertheless, these results suggest that the combined 
effect of rifampicin and CP10A are similar in these two strains as well, and that there is no difference between the WT and the $\Delta \mathrm{PI}-6$ strain in their interaction with pentamidine.

\subsection{Deletion of PI-6, arlA, or arlB did not affect the ability for NRG857c to invade or survive in macrophages}

An important aspect of AIEC is its ability to invade host cells and survive and even replicate intracellularly (38). Also, it was demonstrated that $\alpha$-helical peptides can be found inside macrophages playing an antimicrobial role against intracellular invading bacteria (67). The strain NRG857c does not contain the well-known virulence factors utilized by highly invasive bacteria like $S$. enterica to invade and survive in macrophages (44), thus, it is suspected that it could utilize the genes of PI-6, especially since they were already previously seen to be important for resistance against $\alpha$-helical peptides (16). We therefore tested whether mutants lacking genes in PI-6 could influence the ability for NRG857c to invade and survive in macrophages.

As a final approach to investigate differences between WT NRG857c and the mutants studied here, the bacteria were subjected to RAW264.7 macrophage cultures, were allowed to invade and incubate ( 1 hour or 24 hours), and were then re-harvested by lysing the macrophages and obtaining samples that were spot plated onto LB agar plates to grow into colonies that were counted. The number of colonies, which were analyzed and compared between the strains, is an indication of invasiveness (1-hour samples) or survivability (24-hour samples), as higher counts refer to more bacteria that were derived from inside the macrophages at the two timepoints. A K12 E. coli strain, non-invasive DK K12, and virulent invasive Salmonella strain SL1344 were included as negative and positive controls, respectively. The results from this set of experiments are shown in Figure 18. 


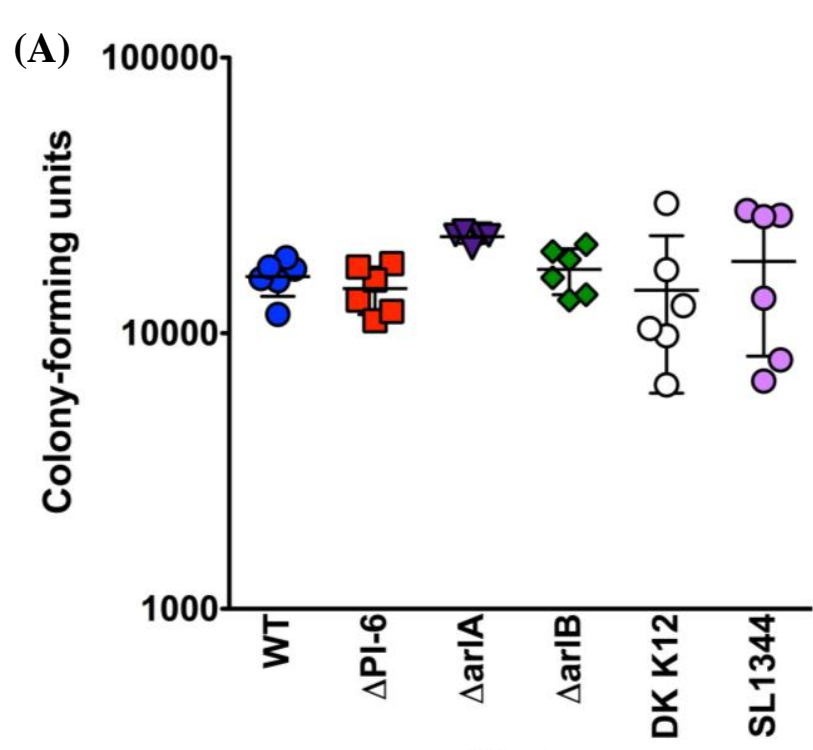

Strain

(C)

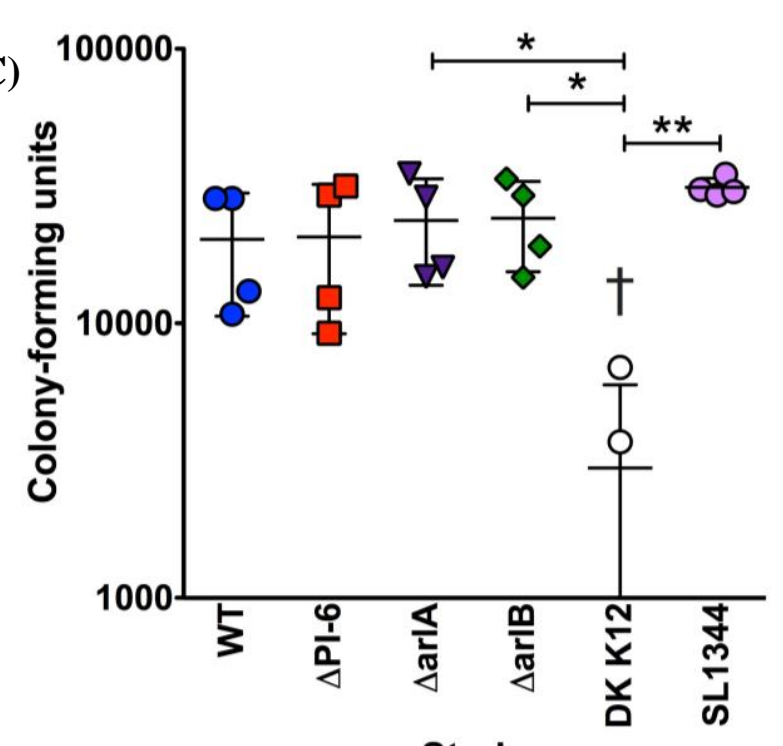

Strain

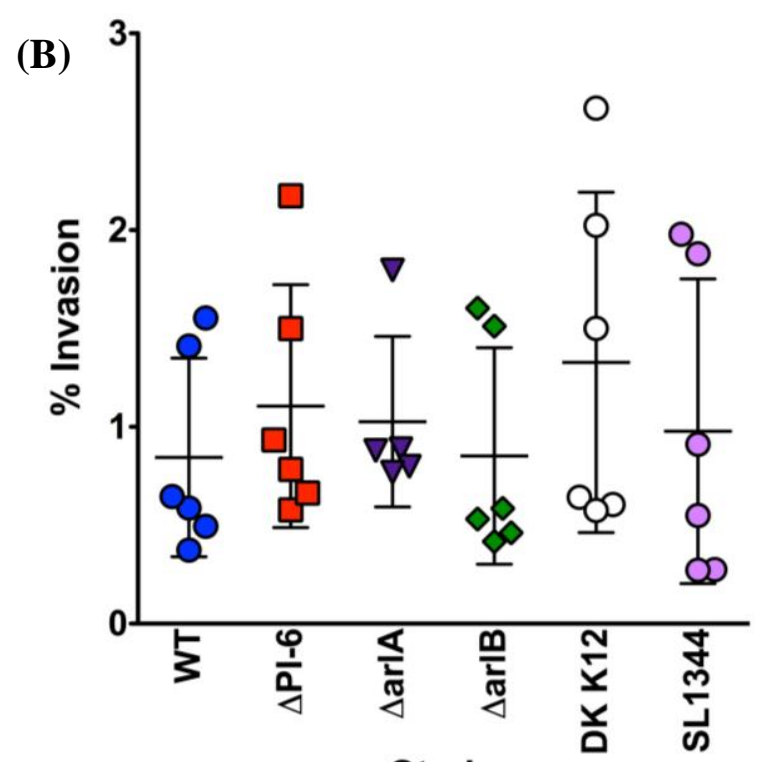

Strain

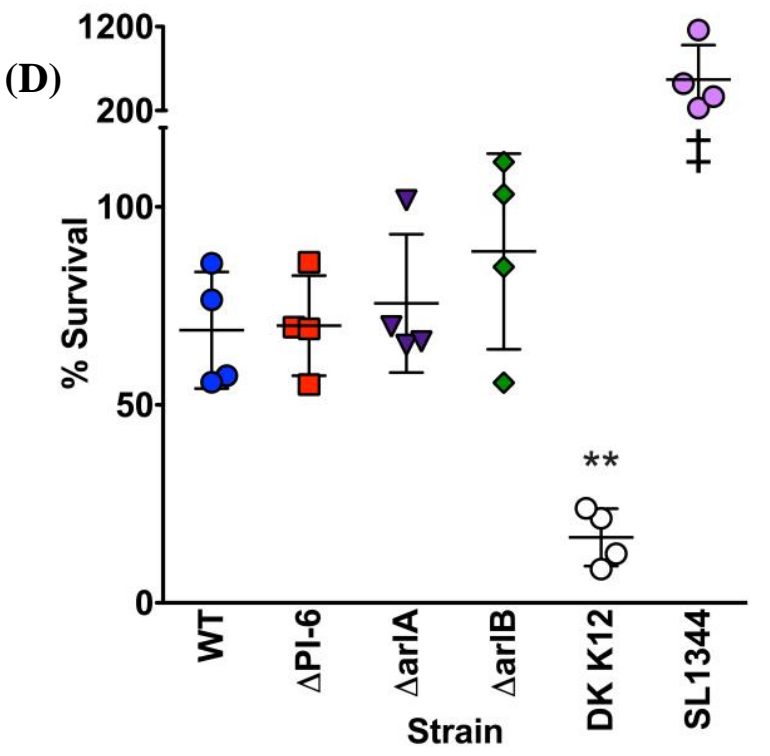

Figure 18. The calculated CFUs, percentage invasion, and percentage survival of WT NRG857c and its isogenic mutants, with $\mathrm{K} 12$ and Salmonella controls, in experiments of bacterial survival after invasion of RAW264.7 macrophages

WT NRG857c, mutants $\triangle \mathrm{PI}-6, \triangle a r l A$, and $\triangle a r l B$, and controls DK K12 and SL1344 were used.

(A) CFUs after $1 \mathrm{~h}$ of incubation and (B) their corresponding percentage invasion. (C) CFUs after $24 \mathrm{~h}$ of incubation and (D) their corresponding percentage survival. Data points in each cluster represent two technical replicates per two or three biological replicates, error bars correspond to the standard deviations of the replicates, and $* p<0.05, * * p<0.01$. Axes for CFUs are presented in log scale, and for clarity, some control data is outside the range of axes scales: $\uparrow$ Two data points for DK K12 are considerably smaller. $\$$ All four data points for SL1344 were considerably larger than the rest of the data. 
The calculated CFUs of the bacteria derived from 1 hour of incubation are shown in Figure 18A. Interestingly, there were no significant differences among any of the strains. We determined the percentage invasion of all the samples and controls. Again, no significant differences were found among the strains. Surprisingly, for the controls, values for DK K12 were comparable to SL1344, even though it is considered a non-invasive strain and the other is considered invasive. Values among the replicates for each strain tended to vary widely, with DK K12 having a larger spread of values than SL1344. It would also be interesting to note that among the strains, there is a bimodal distribution of percentage invasion values, which actually corresponded to one set of biological replicates with invasion values over $1 \%$ and the rest of the replicates with values under $1 \%$ (with the exception of $2.62 \%$ for one replicate of DK K12). Although certain inferences could be made based on all this data, in general it could be said that none of the bacteria showed remarkable percentage invasion values after a 1-hour incubation time, and WT NRG857c and its mutants behaved very similarly in these experimental conditions.

In Figure 18C, the calculated CFUs of the bacteria derived from 24 hours of incubation are shown. Among WT NRG857c, the mutants, and the SL1344 control, there were no significant differences, which would suggest that NRG857c and its mutants were able to behave similar to the invasive SL1344 control in these experimental conditions. With respect to the noninvasive DK K12, there was strangely no significant difference between this strain and either WT NRG857c or its $\triangle$ PI-6 mutant. However, there were significant differences between DK K12 and either $\triangle a r l A, \Delta a r l B$, or the SL1344 control. Despite these results, the DK K12 strain clearly showed smaller counts than all the other strains. This is as expected, since it is a noninvasive strain, and it should have been reducing in numbers over time much faster than the 
strains that are able to persist.

The percentage survival, calculated using the 24-hour CFUs, are shown in Figure 18D. As expected, SL1344 was significantly higher than all strains, due to its enhanced ability to survive (and even replicate) within macrophages, and DK K12 was significantly lower than all strains, due to its inability to persist within macrophages. However, with respect to the NRG857c WT and its isogenic mutants, there were no significant differences among them. These results, along with the 24-hour CFUs, indicate that mutations in the PI-6 genes did not affect the ability of NRG857c to survive within macrophages. The HDP resistance mechanism of the PI-6 genes were not required for intracellular survival in these experiments.

\subsection{The expression of $a r l B$ is increased in the early stationary phase of LB growth}

A common analysis for the determination of gene activity is the use of translational fusions, in which a reporter gene or an epitope tag is inserted into a chromosome or plasmid in frame with the gene of interest being studied (68). There are a variety of uses for using different types of tags, but some examples are the use of short sequences, such as the hemagglutinin (HA) or FLAG-tags, to monitor the expression of a particular gene of interest using antibodies (68). To monitor the expression of the $\operatorname{arlA}$ and $\operatorname{arlB}$ genes in NRG857c, HA encoding gene fusions to arlA and $\operatorname{arlB}$ were constructed, allowing their corresponding protein levels to be detected using western blot analysis. Samples using HA-tagged ArlA or ArlB were obtained over a period of time to determine if expression is affected by bacterial growth phase. Also, by using different types of growth media associated with the activation of certain TCSs, such as the PhoPQ and PmrAB TCSs, and developing mutants in the genes of the response regulators themselves, evidence on the regulation of $\operatorname{arl} A B$ expression was obtained. 
Firstly, bacterial samples of WT, arlA:HA, and $\operatorname{arlB:HA~NRG857c~were~obtained~at~}$ various half-hour time intervals from mid-logarithmic to stationary phases of growth in LB (and one sample of each at 24 hours late stationary). The protein DnaK was used as a control, as it would be evenly expressed in all experiments when the number of cells are normalized, and it was visualized using anti-DnaK antibodies. The images obtained are summarized in Figure 19.

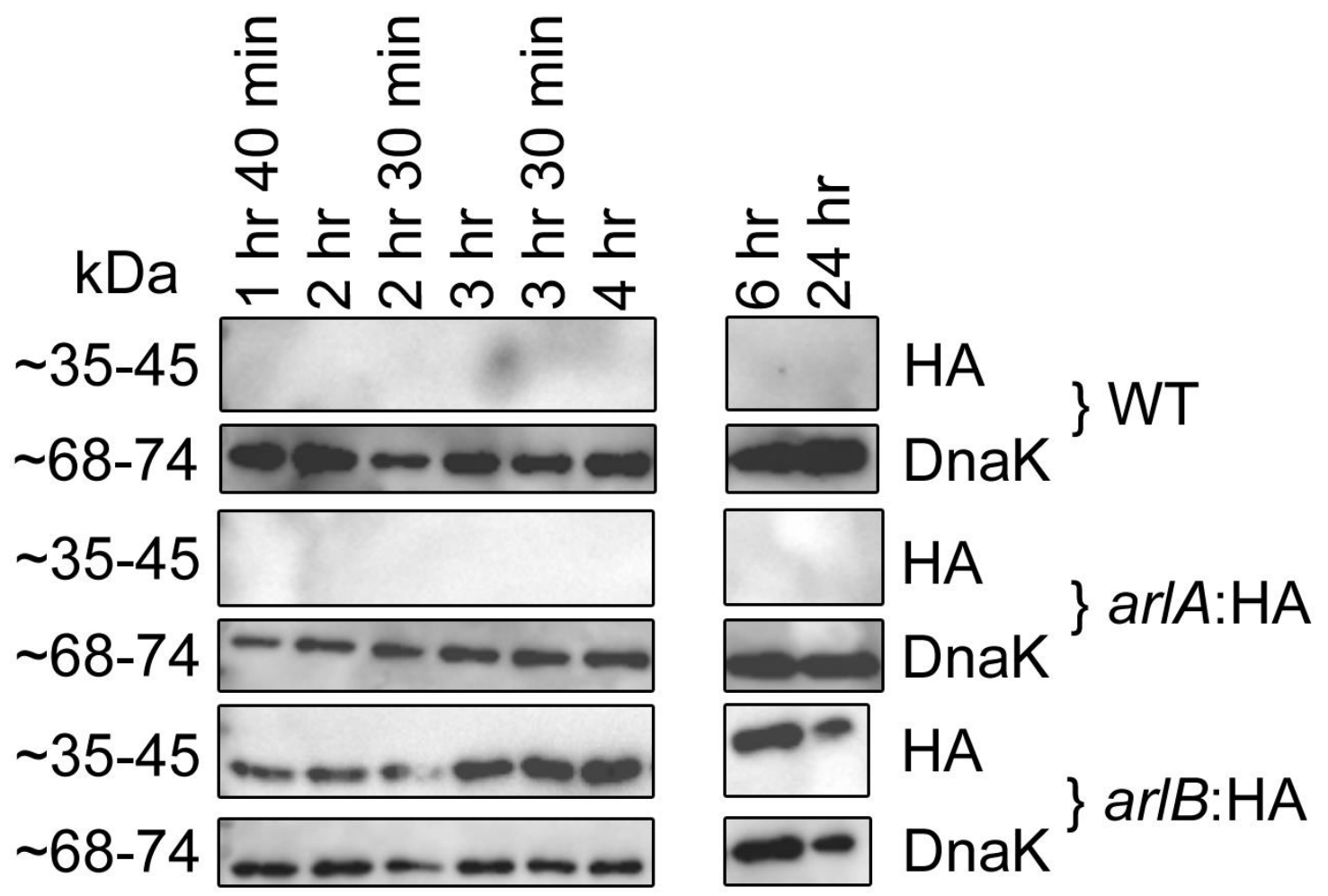

Figure 19. The western blots of membranes with the NRG857c WT, arlA:HA, or arlB:HA, using samples obtained at different time intervals of growth in LB as shown.

HA images were visualized using anti-HA antibodies and DnaK images using anti-DnaK antibodies.

The ArlA:HA, ArlB:HA, and DnaK proteins are expected to be about 36.4, 42.1, and 70.2 kDa, respectively. It was immediately noted that no signal could be obtained anywhere for the HA blots of $\operatorname{arlA}: \mathrm{HA}$ (this confirmed similar results that were already obtained previously with other samples of $\operatorname{arlA}: \mathrm{HA})$. As the sequences of the HA-tagged genes were verified to lack any errors, this could be due to a loss of the HA epitope tag that could have occurred post-translationally as 
the bacteria produced ArlA. In contrast, the ArlB:HA fusion is produced in these bacteria, as shown by the bands in the HA blot for $\operatorname{arlB}: \mathrm{HA}$, allowing us to continue with the use of this approach to study $\operatorname{arlAB}$ expression.

ArlB:HA showed evidence of growth-phase dependent production. It appears that more ArlB:HA is produced as the bacteria go from mid-logarithmic to the stationary phase of growth. This suggests that $\operatorname{arl} B$, and most likely $\operatorname{arl} A$ as well, become increasingly expressed as bacteria move towards the stationary phase in LB growth. This prompted other experiments (lysozyme assay and RDAs shown above) to begin using bacterial samples that were in the stationary phase rather than the usual mid-logarithmic phase, as we hypothesized this could have lead to more prominent differences between the WT and the $\triangle \operatorname{arl} A$ and $\triangle \operatorname{arlB}$ mutants.

\subsection{The expression of arlAB is likely regulated by the PhoPQ TCS, but not by the PmrAB TCS}

\subsubsection{ArlB:HA is expressed in low magnesium conditions, but not in high magnesium conditions}

Next, to test the possibility that $\operatorname{arlAB}$ is regulated in some way by a TCS, such as PhoPQ and/or PmrAB, NRG857 arlB:HA samples were obtained from growths in LB media (control), N minimal media with high $(10 \mathrm{mM}) \mathrm{Mg}^{2+}$ (non-inducing PhoPQ control), and $\mathrm{N}$ minimal media

with low $(10 \mu \mathrm{M}) \mathrm{Mg}^{2+}$ (PhoPQ inducing). Samples were obtained in both the logarithmic and stationary phases of growth. The results of the blots are shown in

Figure 20. Immediately, it is seen that in non-PhoPQ inducing conditions (high magnesium), $a r l B$ was not even detectable. Conversely, in PhoPQ inducing conditions (low magnesium), there were clear bands in both phases of growth, indicating that $a r l B$ was expressed, and even at levels higher than in LB logarithmic phase. These results strongly suggest 
that $\operatorname{arlAB}$ expression is under the regulation of

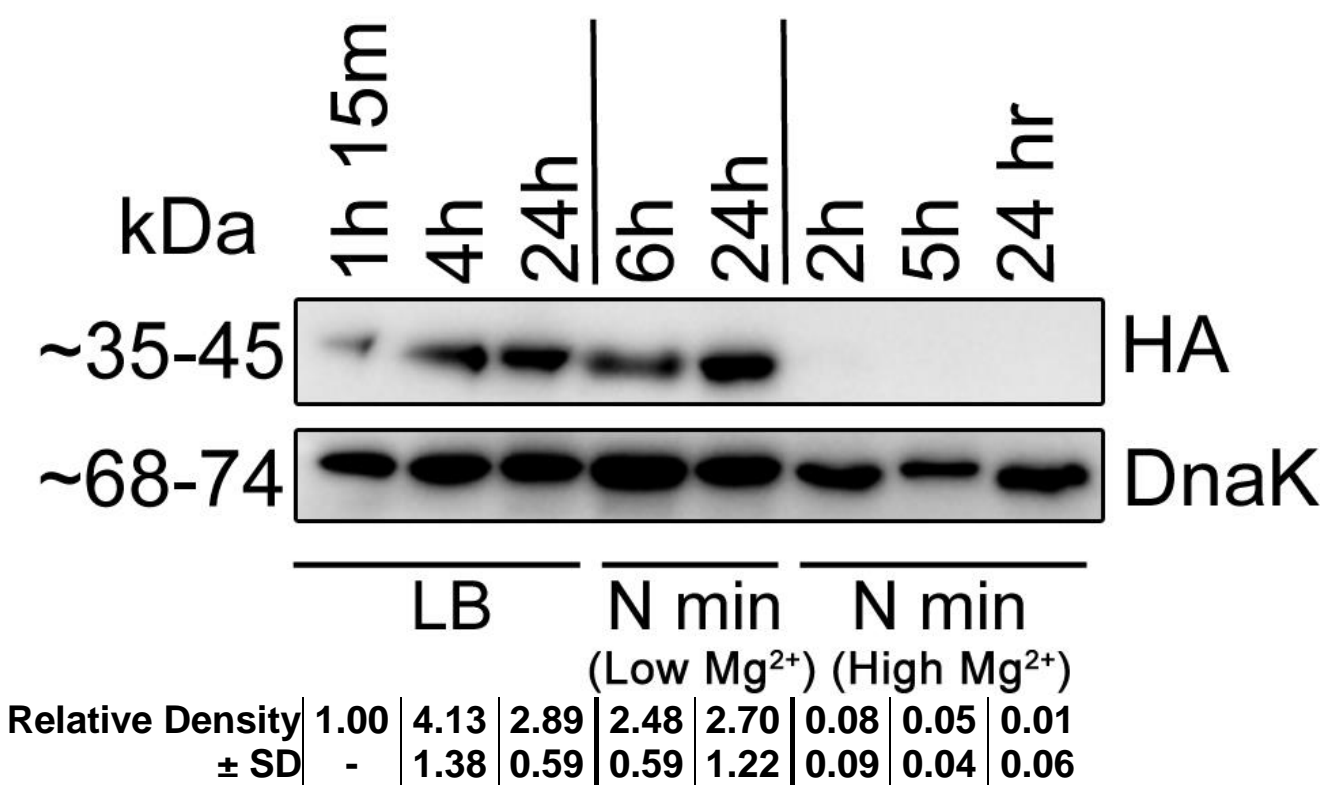

Figure 20. The western blots of membranes with NRG857 arlB:HA, using samples obtained from different growth phases of varying growth media.

This is an image of representative blots from three biological replicates. The mean relative density of the band, normalized to the first band, and their standard deviations, are shown below each lane.

the PhoPQ TCS. However, it is not known whether this is occurring directly by PhoP, or if this TCS is turning on the PmrAB TCS and indirectly controlling arlAB expression.

\subsubsection{ArlB:HA expression is abolished in the $\triangle p h o P$ mutant}

To confirm whether PhoP is required for the expression of $\operatorname{arl} A B$, a $\triangle p h o P$ mutant in the NRG857 arlB:HA background was developed by allelic exchange mutagenesis. Samples using this mutant, NRG857 $\Delta$ phoP arlB:HA, were grown in the same media as the previous set of western blots, and at the same growth phases. The results from this next set of western blots are shown in Figure 21. As shown by this representative set of blots, no bands were detected at any growth phase for all growth medias. This indicates that $\operatorname{arlB}$ expression was completely 
abolished in all tested conditions, whether they were PhoPQ inducing or not. As the $\Delta p h o P$

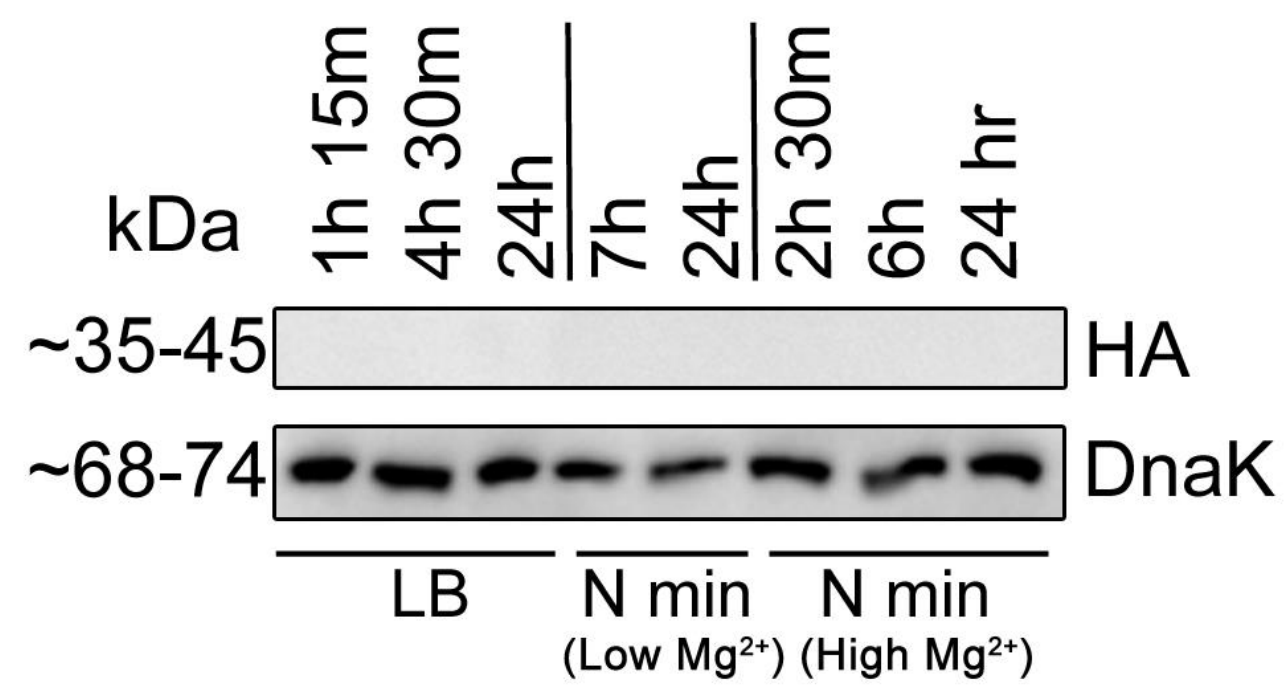

Figure 21. The western blots of membranes with NRG857 $\Delta$ phoP arlB:HA, using samples obtained from different growth phases of varying growth media.

This is an image of representative blots from three biological replicates.

mutant would be unable to induce the expression of any genes under PhoPQ regulation due to the absence of PhoP, these results imply that all arlB expression is lost because it is also under PhoPQ regulation. Again, this does not determine whether this was through the PmrAB TCS, since both TCSs could have been active in low magnesium conditions via PmrD.

\subsubsection{ArlB:HA is not expressed in growth media with high magnesium and high iron}

In a final set of western blots, NRG857 arlB:HA were grown in N minimal media with high $(10 \mathrm{mM}) \mathrm{Mg}^{2+}$ and high $(100 \mu \mathrm{M}) \mathrm{Fe}^{2+}$ (PhoPQ non-inducing, but PmrAB inducing). These new samples, along with the samples grown in $\mathrm{N}$ minimum with high or low $\mathrm{Mg}^{2+}$ (included as controls), were used to prepare and image this final set of western blots. A representative set of blots is shown in Figure 22. As seen before, bands were present in low $\mathrm{Mg}^{2+}$ conditions, but not in high $\mathrm{Mg}^{2+}$ conditions, again indicating that the PhoPQ TCS is involved in arlAB expression. 
Interestingly, no bands were detected in high $\mathrm{Mg}^{2+}$ and high $\mathrm{Fe}^{2+}$ conditions either. As this set of

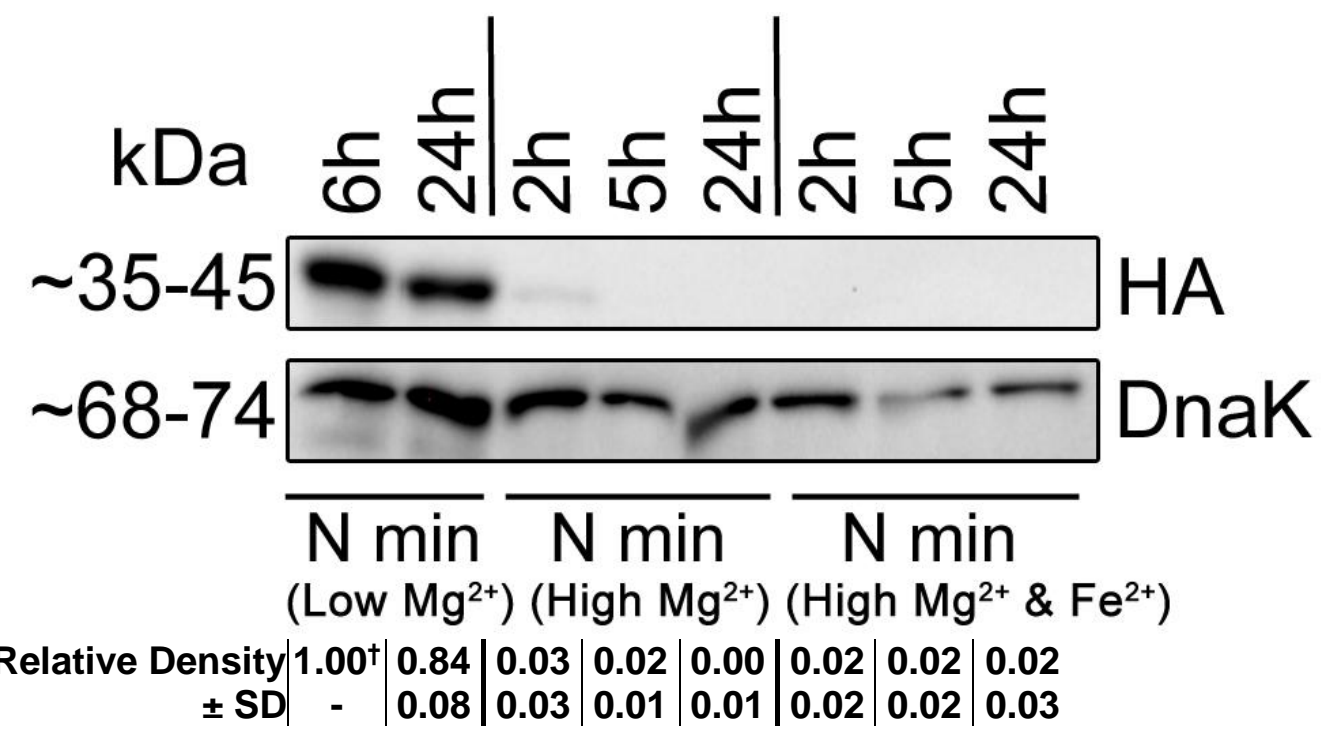

Figure 22. The western blots of membranes with NRG857 arlB:HA, using samples obtained from different growth phases of $\mathbf{N}$ minimal media with varying conditions.

This is an image of representative blots from three biological replicates. The mean relative density of the band, normalized to the first band, and their standard deviations, are shown below each lane. $\uparrow$ The values for the first lane were obtained using only two replicates due to an imaging error in this lane on one of the replicate blots.

conditions would not activate the PhoPQ TCS, but it would activate the PmrAB TCS alone, these results suggest that $\operatorname{arl} A B$ is not under $\mathrm{PmrAB}$ regulation. This result matches what was seen in just high $\mathrm{Mg}^{2+}$ conditions - without PhoPQ inducing conditions, arlB is not expressed. Taking all the western blot results into consideration, it is very likely that the PhoPQ TCS directly regulates the expression of the $\operatorname{arlAB}$ genes, without any involvement of the PmrAB TCS. 


\section{DISCUSSION}

\subsection{The change in bands of the core region of LPS gels suggest that the ArlB protein is involved in an LPS core modification system}

The development of IBDs, such as CD or $\mathrm{UC}$, is a complex process that involves the interplay of several factors, including host genetics, environmental contributions, and the intestinal microbial community known as the microbiome (1). Studies have shown that the microbiome can differ in composition between healthy individuals and IBD patients (1), and this can consist of a decrease in species diversity and an increase in harmful pathobionts such as AIEC (38). Bacteria with this particular pathotype designation are not clonally related strains, and factors shared by all or the majority of strains do not account for the adherent-invasive phenotype. Thus, there is a heterogeneity in the virulence factors of these type of bacteria which can be utilized to colonize the gut successfully in the stressed conditions of the gut in IBD development (43).

One set of AIEC genes, studied previously by McPhee et al., are the arlABC genes of PI6, found on a plasmid in CD clinical isolate NRG857c. This previous work showed that these genes encode proteins involved in HDP resistance mechanisms. In MIC assays using $\alpha$-helical peptides such as LL-37 and CP10A, mutants lacking one or all the PI-6 genes demonstrated significantly higher susceptibility than the WT. Also, the arlA gene was shown to be particularly important for the resistance of HD5, hBD2, and Paneth cell secretions, and necessary for competitive fitness in the murine gut (16). In addition to this work, it was found that PI-6 was required by NRG857c to expand in the inflamed conditions of the gut in mice after infectious gastroenteritis (46).

As it was already determined that ArlC is a member of the OM protease family that 
includes OmpT, and its main role in HDP resistance is likely its ability to cleave peptides such as LL-37 (16), the work in this study focused on the ArlA and ArlB proteins, as their roles in HDP resistance are not clear. ArlA may be an acetyltransferase of the GNAT family similar to FemX and Mig-14 $(48,51)$, and ArlB may be a NAD-dependent epimerase similar in structure to ArnA (49), but the processes that these are involved in are not yet known.

To begin investigating the roles of ArlA and ArlB, visualization of LPS by silver-staining gels was used to determine if differences can be detected among WT NRG857c and relevant mutants. A subtle difference is seen in the core region of the LPS profiles on these gels, and that difference can be attributed to the absence or presence of ArlB in the strains. WT and $\triangle a r l A$, which produce ArlB, had a band in the core region that was not seen in the other strains. The other strains include $\Delta$ PI-6 and $\Delta a r l B$, which lack the $\operatorname{arlB}$ gene, and $\Delta p h o P$, which is likely required for $\operatorname{arl} B$ expression, as seen by the western blot results.

A change in the bands of the core region would be possible if a part of the core became heavier, such as after the addition of a chemical group to mask the negative charge of a phosphate group. This would cause the bands corresponding to this particular section of the core to migrate a bit less far than those from an unmodified core (and would appear as a slight upward shift, separating it from other core bands). This is precisely what is seen in the gels presented here, and a modification of this nature is indicative of a typical HDP resistance method: modifications of LPS. LPS gel profile differences, caused by mutations in LPS modification genes, was already seen previously, such as in the work done by Klena et al. and by Gunn (31, 69). Thus, these results suggest that $a r l B$ encodes a protein involved in HDP resistance by means of LPS modifications in the core region. As the LPS profiles of the WT and $\triangle$ arlA were very similar, no inferences could be made here on the role of the ArlA protein. 
Gradient gels were used to confirm these results by improving the visualization of LPS, but even after this enhancement, an increased resolution of the core region is still desired. Unfortunately, by using whole cell lysates, further improvement may not be possible beyond what is presented here, but future directions, as discussed below, may involve using purified whole LPS or LPS core instead. By characterizing the purified samples, specific chemical groups can be associated with the changes in the strains with $\operatorname{arlB}$. For example, if the shift corresponds to a PEtN addition, this core modification may be similar to the modifications by eptC or $\operatorname{cptA}$ $(30,70)$, or if it corresponds to a sugar unit addition, perhaps arlB plays a similar role to $r f p(31)$.

\subsection{Phenotypic differences among WT NRG857c and its isogenic mutants in the PI-6 genes were usually not significant among various $O M$ permeabilization and susceptibility assays}

The first OM permeabilization assay, the NPN assay, was employed to determine if phenotypic differences can be detected between WT NRG857c and the relevant isogenic mutants. This was because increased NUF can be associated with susceptibility (58). In the optimization trials, the $\Delta p h o P$ mutant consistently had higher NUFs than the WT at varying polymyxin B concentrations and NUFs were generally higher in the low magnesium results than in the high magnesium results. This is consistent with the idea that magnesium is utilized by bacteria to maintain OM integrity, and in lower levels of this cation, permeabilization can increase overall (25). Also, these differences between the WT and $\Delta p h o P$ are consistent with the importance of PhoP in regulating OM integrity mechanisms, especially in PhoPQ-inducing conditions (21).

In further trials using the NPN assay, the WT was compared to isogenic mutants, mainly focusing on the PI-6 genes, but little differences among them were seen. In trials using LL-37, 
only the OM protease activity knockout ( $\Delta \operatorname{cat} \Delta \operatorname{arl} C \Delta o m p T)$ consistently had significantly higher NUFs. This supports the previous MIC work with LL-37, in which differences were the most significant in the OM protease mutants with respect to the WT (16). However, as discussed above, the MIC work also showed intermediate values for the $\operatorname{arlA}$ or $\operatorname{arlB}$ mutants, and values almost identical to $\triangle a r l C$ for $\triangle \mathrm{PI}-6$, yet NUFs for these same strains were all similar to the WT. It appears, in the specific experimental conditions used in these trials, that the combination of the three genes mutated in $\Delta$ cat $\Delta a r l C \Delta o m p T$ caused sufficient impairment in NRG857c that allowed detectable susceptibility differences compared to the WT, while all the other PI-6 gene mutants did not cause sufficient impairment. This can be supported by the fact that in certain contexts, NRG857c can still be pathogenic in the absence of PI-6 by other mechanisms, such as when the $\Delta \mathrm{PI}-6$ mutant resulted in histopathology scores higher than the non-bacterial infection (PBS) control in vivo (16).

Further NPN assays used CP10A and bacteria grown in either LB or N minimal media with low magnesium. The lack of significant differences in certain cases with respect to CP10A concentration may be because the NUFs were possibly already maximized, and future tests could use lower concentrations instead. Maximized NUFs may also be the reason for the lack of differences with respect to strains in the low-magnesium set. In the LB set, however, unexpected or inconsistent differences between strains could have been due to other ramifications of the NPN assay itself, or the possibility that intrinsic permeability changes occur in the mutants even in the absence of CP10A. Mutants that appear to re-establish resistance rather than show increased susceptibility could be due to the possibility that other mechanisms in NRG857c are activated in the absence of one or more of the PI- 6 genes, depending on the context. This type of effect has been seen previously with the PhoP-regulated ArlA-homologous protein Mig-14, in 
which the mutant lacking this protein showed increased PmrD levels and resistance to polymyxin B that was comparable to the WT (51).

With the majority of the NPN assay results being negative, the lysozyme assay was employed as an alternate $\mathrm{OM}$ permeabilization assay. The $\Delta \mathrm{OD}$ values are higher for larger $\mathrm{OD}$ declines over time and is associated to susceptibility. Using polymyxin B, as expected, there was a concentration dependence where larger $\Delta \mathrm{OD}$ values were obtained with higher polymyxin $\mathrm{B}$ concentrations. It was also interesting that among NRG857c WT and mutants $\triangle \mathrm{PI}-6, \Delta a r l A$, and $\triangle \operatorname{arl} B$, the $\Delta \mathrm{PI}-6$ mutant appeared to be the most polymyxin B susceptible, the WT was the most resistant, and the other two mutants produced intermediate values. This indicates that some combination of the genes, perhaps also involving $\operatorname{arl} C$, may be used in some mechanism to resist this type of antimicrobial compound. However, by using CP10A in this assay since it related back to previous work, all strains developed into aggregated clumps, as shown by the microscopy images. These results may have been due to some sort of adherence between the OM of the bacteria and CP10A that has not been described before, and may have been only possible at concentrations as high as the ones used here. This may play a role in the antimicrobial effects of CP10A and perhaps other similar peptides. Other than this, there may have been some indication that $\triangle a r l B$ was the most compromised strain when using CP10A, and this could be related to its potential involvement in a LPS modification system as suggested by the LPS gels. Still, as further investigations would be necessary to determine the mechanisms involved here, not much more can be concluded upon due to the unexpected outcomes of using CP10A in this particular assay.

Next, the RDA was used to determine if phenotypic differences can be observed between WT NRG857c and the relevant mutants. At this stage of the project, it was already determined 
that higher levels of ArlB, and likely ArlA, are produced in the early stationary growth phase in $\mathrm{LB}$, as compared to the mid-logarithmic phase. Thus, bacteria prepared for RDAs were grown to early stationary phase to ensure maximal levels of ArlA and ArlB were produced. However, no significant differences were seen among all the strains tested. From these results, it can only be concluded that $\operatorname{arl} A$ and $\operatorname{arlB}$ do not affect susceptibility to these compounds.

After learning about the synergetic effects of combining pentamidine with rifampicin against Gram-negative bacteria (61), and given the similarity to MIC assays, we decided that the FIC assay would be suitable to test our strains of interest. However, trials comparing WT NRG857c and $\Delta$ PI-6 showed no significant differences even though $\Delta$ PI-6 appeared to be the most susceptible in other assays. But it was interesting to note that the drug combinations were very synergistically effective against both strains, especially when pentamidine was substituted with the more relevant CP10A. It may be that the synergy was so effective, that any differences between the strains played no role in resisting these drug combinations. Core LPS differences between the WT and $\Delta$ PI-6 are much subtler than the entire truncations used in the Stokes et al. study. Thus, these results indicate that the combined effect of a membrane disruptor and rifampicin has a much more pronounced difference among the core truncation strains that is not observed among the NRG857 strains studied here. Oddly, even MIC values between the strains did not show any significant differences, contrary to the previous MIC work (16). As all parameters were carefully controlled to match previous experimental conditions, it is possible that the CP10A, which was older in these experiments, may have experienced some degradation (such as in the tryptophan residues). Other than this, reasons for this could not be determined.

The final set of experiments that explored phenotypic differences between WT NRG857c and the relevant mutants was the bacterial invasion/survival assay. As discussed above, AIEC 
like NRG857c are able to invade and survive within host cells such as epithelial cells and macrophages (38) and they may encounter, and would need to resist, $\alpha$-helical peptides within macrophages, as it has been described previously (67). Given the potential importance of PI-6 against these types of HDPs (16), we found it relevant to use this assay with WT NRG857c and its mutants in the PI-6 genes. After 1 hour of incubation, CFU counts appeared to be reproducible, but there was no significant difference between the WT and the mutants, not even with the complete PI-6 knockout. Also, the range of percentage invasion values was minimal (between 0 to $2.5 \%$ ) and the values were unremarkably low. This may be related to the specific experimental conditions that were used, as values for SL1344 were within the same range despite being a highly invasive strain.

After 24 hours of incubation, CFU counts were slightly higher for the NRG857c strains than from the 1-hour timepoint, which shows their ability to persist within the macrophages. However, there were no significant differences between them. The percentage survival values also demonstrate their ability to survive intracellularly, although not to the extent of SL1344 that had values higher than $100 \%$ (due to successful replication within the macrophages). Again, these were not statistically significant between the WT and the PI-6 gene mutants. This suggests that the contributions of the $\operatorname{arl} A B C$ genes are minimal in the context of intracellular survival, and thus, removal of any or all genes does not affect the ability of NRG857c to persist inside these macrophages. This was seen previously with this type of assay, in which bacteria lacking the arlA homologue mig-14 gene had similar 24-hour CFU counts as the WT. However, when the macrophages were activated using LPS and interferon-gamma, the WT had significantly higher counts than the mig-14 and other mutants (71). It could be that the NRG857c strains were not challenged within the biologically relevant context where the PI-6 genes are necessary to 
survive within the macrophages.

Overall, with respect to determining phenotypic differences among WT NRG857c and the PI-6 gene mutants, several assays were employed, but results were usually negative. The most consistent finding seen in some assays was that the $\Delta$ PI-6 mutant was the most susceptible strain, while single gene deletions usually behaved similarly to the WT. Again, this corresponds with the previous MIC assays, where the $\triangle \mathrm{PI}-6$ mutant had the significantly lowest MICs while $\triangle a r l A$ and $\triangle a r l B$ had intermediate values (16). Also, according to the findings presented here, it appears there are no alterations in $\mathrm{CP} 10 \mathrm{~A}$ resistance in an $\operatorname{arl} A B$ dependent manner, even though the genes may be important for some aspect of HDP resistance, such as a LPS core modification mechanism. In fact, Tamayo et al. showed that the LPS modification genes $p m r C$ and $c p t A$ did not play major roles in polymyxin B resistance even though they were up-regulated in vivo using mouse infection models (70). The contributions of $\operatorname{arl} A B$, especially individually, may be subtle, and their roles only become significant in certain contexts that perhaps were not established in the assays used here. This notion of differences due to context was already seen, as ArlC was the strongest contributor in the MIC assays using $\alpha$-helical peptides, but ArlA was the most important in the in vivo mice experiments (16). Also, as discussed above, it is important to recognize that other factors and pathways likely exist in NRG857c that may become activated in certain contexts using the WT (so that $\operatorname{arlABC}$ is not required) (16) or in the absence of one or more of the PI-6 genes (so that resistance can be restored to WT levels) (51). Bacteria grown in low magnesium conditions is another example of this, as biofilm formation in these conditions could also be a reason why results were not as expected. The effects of the $\operatorname{arl} A B C$ genes may be masked or unnecessary in this context, as there are very specific pathways and meticulous regulation of genes in biofilm-associated bacteria (72). Thus, there are many possibilities to 
explain why the results from these assays were usually negative, and future experiments, as discussed below, may allow further insights on the roles of the PI-6 genes in NRG857c. Also, future directions may instead focus on characterizing LPS isolated from the different strains, or make use of protein assays with isolated and purified ArlA and ArlB.

\subsection{ArlB:HA is regulated by low $\mathrm{Mg}^{2+}$ conditions in a PhoP- dependent manner}

As various virulent factors are regulated in bacteria to ensure proper resource use and pathogenesis development, and the use of TCSs such as PhoPQ and PmrAB were already defined to play major roles in this complex type of regulation (21), we suspected that the PI-6 genes are regulated by these conserved mechanisms. This is especially due to the fact that PhoPQ and PmrAB regulate HDP resistance mechanisms such as LPS modifications (21). By developing the HA-tagged version of the $a r l B$ gene, western blots were utilized in different experimental conditions to provide insight on how the $\operatorname{arl} A B$ genes are regulated and if they are regulated by the TCSs described above. As mentioned before, arlA is likely expressed together with $\operatorname{arlB}$, as these genes are in close proximity of each other on PI-6 and likely have only one promoter region adjacent to them. Also, it is unlikely no bands were detected using arlA:HA due to no expression of $\operatorname{arlA}$, since previous experiments showed that $\operatorname{arlA}$ is certainly expressed in LB-growth conditions.

The western blots gave information on the differential regulation of $\operatorname{arlAB}$ throughout LB growth, and the strong suggestion that PhoPQ, and not PmrAB, is controlling their regulation. Firstly, as the first set of blots showed by the density of bands detected, arlB:HA expression was not even throughout the timepoints representing different phases of LB-growth. There was an increase in $\operatorname{arlB}: \mathrm{HA}$ levels over time, until it appears there was a maximum reached in the early 
stationary phase. This indicates that $\operatorname{arl} A B$ expression, although present at some levels in the logarithmic phase, may be more necessary and play a larger role in the stationary phase, when resources are diminishing. Also, this could be due to one of the limitations of using LB: divalent cation insufficiency. There is about 30 to $40 \mu \mathrm{M}$ of $\mathrm{Mg}^{2+}$ available in $\mathrm{LB}$, and this becomes depleted as bacteria are grown to stationary phase, which can be comparable to $\mathrm{N}$ minimal media with low $\mathrm{Mg}^{2+}(10 \mu \mathrm{M})(73)$. Thus, this could have been an early suggestion that PhoPQ was involved in their regulation, as these low $\mathrm{Mg}^{2+}$ conditions would activate this TCS. Due to this finding, future work could also investigate the possibility that RpoS, a sigma factor that regulates stationary-phase gene expression (74), may be involved directly or indirectly in $\operatorname{arlAB}$ expression. In further sets of western blots, it was apparent, with the absence or presence of bands, that $a r l B: H A$ is not expressed in high magnesium, but it is expressed in low magnesium. As the PhoPQ TCS is activated in low magnesium, this suggests that $\operatorname{arlAB}$ is under PhoPQ regulation. These results were confirmed when no bands were detected (no $\operatorname{arlB}: \mathrm{HA}$ expression) in any growth media when the NRG857 4 phoP arlB:HA strain was used instead, as PhoP was absent and the TCS was unable to drive the expression of any of the genes under its regulation. Using PhoPQ non-inducing (high magnesium) and PmrAB inducing (high iron) conditions, it was shown that $\operatorname{arlB}: \mathrm{HA}$ was not expressed, which suggests that PhoP-induced PmrD was not activating PmrA to regulate $\operatorname{arl} A B$ in the low magnesium conditions, and that it is likely PhoPQ is regulating these genes directly without PmrAB. Although these results were straightforward, as other systems, such as RpoS regulation, may be involved in $\operatorname{arl} A B$ expression, methods are required to validate these findings, as mentioned below in the future directions. 


\subsection{Future Directions}

Although a substantial amount of work was completed in the investigation of the role of the ArlA and ArlB proteins in NRG857c, this work needs to be taken further in additional experiments to develop a better understanding of how they function and what systems they are involved in. To develop the work relating to the LPS visualized on gels, LPS samples taken from the WT and the relevant mutants can be isolated and purified for more detailed characterization and analysis. For example, purified LPS samples can be subjected to matrix assisted laser desorption/ionization-time of flight (MALDI-TOF) mass spectrometry or proton nuclear magnetic resonance (NMR) spectroscopy to determine if differences in detected peaks can be associated with core modifications (70). Also, waaL mutants of the strains can be developed (deletion of the LPS biosynthesis gene that encodes the O-antigen ligase) so that bacteria can be grown with rough LPS, which may be more effective for core region characterization, as it would eliminate O-antigen and improve our ability to study fine differences in the lipid A + core components of LPS. This work was already started using allelic exchange mutagenesis. Also, new LPS gels may be developed with an increased resolution in the core region by using purified LPS, either from the original strains or the waaL mutants, so that the results shown here can be confirmed.

Continued investigations on the phenotypic differences between the WT and the mutants may use approaches that introduce new variables or experimental contexts to provide further insight on the roles of the ArlA and ArlB proteins. For example, other AIEC strains, that may or may not contain the arlABC genes, may be employed to determine if the genes work in similar ways across these different AIEC. For example, MICs, NPN assays, and the bacterial invasion/survival assays may be repeated using the AIEC strains previously identified to contain 
$\operatorname{arlA}$ and $\operatorname{arlC}(16)$, to determine if similar results would be obtained and can be associated with these genes. Also, to distinguish which combined aspects of PI-6 are affected in the different experiments, double mutants can be developed, such as $\triangle \operatorname{arl} \triangle \Delta a r l B$, or mutants with $\triangle \operatorname{arl} C$. Using the RDA, these double mutants can even be used to determine if epistatic effects would be manifested. Furthermore, some of the assays can also utilize HD5 or hBD2 instead of the $\alpha$ helical HDPs, and the survival assay can be revisited by using macrophages activated by interferon-gamma and LPS. These experimental adjustments could explore different contexts that may possibly manifest in phenotypic differences between strains that were not seen here and provide more information on the mechanisms of the $\operatorname{arl} A B C$ genes. Lastly, it would be ideal to complete new experiments in vivo, as this may be the most biologically relevant way to study the effects of these genes.

In further investigations studying the regulation of the $\operatorname{arl} A B$ genes, more work can be completed using further western blots and other protocols. The arlA:HA version of NRG857c can be redeveloped by HA-tagging the arlA gene on the N-terminal rather than the C-terminal, to try to avoid having the tag cleaved post-translationally, as we speculated may have occurred in the original arlA:HA strain. Also, pmrA or $r p o S$ mutants can be developed in NRG857 arlB:HA to confirm the results obtained so far on $\operatorname{arl} A B$ expression regulation. Moreover, since gene regulation can get very complicated, such as how PhoP-regulated mig-14 was still expressed in a phoP mutant in the presence of polymyxin B (51), other protocols, such as the electrophoretic mobility shift assay, will be employed to validate the western blot results. Using purified and isolated PhoP protein, this assay can be used to determine whether PhoP does actually bind to the promoter region of $\operatorname{arl} A B$, which would confirm that its regulation is direct.

Finally, work on ArlA and ArlB will likely lead to the isolation and purification of the 
proteins themselves. This would allow studies on their three-dimensional structures that would illustrate their catalytic domains and would lead to a better understanding of their functions, and further assays, such as complementation experiments, can be used to characterize their roles in HDP resistance more thoroughly.

\subsection{Significance}

Microbial communities within the human host contain numerous species of bacteria that have adapted to their environment and can make a large impact to the health of the host. It is well established that the gut microbiome is involved in the development of IBD, in both CD and UC (1). The study of the various pathotypes of bacteria that are associated with these types of diseases is currently ongoing and the approaches and methods used for their investigation are varied and numerous. This includes the study of AIEC, and the idea that these bacteria are not monophyletic (43). Thus, virulence mechanisms have been found in AIEC strains that are shared among only a subset of other AIEC strains (44). Further investigation into these mechanisms contributes to the growing knowledge of how AIEC can become pathogenic and play a role in the development of these diseases.

One of these mechanisms was discovered in isolate NRG857c, encoded by the arlABC genes of PI-6 on pO83. Previously, it was demonstrated that the genes encode proteins that confer resistance against HDPs, including $\alpha$-helical peptides and human $\alpha$ - and $\beta$-defensins, shown through both in vivo and in vitro studies. ArlC was determined to be an OM protease in the same family as OmpT, which would be involved in cleaving HDP on the bacterial surface. However, previously, little was known about ArlA and ArlB, and how they are involved in HDP resistance. This project served to build upon this previous research and to learn more about these 
particular genes.

The work presented here provides new information in the ongoing study of this important mechanism used by NRG857c, and likely by other AIEC strains as well. It was suggested by LPS gels that the protein encoded by $\operatorname{arlB}$ is required for an LPS modification system that affects the core region, which would correspond to a typical method used by bacteria to evade HDPs. Various OM permeabilization and susceptibility assays were completed, as these techniques have been used extensively previously to show differences between WT and mutant strains. However, many assays showed little difference among WT NRG857c and the mutants in the $\operatorname{arlA}$ and $\operatorname{arlB}$ genes, which indicates that their contributions may be rather subtle and not always necessary in various experimental contexts. Finally, western blots using HA-tagged $\operatorname{arlB}$ showed strong evidence that the $\operatorname{arl} A B$ genes are differentially expressed relative to growth phase and are directly regulated by the PhoPQ TCS.

With this research, a better understanding was developed of the ArlA and ArlB proteins and how they are associated with HDP resistance in AIEC. Also, it lays foundations for further investigations on these proteins and the precise mechanisms they are involved in. It contributes to a better understanding of the methods and regulatory mechanisms that AIEC and other E. coli pathotypes utilize to cause virulent effects in the human host. This knowledge can eventually lead to the development of newer and more effective therapeutic strategies in treating IBD and other diseases related to E. coli pathogens. 


\section{REFERENCES}

1. Sartor RB. 2008. Microbial Influences in Inflammatory Bowel Diseases. Gastroenterology 134:577-594.

2. Strober W, Fuss I, Mannon P. 2007. Science in medicine The fundamental basis of inflammatory bowel disease. J Clin Invest 117:514-21.

3. Jostins L, Ripke S, Weersma RK, Duerr RH, McGovern DP, Hui KY, Lee JC, Schumm LP, Sharma Y, Anderson CA, Essers J, Mitrovic M, Ning K, Cleynen I, Theatre E, Spain SL, Raychaudhuri S, Goyette P, Wei Z, Abraham C, Achkar J-P, Ahmad T, Amininejad L, Ananthakrishnan AN, Andersen V, Andrews JM, Baidoo L, Balschun T, Bampton PA, Bitton A, Boucher G, Brand S, Büning C, Cohain A, Cichon S, D'Amato M, De Jong D, Devaney KL, Dubinsky M, Edwards C, Ellinghaus D, Ferguson LR, Franchimont D, Fransen K, Gearry R, Georges M, Gieger C, Glas J, Haritunians T, Hart A, Hawkey C, Hedl M, Hu X, Karlsen TH, Kupcinskas L, Kugathasan S, Latiano A, Laukens D, Lawrance IC, Lees CW, Louis E, Mahy G, Mansfield J, Morgan AR, Mowat C, Newman W, Palmieri O, Ponsioen CY, Potocnik U, Prescott NJ, Regueiro M, Rotter JI, Russell RK, Sanderson JD, Sans M, Satsangi J, Schreiber S, Simms LA, Sventoraityte J, Targan SR, Taylor KD, Tremelling M, Verspaget HW, De Vos M, Wijmenga C, Wilson DC, Winkelmann J, Xavier RJ, Zeissig S, Zhang B, Zhang CK, Zhao H, Silverberg MS, Annese V, Hakonarson H, Brant SR, Radford-Smith G, Mathew CG, Rioux JD, Schadt EE, Daly MJ, Franke A, Parkes M, Vermeire S, Barrett JC, Cho JH. 2012. Host-microbe interactions have shaped the genetic architecture of inflammatory bowel disease. Nature 491:119-24.

4. Liu JZ, Van Sommeren S, Huang H, Ng SC, Alberts R, Takahashi A, Ripke S, Lee JC, 
Jostins L, Shah T, Abedian S, Cheon JH, Cho J, Daryani NE, Franke L, Fuyuno Y, Hart A, Juyal RC, Juyal G, Kim WH, Morris AP, Poustchi H, Newman WG, Midha V, Orchard TR, Vahedi H, Sood A, Sung JJY, Malekzadeh R, Westra HJ, Yamazaki K, Yang SK, Barrett JC, Franke A, Alizadeh BZ, Parkes M, Thelma BK, Daly MJ, Kubo M, Anderson CA, Weersma RK. 2015. Association analyses identify 38 susceptibility loci for inflammatory bowel disease and highlight shared genetic risk across populations. Nat Genet 47:979-986.

5. De Lange KM, Moutsianas L, Lee JC, Lamb CA, Luo Y, Kennedy NA, Jostins L, Rice DL, Gutierrez-Achury J, Ji SG, Heap G, Nimmo ER, Edwards C, Henderson P, Mowat C, Sanderson J, Satsangi J, Simmons A, Wilson DC, Tremelling M, Hart A, Mathew CG, Newman WG, Parkes M, Lees CW, Uhlig H, Hawkey C, Prescott NJ, Ahmad T, Mansfield JC, Anderson CA, Barrett JC. 2017. Genome-wide association study implicates immune activation of multiple integrin genes in inflammatory bowel disease. Nat Genet $49: 256-261$.

6. Lee JC, Biasci D, Roberts R, Gearry RB, Mansfield JC, Ahmad T, Prescott NJ, Satsangi J, Wilson DC, Jostins L, Anderson CA, Traherne JA, Lyons PA, Parkes M, Smith KGC. 2017. Genome-wide association study identifies distinct genetic contributions to prognosis and susceptibility in Crohn's disease. Nat Genet 49:262-268.

7. Brant SR, Okou DT, Simpson CL, Cutler DJ, Haritunians T, Bradfield JP, Chopra P, Prince J, Begum F, Kumar A, Huang C, Venkateswaran S, Datta LW, Wei Z, Thomas K, Herrinton LJ, Klapproth JMA, Quiros AJ, Seminerio J, Liu Z, Alexander JS, Baldassano RN, Dudley-Brown S, Cross RK, Dassopoulos T, Denson LA, Dhere TA, Dryden GW, Hanson JS, Hou JK, Hussain SZ, Hyams JS, Isaacs KL, Kader H, Kappelman MD, Katz J, 
Kellermayer R, Kirschner BS, Kuemmerle JF, Kwon JH, Lazarev M, Li E, Mack D, Mannon P, Moulton DE, Newberry RD, Osuntokun BO, Patel AS, Saeed SA, Targan SR, Valentine JF, Wang MH, Zonca M, Rioux JD, Duerr RH, Silverberg MS, Cho JH, Hakonarson H, Zwick ME, McGovern DPB, Kugathasan S. 2017. Genome-Wide Association Study Identifies African-Specific Susceptibility Loci in African Americans With Inflammatory Bowel Disease. Gastroenterology 152:206-217.e2.

8. Bevins CL, Salzman NH. 2011. Paneth cells, antimicrobial peptides and maintenance of intestinal homeostasis. Nat Rev Microbiol 9:356-368.

9. Hancock RE, Scott MG. 2000. The role of antimicrobial peptides in animal defenses. Proc Natl Acad Sci U S A 97:8856-61.

10. Wang G. 2014. Human antimicrobial peptides and proteins. Pharmaceuticals 7:545-594.

11. Perminow G, Beisner J, Koslowski M, Lyckander LG, Stange E, Vatn MH, Wehkamp J. 2010. Defective paneth cell-mediated host defense in pediatric ileal Crohn's disease. Am J Gastroenterol 105:452-459.

12. Zilbauer M, Jenke A, Wenzel G, Goedde D, Postberg J, Phillips AD, Lucas M, NobleJamieson G, Torrente F, Salvestrini C, Heuschkel R, Wirth S. 2011. Intestinal alphadefensin expression in pediatric inflammatory bowel disease. Inflamm Bowel Dis 17:2076-2086.

13. Aldhous MC, Noble CL, Satsangi J. 2009. Dysregulation of human beta-defensin-2 protein in inflammatory bowel disease. PLoS One 4:e6285.

14. Schauber J, Rieger D, Weiler F, Wehkamp J, Eck M, Fellermann K, Scheppach W, Gallo RL, Stange EF. 2006. Heterogeneous expression of human cathelicidin hCAP18/LL-37 in inflammatory bowel diseases. Eur J Gastroenterol Hepatol 18:615-621. 
15. Brogden KA. 2005. Antimicrobial peptides: pore formers or metabolic inhibitors in bacteria? Nat Rev Microbiol 3:238-50.

16. McPhee JB, Small CL, Reid-Yu SA, Brannon JR, Moual H Le, Coombes BK. 2014. Host defense peptide resistance contributes to colonization and maximal intestinal pathology by Crohn's disease-associated adherent-invasive Escherichia coli. Infect Immun 82:33833393.

17. Wang G. 2008. Structures of human host defense cathelicidin LL-37 and its smallest antimicrobial peptide KR-12 in lipid micelles. J Biol Chem 283:32637-32643.

18. Friedrich CL, Rozek A, Patrzykat A, Hancock REW. 2001. Structure and Mechanism of Action of an Indolicidin Peptide Derivative with Improved Activity against Gram-positive Bacteria. J Biol Chem 276:24015-24022.

19. Peschel A, Sahl HG. 2006. The co-evolution of host cationic antimicrobial peptides and microbial resistance. Nat Rev Microbiol 4:529-536.

20. Groisman EA, Parra-Lopez C, Salcedo M, Lipps CJ, Heffron F. 1992. Resistance to host antimicrobial peptides is necessary for Salmonella virulence. Proc Natl Acad Sci 89:11939-11943.

21. Olaitan AO, Morand S, Rolain JM. 2014. Mechanisms of polymyxin resistance: Acquired and intrinsic resistance in bacteria. Front Microbiol 5:1-18.

22. Rubin EJ, Herrera CM, Crofts AA, Trent MS. 2015. PmrD is required for modifications to Escherichia coli endotoxin that promote antimicrobial resistance. Antimicrob Agents Chemother 59:2051-2061.

23. Kus J V., Gebremedhin A, Dang V, Tran SL, Serbanescu A, Foster DB. 2011. Bile salts induce resistance to polymyxin in enterohemorrhagic Escherichia coli O157:H7. J 
Bacteriol 193:4509-4515.

24. Wösten MMSM, Kox LFF, Chamnongpol S, Soncini FC, Groisman EA. 2000. A signal transduction system that responds to extracellular iron. Cell 103:113-125.

25. Raetz CRH, Reynolds CM, Trent MS, Bishop RE. 2007. Lipid A modification systems in gram-negative bacteria. Annu Rev Biochem 76:295-329.

26. Yethon JA, Vinogradov E, Perry MB, Whitfield C. 2000. Mutation of the lipopolysaccharide core glycosyltransferase encoded by waaG destabilizes the outer membrane of Escherichia coli by interfering with core phosphorylation. J Bacteriol $182: 5620-5623$.

27. Kato A, Chen HD, Latifi T, Groisman EA. 2012. Reciprocal Control between a Bacterium's Regulatory System and the Modification Status of Its Lipopolysaccharide. Mol Cell 47:897-908.

28. Trent MS, Stead CM, Tran AX, Hankins J V. 2006. Diversity of endotoxin and its impact on pathogenesis. J Endotoxin Res 12:205-223.

29. Bociek K, Ferluga S, Mardirossian M, Benincasa M, Tossi A, Gennaro R, Scocchi M. 2015. Lipopolysaccharide phosphorylation by the WaaY kinase affects the susceptibility of Escherichia coli to the human antimicrobial peptide LL-37. J Biol Chem 290:1993319941.

30. Salazar J, Alarcón M, Huerta J, Navarro B, Aguayo D. 2017. Phosphoethanolamine addition to the Heptose I of the Lipopolysaccharide modifies the inner core structure and has an impact on the binding of Polymyxin B to the Escherichia coli outer membrane. Arch Biochem Biophys 620:28-34.

31. Klena JD, Ashford RS, Schnaitman CA. 1992. Role of Escherichia coli K-12 rfa genes 
and the $r f p$ gene of Shigella dysenteriae 1 in generation of lipopolysaccharide core heterogeneity and attachment of O antigen. J Bacteriol 174:7297-7307.

32. Heinrichs DE, Monteiro MA, Perry MB, Whitfield C. 1998. The Assembly System for the Lipopolysaccharide R2 Core-type of Escherichia coli Is a Hybrid of Those Found in Escherichia coli K-12 and Salmonella enterica. J Biol Chem 273:8849-8859.

33. Klein G, Lindner B, Brade H, Raina S. 2011. Molecular basis of lipopolysaccharide heterogeneity in Escherichia coli: Envelope stress-responsive regulators control the incorporation of glycoforms with a third 3-deoxy- $\alpha$-D-manno-oct-2-ulosonic acid and rhamnose. J Biol Chem 286:42787-42807.

34. Hritonenko V, Stathopoulos C. 2007. Omptin proteins: An expanding family of outer membrane proteases in Gram-negative Enterobacteriaceae (Review). Mol Membr Biol 24:395-406.

35. Gruenheid S, Le Moual H. 2012. Resistance to antimicrobial peptides in Gram-negative bacteria. FEMS Microbiol Lett 330:81-89.

36. Vandeputte-Rutten L, Kramer RA, Kroon J, Dekker N, Egmond MR, Gros P. 2001.

Crystal structure of the outer membrane protease OmpT from Escherichia coli suggests a novel catalytic site. EMBO J 20:5033-5039.

37. Croxen M a, Finlay BB. 2010. Molecular mechanisms of Escherichia coli pathogenicity. Nat Rev Microbiol 8:26-38.

38. Rolhion N, Darfeuille-Michaud A. 2007. Adherent-invasive Escherichia coli in inflammatory bowel disease. Inflamm Bowel Dis 13:1277-1283.

39. Darfeuille-Michaud A, Neut C, Barnich N, Lederman E, Di Martino P, Desreumaux P, Gambiez L, Joly B, Cortot A, Colombel J-F. 1998. Presence of adherent Escherichia coli 
strains in ileal mucosa of patients with Crohn's disease. Gastroenterology 115:1405-1413.

40. Boudeau J, Glasser A, Masseret E, Joly B, Darfeuille-Michaud A. 1999. Invasive Ability of an Escherichia coli Strain Isolated from the Ileal Mucosa of a Patient with Crohn's

Disease. Infect Immun 67:4499-4509.

41. Zhang Y, Rowehl L, Krumsiek JM, Orner EP, Shaikh N, Tarr PI, Sodergren E, Weinstock GM, Boedeker EC, Xiong X, Parkinson J, Frank DN, Li E, Gathungu G. 2015. Identification of candidate adherent-invasive $E$. coli signature transcripts by genomic/transcriptomic analysis. PLoS One 10.

42. Desilets M, Deng X, Deng X, Rao C, Ensminger AW, Krause DO, Sherman PM, GrayOwen SD. 2016. Genome-based Definition of an Inflammatory Bowel Disease-associated Adherent-Invasive Escherichia coli Pathovar. Inflamm Bowel Dis 22:1-12.

43. O’Brien CL, Bringer M-A, Holt KE, Gordon DM, Dubois AL, Barnich N, DarfeuilleMichaud A, Pavli P. 2016. Comparative genomics of Crohn's disease-associated adherentinvasive Escherichia coli. Gut gutjnl-2015-311059.

44. Nash JHE, Villegas A, Kropinski AM, Aguilar-Valenzuela R, Konczy P, Mascarenhas M, Ziebell K, Torres AG, Karmali MA, Coombes BK. 2010. Genome sequence of adherentinvasive Escherichia coli and comparative genomic analysis with other E. coli pathotypes. BMC Genomics 11:1-15.

45. Eaves-Pyles T, Allen CA, Taormina J, Swidsinski A, Tutt CB, Eric Jezek G, Islas-Islas M, Torres AG. 2008. Escherichia coli isolated from a Crohn's disease patient adheres, invades, and induces inflammatory responses in polarized intestinal epithelial cells. Int J Med Microbiol 298:397-409.

46. Small CL, Xing L, McPhee JB, Law HT, Coombes BK. 2016. Acute Infectious 
Gastroenteritis Potentiates a Crohn's Disease Pathobiont to Fuel Ongoing Inflammation in the Post-Infectious Period. PLoS Pathog 12.

47. Kelley LA, Mezulis S, Yates CM, Wass MN, Sternberg MJE. 2015. The Phyre2 web portal for protein modeling, prediction and analysis1. Kelley LA, Mezulis S, Yates CM, Wass MN, Sternberg MJE. 2015. The Phyre2 web portal for protein modeling, prediction and analysis. Nat Protoc 10:845-858. Nat Protoc 10:845-858.

48. Biarrotte-Sorin S, Maillard AP, Delettré J, Sougakoff W, Arthur M, Mayer C. 2004. Crystal Structures of Weissella viridescens FemX and Its Complex with UDP-MurNAcPentapeptide: Insights into FemABX Family Substrates Recognition. Structure 12:257267.

49. Gatzeva-Topalova PZ, May AP, Sousa MC. 2005. Structure and mechanism of ArnA: Conformational change implies ordered dehydrogenase mechanism in key enzyme for polymyxin resistance. Structure 13:929-942.

50. Hankins J V, Madsen JA, Giles DK, Brodbelt JS, Trent MS, Tor E. 2012. Pnas201201313 8722..8727 1-14.

51. Brodsky IE, Ernst RK, Miller SI, Falkow S. 2002. mig-14 is a Salmonella gene that plays a role in bacterial resistance to antimicrobial peptides. J Bacteriol 184:3203-3213.

52. Jochumsen N, Liu Y, Molin S, Folkesson A. 2011. A Mig-14-like protein (PA5003) affects antimicrobial peptide recognition in Pseudomonas aeruginosa. Microbiology $157: 2647-2657$.

53. Gatzeva-topalova PZ, May AP, Sousa MC. 2004. Crystal Structure of Escherichia coli ArnA ( PmrI ) Decarboxylase Domain . A Key Enzyme for Lipid A Modification with 4Amino-4-deoxy-L-arabinose and Polymyxin Resistance. Biochemistry 43:13370-13379. 
54. Hoiseth SK, Stocker BAD. 1981. Aromatic-dependent Salmonella typhimurium are nonvirulent and effective as live vaccines. Nature.

55. Hitchcock PJ, Brown TM. 1983. Morphological heterogeneity among Salmonella lipopolysaccharide chemotypes in silver-stained polyacrylamide gels. J Bacteriol 154:269-277.

56. Zhu ZX, Cong WT, Ni MW, Wang X, Ma W De, Ye WJ, Jin LT, Li XK. 2012. An improved silver stain for the visualization of lipopolysaccharides on polyacrylamide gels. Electrophoresis 33:1220-1223.

57. Loh B, Grant C, Hancock RE. 1984. Use of the fluorescent probe 1- $N$ phenylnaphthylamine to study the interactions of aminoglycoside antibiotics with the outer membrane of Pseudomonas aeruginosa. Antimicrob Agents Chemother 26:546-551.

58. Helander IM, Mattila-Sandholm T. 2000. Fluorometric assessment of Gram-negative bacterial permeabilization. J Appl Microbiol 88:213-219.

59. Hancock REW, Wong PGW. 1984. Compounds Which Increase the Permeability of the Pseudomonas aeruginosa Outer-Membrane. Antimicrob Agents Chemother 26:48-52.

60. Lehrer RI, Rosenman M, Harwig SSSL, Jackson R, Eisenhauer P. 1991. Ultrasensitive assays for endogenous antimicrobial polypeptides. J Immunol Methods 137:167-173.

61. Stokes JM, MacNair CR, Ilyas B, French S, Côté J-P, Bouwman C, Farha MA, Sieron AO, Whitfield C, Coombes BK, Brown ED. 2017. Pentamidine sensitizes Gram-negative pathogens to antibiotics and overcomes acquired colistin resistance. Nat Microbiol 2:17028.

62. Uzzau S, Figueroa-Bossi N, Rubino S, Bossi L. 2001. Epitope tagging of chromosomal genes in Salmonella. Proc Natl Acad Sci U S A 98:15264-15269. 
63. Datsenko KA, Wanner BL. 2000. One-step inactivation of chromosomal genes in Escherichia coli K-12 using PCR products. Proc Natl Acad Sci U S A 97:6640-5.

64. Mahmood T, Yang PC. 2012. Western blot: Technique, theory, and trouble shooting. N Am J Med Sci 4:429-434.

65. Helgerson SL, Cramer WA. 1977. Changes in Escherichia coli Cell Envelope Structure and the Sites of Fluorescence Probe Binding Caused by Carbonyl Cyanide. Biochemistry 16:4109-4117.

66. Lee DL, Powers JS, Pflegerl K, Vasil ML, Hancock REW, Hodges RS. 2004. Effects of single D-amino acid substitutions on disruption of $\beta$-sheet structure and hydrophobicity in cyclic peptide analogs related to gramicidin S. J Pept Res 63:69-84.

67. Rosenberger CM, Gallo RL, Finlay BB. 2004. Interplay between antibacterial effectors: A macrophage antimicrobial peptide impairs intracellular Salmonella replication. Proc Natl Acad Sci 101:2422-2427.

68. Hopp TP, Prickett KS, Price VL, Libby RT, March CJ, Pat Cerretti D, Urdal DL, Conlon PJ. 1988. A Short Polypeptide Marker Sequence Useful for Recombinant Protein Identification and Purification. Nat Biotechnol 6:1204-1210.

69. Gunn JS. 2001. Bacterial modification of LPS and resistance to antimicrobial peptides. J Endotoxin Res 7:57-62.

70. Tamayo R, Choudhury B, Septer A, Merighi M, Carlson R, Gunn JS. 2005. Identification of $c p t A$, a PmrA-regulated locus required for phosphoethanolamine modification of the Salmonella enterica serovar typhimurium lipopolysaccharide core. J Bacteriol 187:33913399.

71. Brodsky IE, Ghori N, Falkow S, Monack D. 2005. Mig-14 is an inner membrane- 
associated protein that promotes Salmonella typhimurium resistance to CRAMP, survival within activated macrophages and persistent infection. Mol Microbiol 55:954-972.

72. Beloin C, Roux A, Ghigo JM. 2008. Escherichia coli biofilms. Curr Top Microbiol Immunol.

73. Papp-Wallace KM, Maguire ME. 2008. Magnesium Transport and Magnesium Homeostasis. EcoSal Plus 1.

74. Lange R, Hengge-Aronis R. 1991. Identification of a central regulator of stationary phase gene expression in Escherichia coli. Molec Microbiol 5:49-59. 